University of Louisville

ThinkIR: The University of Louisville's Institutional Repository

$5-2020$

\title{
Role of plant volatile organic compounds (VOCS) in seed priming and plant-herbivore interactions.
}

Abhinav Kumar Maurya

University of Louisville

Follow this and additional works at: https://ir.library.louisville.edu/etd

Part of the Ecology and Evolutionary Biology Commons, Entomology Commons, and the Plant Biology Commons

\section{Recommended Citation}

Maurya, Abhinav Kumar, "Role of plant volatile organic compounds (VOCS) in seed priming and plantherbivore interactions." (2020). Electronic Theses and Dissertations. Paper 3404.

https://doi.org/10.18297/etd/3404

This Doctoral Dissertation is brought to you for free and open access by ThinkIR: The University of Louisville's Institutional Repository. It has been accepted for inclusion in Electronic Theses and Dissertations by an authorized administrator of ThinkIR: The University of Louisville's Institutional Repository. This title appears here courtesy of the author, who has retained all other copyrights. For more information, please contact thinkir@louisville.edu. 
ROLE OF PLANT VOLATILE ORGANIC COMPOUNDS (VOCS) IN SEED PRIMING AND PLANTHERBIVORE INTERACTIONS

By

Abhinav Kumar Maurya

M.S., University of Northern Colorado 2016

\begin{abstract}
A Dissertation
Submitted to the Faculty of the

College of Arts and Sciences of the University of Louisville

in Partial Fulfillment of the Requirements

for the Degree of
\end{abstract}

Doctor of Philosophy

in Biology

Department of Biology

University of Louisville

Louisville, Kentucky

May 2020 
Copyright 2020 Abhinav Kumar Maurya All rights reserved 

ROLE OF PLANT VOLATILE ORGANIC COMPOUNDS (VOCS) IN SEED PRIMING AND PLANTHERBIVORE INTERACTIONS

\author{
By \\ Abhinav Kumar Maurya \\ M.S., University of Northern Colorado 2016
}

A Dissertation Approved on

January 13,2020

By the following Dissertation Committee:

Dissertation Director

Dr. Sarah M. Emery

Dr. Stephen P. Yanoviak

Dr. Michael Perlin

Dr. Patrick Abbot

Dr. David J. Schultz 


\section{DEDICATION}

This dissertation is dedicated to my grandfather Late Dr. Devendra Nath Maurya and my parents, Awadhesh Maurya and Gayatri Devi, who inspired and motivated me to always follow the path of righteous actions. This thesis is also dedicated to my uncles Ashok

Kumar, Late Arvind Kumar and all my teachers who inculcated the value of hard work in me.

कर्मण्येवाधिकारस्ते माफलेषुकदाचन । माकर्मफलहेतुर्भूर्मा ते सड़गेस्वकर्मणि।।

You are entitled to do your duties and actions, but never to the results of your actions. Let not the results be your motivation, and do not be attached to inaction. 


\section{ACKNOWLEDGEMENTS}

First, I would like to thank Dr. Sarah Emery for taking me in her lab and guiding and supporting me through the completion of my Ph.D. She graciously taught me what true mentorship is all about and has helped me become a better person and scientist. It has been an honor to be her student.

I would like to express my deepest appreciation to my committee members for their support, guidance, and kindness. Thank you to Dr. Yanoviak for providing valuable suggestions on my project proposal, presentations, and writing. I'd also like to thank Dr. Perlin and Dr. Schultz for taking valuable time to help me with last-minute research questions, providing access to use their lab equipment, and preparing me for comprehensive exams. Finally, I'm grateful to Dr. Abbot for serving on my committee and providing me with critical scientific suggestions and guidance.

I would like to thank Dr. Gary Cobbs for his countless hours of help with statistical analysis. I'd like to thank the Biology Department for providing financial support for my conference travels. I'm also grateful to Dr. Frost, for helping me with research design, data analysis and editing the second and third chapters of this thesis. Thank you to my MS advisor Dr. Gomez for her continued help and guidance during my Ph.D. research. For research assistance, I thank Allie Peot, Rachel Haslem, Rakhi Patel, 
Amit Lamba, Travis Ray, and Griffin McHugh. Their support and work played a crucial role in making this dissertation possible. I would also like to thank Terri Norris, and Doris Meadows for their patience in helping me manage my research ordering, administrative paperwork and conference travels.

I can't imagine this journey without the friendship and immense support of Binod Basyal, Grace Freundlich, Nik Sort and Leila Pazouki. Their support during challenging times helped keep me going. A special thanks to Nora Covy for moving all the way from Colorado to help me pursue my dream. Thank you and the whole Covy family for your continuous support and encouragement throughout every aspect of this Ph.D. journey.

I would also like to extend my deepest gratitude to my Mom, Dad, and my childhood friend, Balwant Singh; this dissertation wouldn't have been possible without their unconditional belief in me. I'm thankful for their many hours-long phone calls from India to support me. Finally, thanks to my brother, sister and members of the joint family. The lessons of hard work I learned from all of them in childhood kept me going through tough times I faced during my Ph.D. journey. 


\begin{abstract}
ROLE OF PLANT VOLATILE ORGANIC COMPOUNDS (VOCS) IN SEED PRIMING AND PLANTHERBIVORE INTERACTIONS

Abhinav Kumar Maurya
\end{abstract}

January 13, 2020

This dissertation explores and expands the existing knowledge on the role of plant volatiles in facilitating seed priming and providing direct defense against herbivore. Although the roles of plant volatiles in priming a plant's defenses and providing direct defense against pests is well known, information regarding their effects on seed and the fitness of future plants and direct toxicity to herbivores is understudied. This dissertation does a thorough examination of these two understudied aspects of plant volatiles and provides novel insight into the role of plant volatiles in seed priming and direct defense (Chapter I). Seeds in the soil can be exposed to plant volatiles, however, the long-term effects of seed exposure to VOCs on growth and defenses of the germinated and growing plant are unknown. Here, I quantified the effect of seed exposure to six different plant volatiles on the growth of Arabidopsis thaliana and Medicago truncatula plants. I, also, measured the defenses of volatile exposed seed plants against herbivores of two different feeding guilds i.e., chewing insect; caterpillars and phloem-feeding insect; aphids. Seed exposure to a green leaf volatile enhanced the 
vegetative growth of Medicago and exposure to indole lead to enhanced primed defense against beet armyworm caterpillar (Spodoptera exigua) and pea aphid (Acyrthosiphon pisum) in Arabidopsis and Medicago respectively (Chapter II). Plant volatiles showed direct biocidal effects against beet armyworm caterpillars in feeding bioassay. Five of the six tested volatiles were toxic to caterpillars at concentrations ranging from 0.5 to $10 \mathrm{mg} / \mathrm{ml}$ or $\mu \mathrm{l} / \mathrm{ml}$. Indole and linalool were found to be the most toxic. I tested the indole toxicity against five agricultural pest caterpillars; fall armyworm (Spodoptera frugiperda), cotton bollworm (Helicoverpa zea), tobacco budworm (Heliothis virescens), velvetbean caterpillar (Anticarsia gemmatalis), and cabbage looper (Trichoplusia ni) with different host range. Indole toxicity varied with the caterpillar host range (Chapter III). In choice assays, indole spray on maize plants repelled beet armyworm caterpillar while linalool spray elicited no such response. However, both indole and linalool spray showed to reduce caterpillar feeding. Vegetative growth of maize plants was not affected by Indole or linalool spray (Chapter IV).

Collectively, this work reveals the role of plant VOCs in seed priming and improves our understanding of direct toxicity of plant volatiles against herbivores which have the potential to be used for pest control. 
TABLE OF CONTENTS

Page

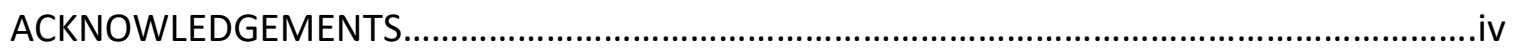

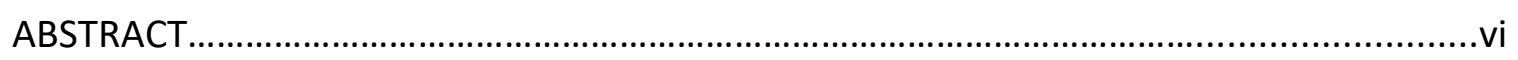

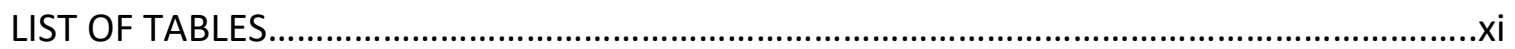

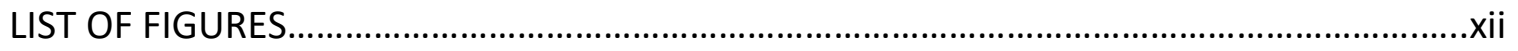

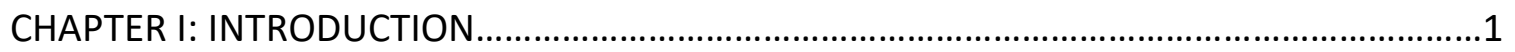

CHAPTER II: PLANT SEEDS ARE PRIMED BY HERBIVORE-INDUCED PLANT VOLATILES........5

SUMMARY

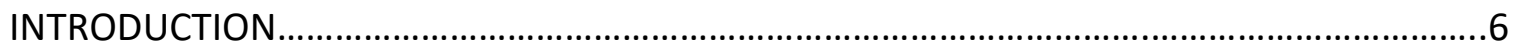

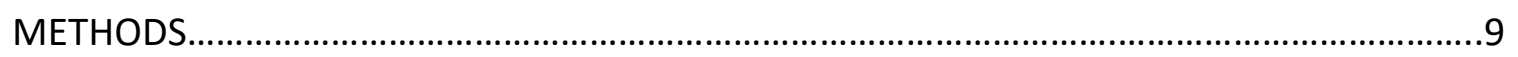

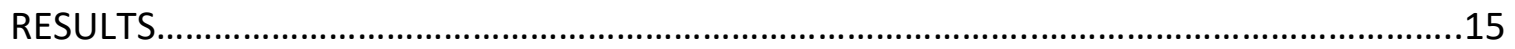

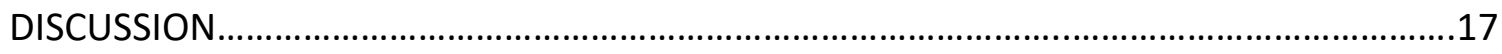

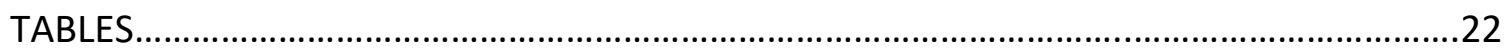

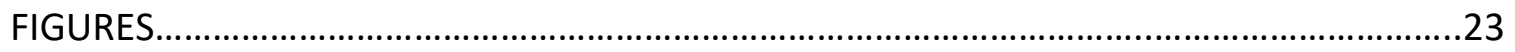


CHAPTER III: VOLATILE IDENTITY AND HERBIVORE HOST BREADTH AFFECT THE DIRECT

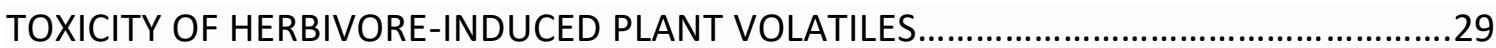

SUMMARY

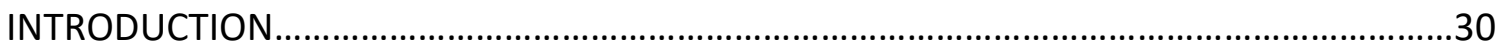

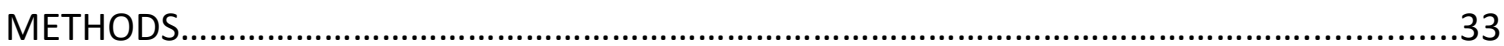

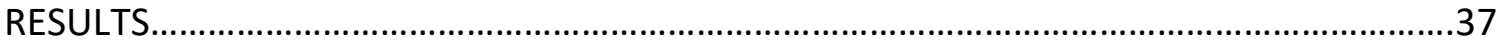

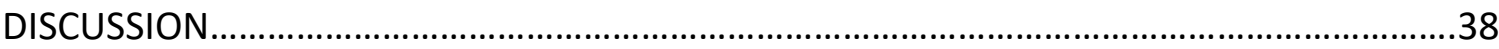

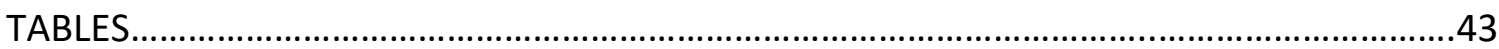

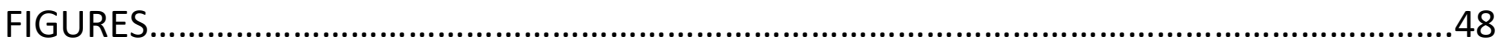

CHAPTER IV: REPELLENT AND ANTIFEEDANT ACTIVITY OF PLANT VOLATILE COMPOUNDS

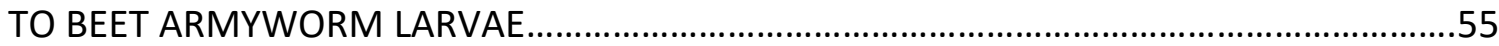

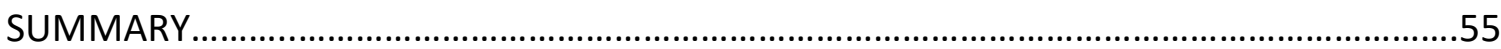

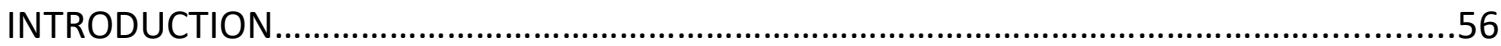

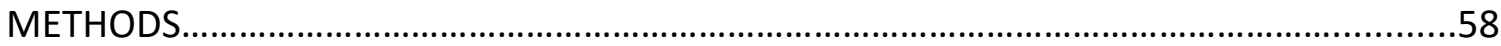

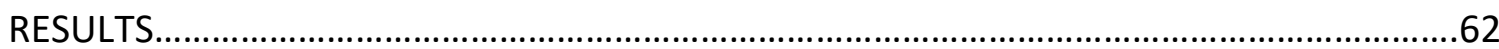

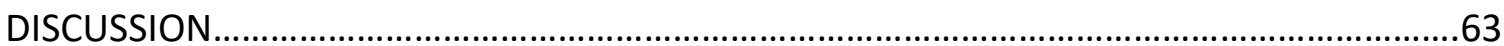

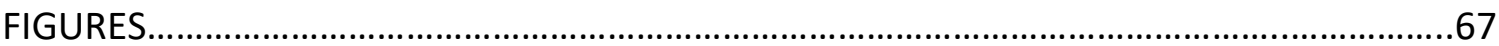

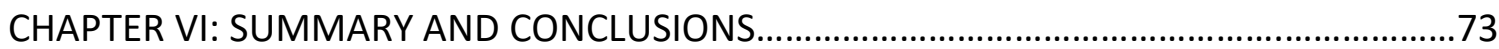




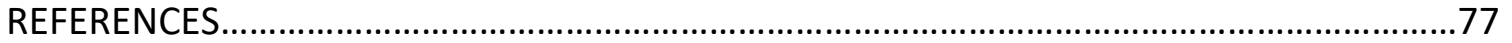

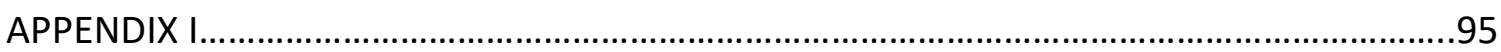

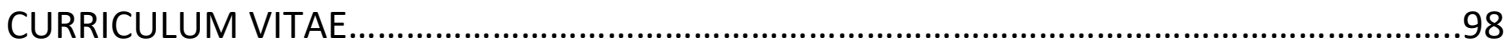




\section{LIST OF TABLES}

Table

Page

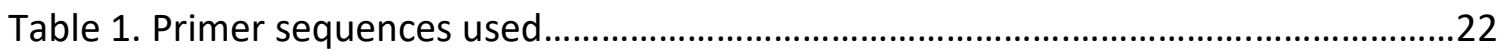

Table 2. Host range and common hosts of six tested caterpillars ...................................43

Table 3. Between-treatment effect of plant volatiles......................................................45

Table 4. Within treatment effect of plant volatile ............................................................47 


\section{LIST OF FIGURES}

$\begin{array}{ll}\text { Figures } & \text { Page }\end{array}$

Figure 1 The effect of seed exposure to plant volatiles on the herbivore fitness.............25

Figure 2. Seeds exposure to plant volatiles does not affect Arabidopsis thaliana............26

Figure 3. Seeds exposure to cis configuration green leaf volatiles enhances...................27

Figure 4. Seed treatment with indole does not enhance herbivore-induced....................28

Figure 5. Volatile delivery system for headspace bioassay ...........................................49

Figure 6. Direct toxicity of plant volatiles at different concentrations.............................50

Figure 7. LC $_{50}$ of individual plant volatiles on $S$. exigua caterpillars..................................51

Figure 8. Direct toxicity of indole on the survival of five different caterpillars.................52

Figure 9. Effect of varying concentrations of indole on the survival ................................53

Figure 10. Effect of varying concentrations of indole on percent egg hatch .....................54

Figure 11. Indole and linalool are non-toxic to beet armyworms.................................69

Figure 12. Indole shows repellent and antifeedant activity to beet armyworms..............70

Figure 13. Linalool shows antifeedant activity to beet armyworms in choice assays.......71

Figure 14. Volatile spray had no effect on plant growth ................................................72 


\section{CHAPTER I}

\section{INTRODUCTION}

Plants produce a diverse set of volatile organic compounds (VOCs) that are emitted in the atmosphere in gaseous form. Undamaged plants emit VOCs to attract pollinators (Raguso, 2008) and acclimatize to a changing environments (Loreto et al., 1998; Sharkey \& Singsaas, 1995). However, biotic stresses such as herbivory and pathogen infection can induce the release of VOCs (Holopainen, 2004; Huang et al., 2003; Sharifi et al., 2018). The specific release of a subset of VOCs after herbivory is known as herbivoreinduced plant volatiles (HIPVs). HIPV release provides many direct and indirect benefits to emitting plants as well as plants receiving HIPV exposure.

HIPVs directly defend plants by repelling herbivores and ovipositing females (Beale et al., 2006; Bernasconi et al., 1998a; Heil, 2004a; Kessler \& Baldwin, 2001; Liu et al., 2014; Veyrat et al., 2016a; Zakir et al., 2013). Recent studies also demonstrated that the HIPVs reduce the fitness of herbivores by affecting their feeding and growth and thus provide a direct defense (Veyrat et al., 2016a; von Mérey et al., 2013). HIPVs also provide indirect defense by attracting the natural enemies of herbivores that prey upon plant infesting herbivores both above and belowground (Dicke, 1986; Rasmann et al., 2005; Turlings et al., 1995; Turlings et al., 1990). Apart from benefiting the emitter, 
HIPVs released from herbivore damaged plants prime the defense responses in neighboring plants against herbivorous arthropods (Bate \& Rothstein, 1998; Engelberth et al., 2004a; Karban et al., 2014; Yan \& Wang, 2006). The multifaceted role of plant volatiles as the facilitator of plant-herbivore and natural enemy interactions opens a new avenue for their use in sustainable agriculture. To date, considerable progress has been made in utilizing plant volatiles in pest repellants or attractants and regulators of plant growth and defense (Lopez Jr et al., 2000; Pair \& Horvat, 1997; Tumlinson III et al., 2001). Recent interest in utilization of plant volatiles in agriculture has focused on pest attraction or repellence and natural enemy attraction through VOC bait and priming of innate plant immunity by in-field foliar application or soil drenching to induce plant resistance against herbivores (Baker et al., 2003; Beyaert et al., 2012; Bruce et al., 2003; Dickens, 2002; Lopez Jr et al., 2000; Song \& Ryu, 2013a). Despite this progress, there is still a knowledge gap in understanding whether seeds can be primed to HIPVs in a similar manner. For example, large scale field application of plant volatiles for priming innate plant immunity is prohibitively costly while seed treatments with HIPVs could provide a more viable priming-mediated solution to pest management.

In the context of plant-herbivore interactions, blends of plant essential oils containing plant VOCs are well-known toxicants against insect pests and are being used as a natural pesticide in agriculture (Isman, 2016; Maffei et al., 2011; Mohan et al., 2011; Mossa, 2016). However, the variation in the chemical profile of essential oils due to plant species, geography, and environmental factors create a great barrier in the large-scale commercial production of essential-oil-based pesticides (Koul et al., 2008). 
This constraint can be overcome by understanding the effect of individual compounds of the essential oil blend. Nonetheless, our understanding of the direct repellent, antifeedant and biocidal effect of individual plant volatiles of different chemical classes on insect pests is still inadequate. If individual plant volatiles show repellent, antifeedant and acute toxicity at low concentrations, mass production of synthetic plant volatile and their synergistic blends might provide a viable replacement of toxic pesticides in sustainable agriculture.

\section{ORGANIZATION OF THE DISSERTATION}

This dissertation investigates the role of plant volatiles in seed priming and measures the direct toxicity and behavioral effects of individual plant volatiles on chewing caterpillars. The second chapter explores the effect of plant VOCs seed treatment on plant fitness and performance of herbivores of different feeding guilds. The third chapter quantifies the median lethal concentration of six plant volatiles on beet armyworm and the median lethal concentration of volatile indole against six agriculturally important pests. The fourth chapter examines the repellent and antifeedant activity of toxic volatile compounds indole and linalool to beet armyworm. The fifth summarizes the findings from these experiments, their implications on plantherbivore interactions and agriculture and identifies the future steps. Overall, the finding of this research project advances our understanding of the role of plant volatiles as seed priming agents and as direct defense barriers against herbivory. These results 
have the potential to be used as a foundation for the development of crop protection agents for agriculture. 
CHAPTER II

PLANT SEEDS ARE PRIMED BY HERBIVORE-INDUCED PLANT VOLATILES

\section{SUMMARY}

Mature plants can detect and respond to herbivore-induced plant volatiles (HIPVs) by priming or directly activating defenses against future herbivores. Whether seeds can respond to HIPVs in similar manners is poorly understood. Here, we investigated the effect of seed exposure to common HIPVs on growth, reproduction and defense characteristics in the model plants Arabidopsis thaliana and Medicago truncatula using herbivores from two feeding guilds. Of all the HIPVs tested, indole specifically reduced both beet armyworm (Spodoptera exigua) growth on A. thaliana and pea aphid (Acyrthosiphon pisum) fecundity on M. truncatula. Induction of defense genes was not affected by seed exposure to indole in either plant species, suggesting that seed priming operates independently of induced resistance. Moreover, neither species showed any negative effect of seed exposure to HIPVs on vegetative and reproductive growth. Rather, M. truncatula plants derived from seeds exposed to $z$-3-hexanol and $z$-3-hexenyl acetate grew faster and produced larger leaves compared to controls. The results of this study indicate that seeds are sensitive to specific HIPVs in ways that enhance defense profiles with no apparent costs in terms of growth and 
reproduction. Seed priming by HIPVs represents a novel ecological mechanism of plantto-plant communication, with broad potential applications in agriculture and seed conservation.

\section{INTRODUCTION}

Spermatophytes (or seed plants) are a dominant clade of vascular plants on earth (Friis et al., 2011; Simonin \& Roddy, 2018). Their dominance is due to large part to the evolution of the seed, which provides protection to the embryo prior to germination and nutrition during the transition to autotrophy. One advantage of the seed is the ability to survive long periods of time in dormancy until environmental conditions are suitable for germination and growth. During dormancy, seeds are inevitably exposed to a variety of biotic and abiotic environmental conditions such as temperature, moisture, fire, soil chemicals, and chemical exudates of plant and microbial origin that may affect their germination (Fenner, 2000). Many of these conditions are well-established cues that seeds use to coordinate their physiology and metabolism to properly time germination to maximize viability and establishment (Bentsink \& Koornneef, 2008; Karssen \& Hilhorst, 2000). Temperature (Probert, 2000; Reynolds et al., 2001), rainfall (Gutterman, 1994; Levine et al., 2008; Pake \& Venable, 1996), and light (Flores et al., 2006; Milberg et al., 2000; Wesson \& Wareing, 1969) are well-documented abiotic environmental cues that affect the germination of seeds, and responses to these cues are regulated through phytohormone signaling pathways (Chen et al., 2008; Forcat et al., 2008; Seo et al., 2008). 
In addition to abiotic cues, seeds can perceive a variety of chemical cues of biological origins that can affect germination and subsequent defensive profiles. For example, low molecular weight phenolic compounds in soil (Muscolo et al., 2001), artemisinin released from leaves (Chen \& Leather, 1990) and catechin released from plants after herbivory (Thelen et al., 2005) inhibit seed germination. In contrast, smokederived karrikins (Dixon et al., 2009; Flematti et al., 2004; Nelson et al., 2012) and strigolactone (SL) phytohormones released from plant roots can stimulate seed germination (Bergmann et al., 1993; Cook et al., 1966). Moreover, recent studies have shown that seeds are receptive to the direct application of exogenous phytohormones that can activate plant defenses (Jucelaine et al., 2018; Rajjou et al., 2006; Worrall et al., 2012). For example, treating tomato seed with the phytohormone jasmonic acid (JA) and $\beta$-aminobutyric acid (BABA) lead to JA- and ethylene (ET)-dependent resistance in future plants against spider mite, caterpillars, aphids, and fungal pathogens (Worrall et al., 2012). Seed treatment with JA also changes the volatile composition of mature plants, making their blends more attractive to predatory mites (Smart et al., 2013). Similarly, seed treatment with salicylic acid (SA) enhances the expression of SA-related genes and the endogenous SA level against root holoparasite (Orobanche cumana) (Yang et al., 2016). Additionally, seed coating with plant growth-promoting rhizobacteria (PGPR) and plant growth-promoting fungus (PGPF) enhances seed germination, seedling establishment, and boosts induced defenses in future plants in SA-, ET-, and JAdependent manners (Rudrappa et al., 2010; Ryu et al., 2004; Sharifi \& Ryu, 2016). 
Seeds also come in contact with biotic agents that are volatile. Inhibitory and allelopathic effects of some plant and microbial-derived volatile organic compounds (VOCs) are known (Bradow \& Connick, 1990; Koitabashi et al., 1997; Mirabella et al., 2008; Muller, 1965; Muller \& Muller, 1964; Oleszek, 1987). Whereas these VOCs do not necessarily provide contextual information about future environmental conditions, herbivore-induced plant volatiles (HIPVs) represent potentially reliable and adaptive indicators of herbivory. The function of HIPVs in priming or directly inducing plant defenses is now well established (Engelberth et al., 2004a; Frost et al., 2007; RodriguezSaona \& Frost, 2010), and exposure of undamaged plants to HIPVs induces or primes the genes in phytohormone pathways (Bate \& Rothstein, 1998; Engelberth et al., 2007; Frost et al., 2008). Moreover, aboveground HIPV priming cues are also produced below ground by plant roots (Barsics et al., 2017; Gfeller et al., 2013; Lawo et al., 2011; Palma et al., 2012) and rhizosphere organisms (Bhattacharyya et al., 2015; Kanchiswamy et al., 2015). Therefore, there are multiple routes by which seeds could be exposed to HIPVs, including simple diffusion of HIPVs produced belowground (Peñuelas et al., 2014) and precipitation and leaching of HIPVs produced aboveground (H B Tukey, 1970; Muller et al., 1964). While some HIPVs may have allelopathic effects on seed germination (Karban, 2007; Mirabella et al., 2008; Preston et al., 2002), whether exposure of seeds to HIPVs alters subsequent plant physiology and defense is currently unknown.

Here, we determined the effect of seed exposure to HIPVs on plant growth and direct defenses. Specifically, we used a comparative approach to investigate the effects of HIPV exposure to the seeds of (1) A. thaliana on the performance of a chewing 
herbivore (beet armyworm; Spodoptera exigua) and (2) M. truncatula on the performance of a phloem-feeding herbivore (pea aphid; Acyrthosiphon pisum). We also tested the effect of seed exposure to plant volatiles on the growth, development, and defense gene expression of $A$. thaliana and $M$ truncatula. We specifically tested HIPVs that have been shown previously to prime mature plants: indole, cis-3-hexenol $(z 3 \mathrm{HOL})$, cis-3-hexenyl acetate (z3HAC), $\beta$-caryophyllene (BCP), and trans-2-hexanol (e2HAL). We predicted that HIPV exposure to seeds would prime the resulting mature plants for enhanced resistance against both chewing and phloem-feeding herbivores.

\section{MATERIALS AND METHODS}

\section{Plant material}

A. thaliana (Col-0) seeds were surface sterilized in $75 \%(\mathrm{v} / \mathrm{v})$ ethanol for five minutes and $20 \%$ bleach $(\mathrm{v} / \mathrm{v})$ in $0.1 \%$ Tween-20 for ten minutes. After sterilization, the seeds were washed three times with distilled water and spread on petri-plates with wet Whatman paper. Petri plates were kept at $4^{\circ} \mathrm{C}$ for 2 days, this allowed the seeds to break dormancy and synchronize germination.

All M. truncatula, A-17 seeds were scarified in concentrated $\mathrm{H}_{2} \mathrm{SO}_{4}$ for 10 min and surface sterilized in $20 \%(\mathrm{v} / \mathrm{v})$ bleach in $0.1 \%(\mathrm{v} / \mathrm{v})$ Tween-20 solution for $10 \mathrm{~min}$. Seeds were rinsed five times with sterile water and were spread on petri plates with wet Whatman paper. Petri plates were covered with aluminum foil and kept at $4^{\circ} \mathrm{C}$ for two days.

Seed treatment with plant volatiles 
Volatile dispensers were used to expose $A$. thaliana and $M$. truncatula seeds to individual plant volatiles. Volatile dispensers consisted of $2.0 \mathrm{ml}$ amber glass vials (Agilent Technologies) containing 1 mg glass wool (Appendix I: Figure S1). Each dispenser contained $20 \mathrm{mg} / \mu \mathrm{l}$ of one of the following compounds: cis-3-hexenol, cis-3hexenyl acetate (Engelberth et al., 2004a), trans-2-hexenal, $\beta$-caryophyllene and $20 \mathrm{mg}$ indole (Erb et al., 2015b). Control volatile dispensers had only glass wool without any volatile. The amber vials with volatiles were sealed with a rubber septum and connected to the 2-ounce plastic cup by piercing the attached plastic cup lid and amber vial rubber septum with an 18-gauge needle. This procedure is similar to what has been used previously for the controlled administration of HIPVs (Erb et al., 2015b). Each volatile was administered to seeds in multiple plastic cups (biological replicates) and the number of seeds planted from each plastic cups constituted the technical replicates.

\section{A. thaliana Seed germination}

Each volatile was administered to seeds in 5 replicates (10 seeds/plastic cups). After one day of volatile treatment, two $A$. thaliana seeds were transferred from each plastic cups to agar plates containing 1.0\% (w/v) agar (Sigma) and standard 0.5X MS medium (Murashige and Skoog basal at an adjusted pH of 7.0). A total of 9 agar plates were used for each volatile treatment. The Petri dishes were kept in random order a growth chamber at $25^{\circ} \mathrm{C}$ under a $16 \mathrm{~h}$ light: $8 \mathrm{~h}$ dark (16L: 8D) day/night cycle for two days. Percent seed germination was measured after two days.

\section{A. thaliana growth}


After one day of volatile treatment, $A$. thaliana seeds were transferred to $5.5 \mathrm{x}$ $5.5 \times 5.5 \mathrm{~cm}$ pots filled with sterile Metro-Mix 360 soil. After transplanting, pots were randomly placed on trays $(54 \times 28 \times 6 \mathrm{~cm})$ in a growth chamber at $25^{\circ} \mathrm{C}$ under a $12 \mathrm{~h}$ light: $12 \mathrm{~h}$ dark (12L: 12D) cycle. Once germinated seedlings reached to 4-6 leaf stage, they were fertilized twice a week with $10 \mathrm{ml}$ 1/2 strength Hoagland's solution. Arabidopsis growth and fitness were measured in terms of the number of leaves, maximum rosette diameter, the length of the bolt and number of siliques produced.

\section{M. truncatula growth}

Volatile exposed M. truncatula seeds were planted in $9 \times 6.5 \times 6.5 \mathrm{~cm}$ pots as described above. The trays were randomly kept in the growth chamber at $25^{\circ} \mathrm{C}$ under a $12 \mathrm{~h}$ light: $12 \mathrm{~h}$ dark (12L: 12D) day/night cycle for ten days. After 10 days the trays were moved to the greenhouse and kept there till the end of the experiment. M. truncatula growth and fitness parameters were measured in terms of petiole length, leaf blade length, leaf blade width, main shoot length, axillary shoot length and the number of fruits using numerical nomenclature coding system developed by Bucciarelli et al. (2006). The numerical nomenclature for vegetative growth (Appendix I: Figure S3) starts with the first unifoliate leaf as metamer $1(\mathrm{~m} 1)$ followed by the first trifoliate as metamer $2(\mathrm{~m} 2)$ and so on. The axillary shoots are coded as per their metamer of origin (e.g. the axillary shoot originating from first unifoliate or metamer 1 is also designated as $\mathrm{m} 1$ ). Additionally, decimal addition to numerical coding system defines the development stage of the leaf (e.g. m2.1 represents the bud break for the first trifoliate, 
m2.5 represents the half-open blade of first trifoliate while $\mathrm{m} 2.9$ represent fully developed first trifoliate).

Caterpillar herbivory

Beet armyworm (Spodoptera exigua) was used to evaluate the effect of seed exposure to HIPVs on herbivore defense of Arabidopsis plants. Caterpillar eggs were ordered from Benzon Research Inc. USA (Permit \#P526P-16-02563). Egg masses were immediately transferred to the artificial diet in 2-ounce plastic cups. Eggs in plastic cups were maintained at $24^{\circ} \mathrm{C}$ on artificial diet until the desired instar. Third instar caterpillars were used for feeding experiment on five to six-week-old, vegetative stage, $A$. thaliana plants. For the first feeding experiment, each volatile was administered to seeds in six plastic cups (biological replicates) and three seeds were planted from each plastic cups (three technical replicates). For the second feeding experiment, each volatile treatment had 10 biological replicates and three technical replicates. For feeding experiment caterpillars were starved for 3 hours and weighed before their transfer to Arabidopsis plants. One third-instar caterpillar was placed on each Arabidopsis plants. The plants were covered with a nylon mesh bag to avoid the caterpillar escape. The caterpillars were allowed to feed freely for $24 \mathrm{~h}$ before being removed from the plants. After their removal, the caterpillars were kept at room temperature for three hours to allow the digestion of ingested plant material. Caterpillars that molted during the second experiment were removed from the assay analysis. After $3 \mathrm{~h}$ the caterpillars were weighed on a microbalance. Aboveground plant material was also collected in liquid nitrogen and stored at $-80 \stackrel{\circ}{\circ}$ for later molecular work. 


\section{Aphid herbivory}

Pea Aphids were used to evaluate the effect of seed exposure to HIPVs on herbivore defense of Medicago plants. A single clone colony of Pea aphid (Acyrthosiphon pisum Harris) obtained from Dr. Susana Karen Gomez lab (University of Northern Colorado) was maintained on a fava bean plants kept in a growth chamber (20 ${ }^{0} \mathrm{C}, 12: 12 \mathrm{~h}$ light:dark). For aphid feeding experiment, three adult aphids (defined as $\mathrm{F}_{0}$ generation) (Tomczak \& Müller, 2017) were placed in an insect bag (L15 X W6, BugDorm) on three trifoliate (M1, M2, and M3) (8 to 10 plants per treatment). After 24 h, the adults were removed, and one trifoliate leaf was collected while 5 nymphs (defined as $F_{1}$ generation) were left on the plant for 13 more days. The nymphs grew and produced offspring ( $\mathrm{F}_{2}$ generation). On the $14^{\text {th }}$ day all the aphids were collected, the total offspring $\left(F_{2}\right)$ were counted and weighed on a microbalance. Aboveground plant material was also collected on day 14 in liquid nitrogen and stored at $-80{ }^{\circ} \mathrm{C}$ for later molecular work.

Gene expression analysis

Aboveground tissue collected from $A$. thaliana plants after one day of caterpillar herbivory and $M$. truncatula after 14 days of aphid feeding were used for gene expression analysis. Total RNA was isolated from approx. $150 \mathrm{mg}$ of ground tissue using a modified cetyltrimethylammonium bromide (CTAB) method (Frost et al., 2012). RNA was quantified with Nanodrop and integrity was confirmed using a native $1 \%$ agarose0.5x TAE gel. Total RNA (2.5 $\mu$ g per sample) was treated with DNAse (Turbo DNAse, Ambion), then $0.7 \mu \mathrm{g}$ of DNA-free RNA was reverse-transcribed to cDNA using High 
Capacity cDNA Reverse Transcript Kit (Applied Biosystems). Real-time PCR was done using the Quant Studio-3 PCR System (Applied Biosystems) with each reaction containing $2 \mu \mathrm{l}$ of EvaGreen ${ }^{\circledR}$ PCR Master Mix (Mango Biotechnology), $0.3 \mu \mathrm{l}$ of $10 \mu \mathrm{M}$ forward and reverse primer, $5.4 \mu \mathrm{l}$ of DI water, and $2 \mu \mathrm{l}(2.5 \mathrm{ng})$ of cDNA in a total volume of $10 \mu \mathrm{l}$. Primer specificity was confirmed by melting curve analysis, and relative transcript levels were calculated using the $2^{-\Delta C T}$ method (Livak \& Schmittgen, 2001) with elongation factor 1-alpha (EF1- $\alpha)$ and Glyceraldehyde 3-phosphate dehydrogenase (GAPDH) as reference genes for $M$. truncatula and Actin-7 and GAPDH as reference genes for $A$. thaliana. Primer sequences for all $M$. truncatula and $A$. thaliana genes tested are listed in Table 1.

\section{Statistical analyses}

Raw data were checked for normality and homogeneity of variance before performing the parametric tests. For $A$. thaliana, differences in leaf number and, rosette diameter were analyzed using repeated-measures ANOVA. For M. truncatula, leaf petiole length, leaf blade length and width, main shoot and axillary shoot length were analyzed using one-way ANOVA followed by Dunnett posthoc test. Other response variables for $A$. thaliana and $M$. truncatula growth along with caterpillar growth rate, aphid fecundity, and aphid nymph weight were analyzed for significance using student's t-test. For the t-test, treatments were compared to controls. The gene expression data were analyzed using one-way ANOVA followed by Tukey's posthoc test. Statistical analyses were performed using R version 3.4.2 and GraphPad Prism and figures were generated via GraphPad Prism. 


\section{RESULTS}

Seed exposure to indole enhances plant resistance against chewing and sap-feeding herbivores

Indole exposure to seeds reduced the relative growth rate of S. exigua caterpillars feeding on mature foliage by $33 \%(p=0.0706$, Figure $1 \mathrm{~A})$ and $30 \%$ respectively ( $p=0.0124$, Figure $1 B$ ) in separate experiments. In contrast, seed exposure to green leaf volatiles (cis-3-hexenol, cis-3-hexenyl acetate, and trans-2-hexenal) and terpenes ( $\beta$-Caryophyllene) had no effect on caterpillar growth ( $p>0.05$, Figure $1 A)$. I observed similar effects of indole exposure in $M$. trucatula, where pea aphid fecundity and total weight were reduced by $28 \%(p=0.007$, Figure $1 C)$ and $41 \%(p=0.015$, Figure 1D), respectively. Additionally, z3HAC seed treatment to M.trucatula reduced pea aphid fecundity by $27 \%$ ( $p=0.0354$ Figure $1 C)$ and total nymph weight by $35 \%(p=0.067$ Figure 1D).

Seed exposure to indole does not affect growth and development of $A$. thaliana

A. thaliana seed exposure to HIPVs resulted in no significant differences relative to controls on the vegetative and reproductive growth. We found no differences in leaf number $\left(p_{\text {trt }}=0.997\right.$, Figure $\left.2 A\right)$, rosette diameter $\left(p_{\text {trt }}=0.672\right.$, Figure $\left.2 B\right)$, bolt length $(p=0.333$, Figure $2 C)$, silique number $(p=0.460$, Figure $2 D)$, and fresh shoot weight $(p=0.107$, Figure $2 E)$ of plant that were grown from seeds exposed to any HIPV relative to control plants.

We also measured the effect of HIPV exposure on seed germination of $A$. thaliana on MS media. Of all the HIPVs tested, only GLV e2HAL significantly reduced 
seed germination compared to control seeds ( $p<0.001$, Figure $2 F)$. Specifically, seeds exposed to this volatile had $26 \%$ lower germination relative to controls. Seed exposure to GLVs enhances $M$. truncatula growth

M. truncatula seed exposure to $z 3 \mathrm{HOL}$ and $z 3 \mathrm{HAC}$ increased plant vegetative growth (Figure $3 A)$. Petiole length $(p<0.05$, Figure $3 B)$, leaf blade length $(p<0.05$, Figure $3 C$ ), leaf blade width (Figure 3D) and axillary shoot length ( $p<0.05$, Figure $3 E$ ) of the $z 3 \mathrm{HOL}$ and $z 3 \mathrm{HAC}$ exposed seed plants were higher compared to control plants while no such effect was seen on main shoot length $\left(p_{\text {global }}=0.016, p_{\text {Dunnett's }}>0.05\right.$, Appendix I: Figure S2A). No other HIPV affected vegetative growth in $M$. truncatula. Furthermore, while $z 3 \mathrm{HOL}$ and $z 3 \mathrm{HAC}$ affected the vegetative growth, there was no difference in the reproductive output of plants grown from HIPV-exposed seeds than control seeds $(p=0.929$, Appendix I: Figure S2B).

Seed exposure to indole does not affect herbivore-inducible defense gene expression after caterpillar or aphid herbivory

Given the clear effect of indole seed treatment on caterpillar and aphid fecundity, I subsequently assessed whether this effect was due to indole-mediated changes in inducible defenses. In A. thaliana challenged with S. exigua, we analyzed the expression of genes related to JA synthesis (LOX2, Figure 4A) and signaling (MYC2, Figure 4B), and glucosinolate biosynthesis (CYB79-B2 and CYB79-B3, Figure 4C-D). Caterpillar herbivory induced the expression of these four marker genes as expected, but indole-seed treatment neither directly stimulated nor statistically altered the caterpillar-induced expression patterns of these genes. In M. truncatula challenged with aphids, I analyzed 
two SA-regulated marker genes, $P R 5$ and $B G L-1$, which have previously been shown to be responsive to aphid feeding (Gao et al., 2008; Moran \& Thompson, 2001). PR5 and $B G L-1$ were induced by aphid feeding (Figure $4 \mathrm{E}-\mathrm{F}$ ), but indole seed treatment neither directly stimulated nor statistically altered the aphid-induced expression patterns of these genes. That is, in all cases, indole did not directly induce, indirectly prime, or affect the magnitude of herbivore induction of these defense genes.

\section{DISCUSSION}

The results of this study show that seeds are viable receivers of HIPVs in ways that prime defenses and, in some cases, directly stimulate growth. Specifically, this study demonstrates that the pre-germination exposure of seeds to indole enhances resistance against herbivores of two feeding guilds in two different plant species without any apparent effects on plant growth or fitness. The results also showed that seed exposure to $z 3 \mathrm{HOL}$ and $z 3 \mathrm{HAC}$ can enhance plant growth in $M$. truncatula. Biotic cues that reliably indicate future biotic stress can prime plant defenses for faster and/or stronger defenses following subsequent stress events (Conrath et al., 2006; Frost et al., 2008). The phenomenon of HIPV-mediated priming is now well established in mature plants (Engelberth et al., 2004a; Erb et al., 2015b; Frost et al., 2007; Frost et al., 2008; Rodriguez-Saona et al., 2009). To my knowledge, this study is the first to show that seeds can also be primed by HIPVs. Moreover, seed exposure to HIPVs had no adverse effect on seed germination, vegetative growth and reproductive output of the primed mature plants (Figure $2 \& 3$ ). Such a long-persisting defense response without apparent 
negative consequence on plant growth and development may be indicative of defense priming rather than direct activation of induced defenses.

HIPV-mediated defense priming is theoretically a component of an inducible resistance phenotype (Frost et al., 2008; Hilker et al., 2016). Since seed treatment with defense phytohormones (e.g., JA, SA, and BABA) primes defenses by modulating stressrelated signaling pathways (Azooz, 2009; Jucelaine et al., 2018; Worrall et al., 2012), I hypothesized that volatile indole would prime seeds through inducible signaling pathways. I, therefore, predicted that seed-primed plants would show primed inducible defenses compared to controls when challenged with herbivores. For example, Worrall et al. (2012) showed that seed treatment with JA and BABA primed the antiherbivore and antipathogen defenses in mature Arabidopsis plants by JA-dependent processes. However, in this study, JA-related octadecanoid pathway (Ballaré, 2011; Wasternack, 2007) and glucosinolate biosynthesis (Hopkins et al., 1998; Reymond et al., 2004) marker genes were induced by S. exigua feeding to similar levels independent of indole seed treatment (Figure 4). Similarly, marker genes for SA-related defense (Walling, 2008 ) in M. truncatula were induced by $A$. pisum but were not additionally enhanced by seed treatment (Figure 4). Base on the gene expression profile the result indicates that HIPV-mediated seed priming might operate through a mechanism independent of inducible resistance. However other parameters of inducible resistance need to be evaluated before ruling out the involvement of inducible resistance in seed priming. Moreover, indole seed treatment did not directly induce any marker gene before herbivory, further ruling out direct activation of induced resistance via seed priming 
(Figure 4). Given that I, measured single time points as indicators of inducible defense, it is possible that seed priming altered the temporal dynamics of induced defense in complex ways. However, the time points chosen for this study are reflective of sustained defense activation, which is one important aspect of defense priming. The enhanced defense in indole-exposed seed plants in this study is therefore likely a result of the changes in plant nutritive and defense chemistry.

Indole was the only HIPV we tested that primed plant defenses after seed exposure, and this effect was consistent across two model plants against herbivores of different feeding guilds. Indole is a ubiquitous, inter-kingdom intermediate in critical biochemical pathways (Chen et al., 2008) and a signaling molecule (Ameye et al., 2015). In plants, indole is also a common HIPV that contributes to direct and indirect defenses (Gasmi et al., 2018; Veyrat et al., 2016a) and also acts as a defense priming cue (Bruce et al., 2003; Erb et al., 2015b). This study adds an additional facet to the ecological role of indole in plant communication. That said, rhizosphere inhabiting bacteria also produce volatile indole, which can modulate plant growth via auxin pathway (Bailly et al., 2014; Bhattacharyya et al., 2015; Blom et al., 2011). I tested the genes CYP79B2 and CYP79B3 in A. thaliana which involve in enzyme production that convert tryptophan (Trp) to indole-3-acetaldoxime (IAOx), a rate-determining intermediate in auxin biosynthesis pathway and plant defense compound indole glucosinolates biosynthesis (Zhao et al., 2002). Seed exposure to indole alone did not upregulate either gene, but S. exigua feeding induced their expression independent of seed exposure to indole (Figure 4. C \& D). Therefore, the auxin pathway may not be involved in indole-mediated seed priming. 
Nevertheless, seed priming was consistent in two different plant species against different feeding guilds of herbivores, suggesting a clear role for indole in mediating plant-seed communication.

Exposure of M. truncatula seeds to two GLVs (z3HOL and $z 3 \mathrm{HAC})$ stimulated vegetative growth. Similar vegetative and reproductive growth stimulation using a lowdose, persistent application of z3HAC in lima bean plants (Freundlich \& Frost, 2018). In lima bean and $M$. truncatula, plants with increased growth also were better defended ( (Freundlich \& Frost, 2018) and Figs 1\&3). GLVs are well-established priming cues against biotic stress (Engelberth et al., 2004a; Frost et al., 2008), and volatile communication between plants can alter biomass allocation (Ninkovic, 2003). These results suggest that GLVs can also stimulate plant growth and ostensibly overcome the growth-defense dilemma (Herms \& Mattson, 1992) in some plant species. One caveat, though, is that persistent exposure to z3HAC reduces growth in Capsicum annuum (Freundlich \& Frost, 2018), therefore the stimulating effect of GLVs is not universal.

As a final point, the results of this study have potential applications in pest control and seed management. Recent attention has focused on leveraging priming of innate plant immunity (Dervinis et al., 2010; Mozgova et al., 2015; Pichersky \& Gershenzon, 2002; Pickett \& Khan, 2016; Song \& Ryu, 2013a), due in part to presumed lower fitness costs of priming based defenses (Buswell et al.; van Hulten et al., 2006). Infield foliar or soil application of these agents can induce plant defenses against herbivores (Beyaert et al., 2012; Bruce et al., 2003; Song \& Ryu, 2013a), but can also be prohibitively costly for large-scale application. In contrast, seed treatments are a 
common method of inoculating crops (Paparella et al., 2015), and direct application of HIPVs to seeds could provide a more viable priming-mediated solution to pest management. Moreover, M. thaliana is a close relative of fodder crop alfalfa, and improved vegetative growth after seed treatment with GLVs may provide a mechanism for enhancing fodder capacity and rejuvenating soils during crop rotations.

Furthermore, HIPV-mediated seed priming may be a valuable tool in conservation efforts for rare or endangered species (Laetz et al., 2009), if HIPV-mediated seed priming can enhance their innate immunity. Ultimately, seed priming via HIPVs represents a novel mechanism in plant-plant communication that may have transgenerational effects on ecological communities. 
TABLE

Table 1: Primer sequences used in this study.

\begin{tabular}{|c|c|c|c|c|}
\hline Plant & Genes & $\begin{array}{l}\text { Primer sequence } \\
\qquad\left(5^{\prime} \rightarrow 3^{\prime}\right)\end{array}$ & $\begin{array}{c}\text { Amplicon } \\
\text { length } \\
\text { (pb) }\end{array}$ & Reference \\
\hline \multirow{6}{*}{$\begin{array}{l}\text { Arabidopsis } \\
\text { thaliana }\end{array}$} & Actin 7 & $\begin{array}{l}\text { F: AGTGGTCGTACAACCGGTATTGT } \\
\text { R: GATAGCATGAGGAAGAGCATACC }\end{array}$ & 91 & $\begin{array}{l}\text { (Martínez- } \\
\text { Medina et } \\
\text { al., 2017) }\end{array}$ \\
\hline & GAPDH & $\begin{array}{l}\text { F: CCATGGGCCGAGGCTGGAG } \\
\text { R: ACCTTCTTGGCACCACCCTTCA }\end{array}$ & 101 & $\begin{array}{c}\text { GenScript } \\
\text { (GenScript, } \\
\text { 2006) }\end{array}$ \\
\hline & LOX2 & $\begin{array}{l}\text { F: AAGAGTTCTATGAGTCGCCAGA } \\
\text { R: TGTACTCTTCGTCAGGTGAATG }\end{array}$ & 119 & $\begin{array}{l}\text { (Kuśnierczyk } \\
\text { et al., 2007) }\end{array}$ \\
\hline & MYC2 & $\begin{array}{l}\text { F: CGGAGATCGAGTTCGCCGCC } \\
\text { R: AATCCCGCACCGCAAGCGAA }\end{array}$ & 191 & $\begin{array}{c}\text { GenScript } \\
\text { (GenScript, } \\
\text { 2006) }\end{array}$ \\
\hline & СYР79B2 & $\begin{array}{l}\text { F: ATCACATCCCTAAAGGAAGTCA } \\
\text { R: CCGGTACTGAACGAGATAAACC }\end{array}$ & 165 & $\begin{array}{l}\text { (Kuśnierczyk } \\
\text { et al., 2007) }\end{array}$ \\
\hline & СУР79В3 & $\begin{array}{l}\text { F: GGTTTGGTCTGATCCACTTAGC } \\
\text { R: CTAGCATCATGGTCGTTATCGC }\end{array}$ & 160 & $\begin{array}{l}\text { (Kuśnierczyk } \\
\text { et al., 2007) }\end{array}$ \\
\hline \multirow{4}{*}{$\begin{array}{l}\text { Medicago } \\
\text { truncatula }\end{array}$} & $E F 1 \alpha$ & $\begin{array}{l}\text { F: TGACAGGCGATCTGGTAAGG } \\
\text { R: CAGCGAAGGTCTCAACCAC }\end{array}$ & 108 & $\begin{array}{l}\text { (Liu et al., } \\
\text { 2007) }\end{array}$ \\
\hline & GAPDH & $\begin{array}{l}\text { F: AACATCATTCCCAGCAGCAC } \\
\text { R: AACATCGACGGTAGGCACAC }\end{array}$ & 108 & $\begin{array}{l}\text { (Liu et al., } \\
\text { 2007) }\end{array}$ \\
\hline & PR5 & $\begin{array}{l}\text { F: TGCCTTAGCTTTGCATTCCT } \\
\text { R: AATTTCCGCTGAGTTCGTTG }\end{array}$ & 168 & $\begin{array}{c}\text { (Gao et al., } \\
\text { 2007) }\end{array}$ \\
\hline & $B G L$ & $\begin{array}{l}\text { F: CAAATTGGGTCCAAAAATATGTGAC } \\
\text { R: GCACCATCATTGGGTGGATATGAAG }\end{array}$ & 229 & $\begin{array}{l}\text { (Gao et al., } \\
\text { 2007) }\end{array}$ \\
\hline
\end{tabular}




\section{FIGURE LEGENDS}

Figure 1. The effect of seed exposure to plant volatiles on the herbivore fitness (A) Relative growth rate (RGR) of Spodoptera exigua caterpillars after $24 \mathrm{~h}$ herbivory on Arabidopsis thaliana plants grown from control and volatile-exposed seeds $(n=6$, each biological replicate had 1-3 technical replicates), (B) Relative growth rate of S. exigua caterpillars after $24 \mathrm{~h}$ herbivory on $A$. thaliana plants grown from control and indoleexposed seeds in a separate caterpillar herbivory experiment ( $n=8-10$, each biological replicate had 1-3 technical replicates), (C) Fecundity (nymph number per adult) and, (D) nymph weight after 14 days of Acyrthosiphon pisum herbivory on $M$. truncatula plant grown from control and volatile-exposed seed $(n=6-8)$. Values are shown as means $\pm 95 \% \mathrm{Cl}$ and significance were calculated by the student's $t$-test (two-tailed).

Figure 2. Seed exposure to plant volatiles does not affect Arabidopsis thaliana plant growth and reproductive output. The effect of seed exposure to plant-derived volatiles on $(A)$ leaf number, (B) rosette diameter, $(C)$ bolt length, (D) silique number and (E) shoot weight of plants. DPS represents days after seed sowing. Values are shown as means $\pm 95 \% \mathrm{Cl}(n=8-10)$. (F) Percent seed germination. Seed exposure to e2HAL reduced the seed germination on agar plates. Values are shown as means \pm SEM $(n=90)$. Significance was calculated by repeated measures ANOVA and one-way ANOVA.

Figure 3. Seeds exposure to cis-3-hexenol and cis-3-hexenyl acetate enhances the growth of Medicago truncatula. (A) M. truncatula plants (define age) from control seed 
and $z 3 \mathrm{HAC}$ exposed seed. The effect of seed exposure to plant-derived volatiles on (B) leaf petiole length, (C) Leaf blade length, (D) Leaf blade width and, (E) axillary shoot length. For leaf petiole length, leaf blade length and width all the measurements were taken when the leaves were fully developed. The axillary shoot was measured at 64 days after seed sowing. Values for each metamer are shown as means $+95 \% \mathrm{Cl}(n=5-10)$ and asterisks represent significant differences $(p<0.05)$ from controls based on one-way ANOVA followed by Dunnett's post-hoc analysis.

Figure 4. Seed treatment with indole does not enhance herbivore-induced expression of defense marker genes. Relative transcript levels of the genes $L O X 2, M Y C 2, C Y B-B 2$ and $C Y B-B 3$ in $A$. thaliana after $24 \mathrm{~h}$ of Spodoptera exigua herbivory was measured by quantitative RT-PCR analysis (A-D). Similarly, transcript levels of SA regulated marker genes $P R 5$ and $B G L$ were measured in Medicago trunacatula after 14 days of Acyrthosiphon pisum aphid herbivory (E \& F). Relative expression was determined $\left(2^{-\Delta C t}\right)$ using the geometric mean of two housekeeping genes for normalization. Bars represent mean \pm SEM determined from three-five biological replicate assays, each biological replicate had two technical replicates. Different letters on the bar represent a significant difference $(p<0.05)$. 
Figure 1
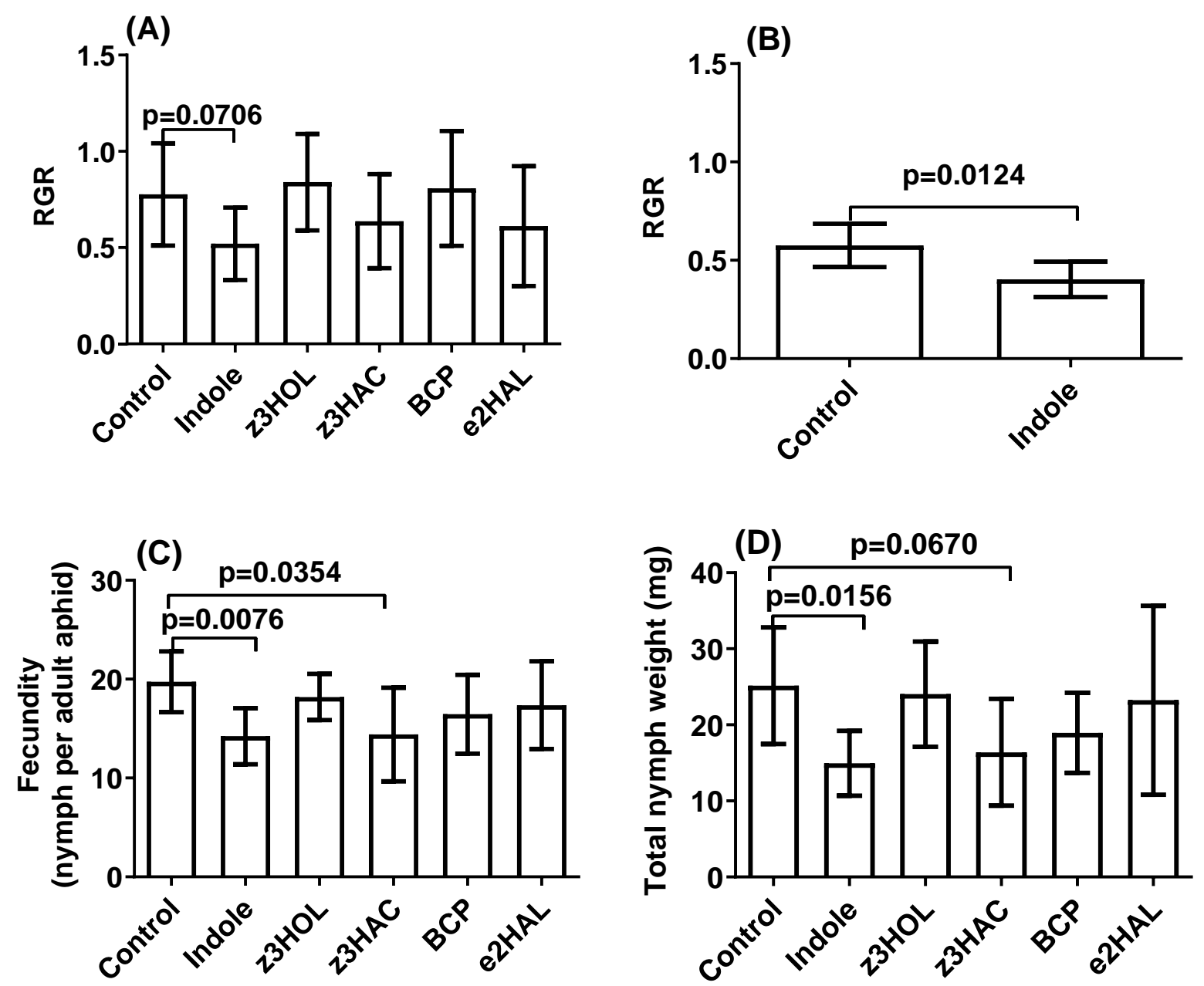
Figure 2
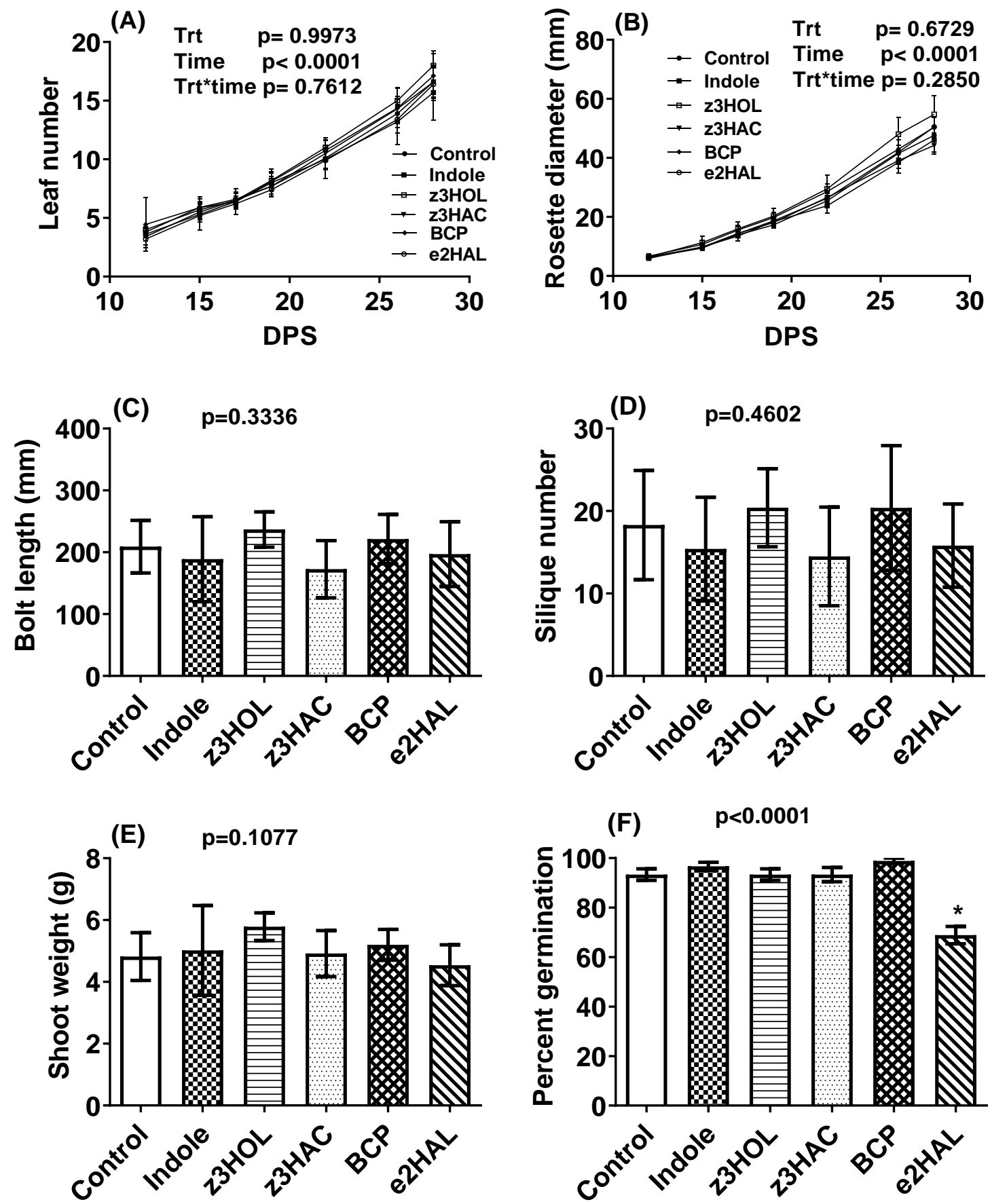
Figure 3
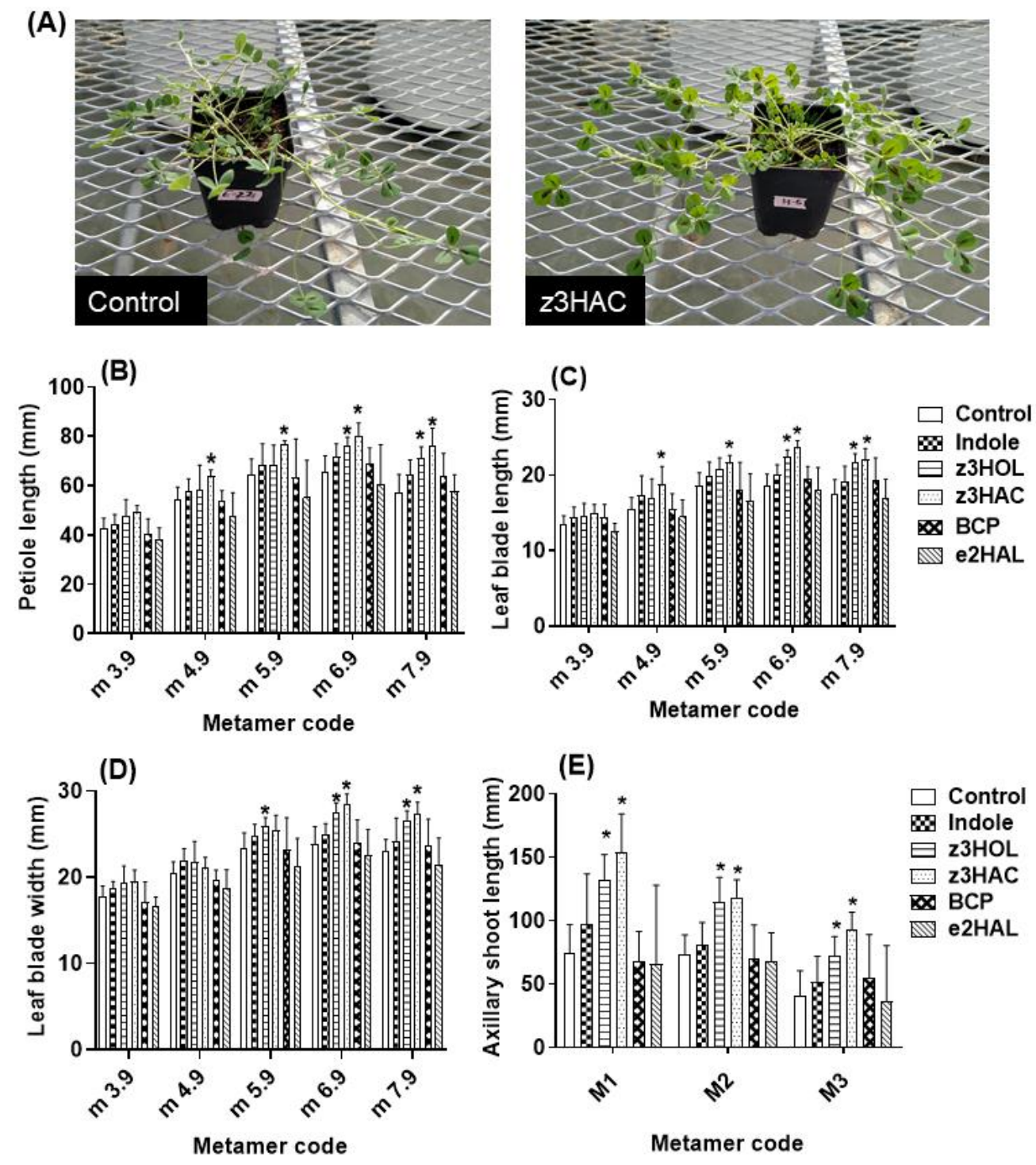
Figure 4
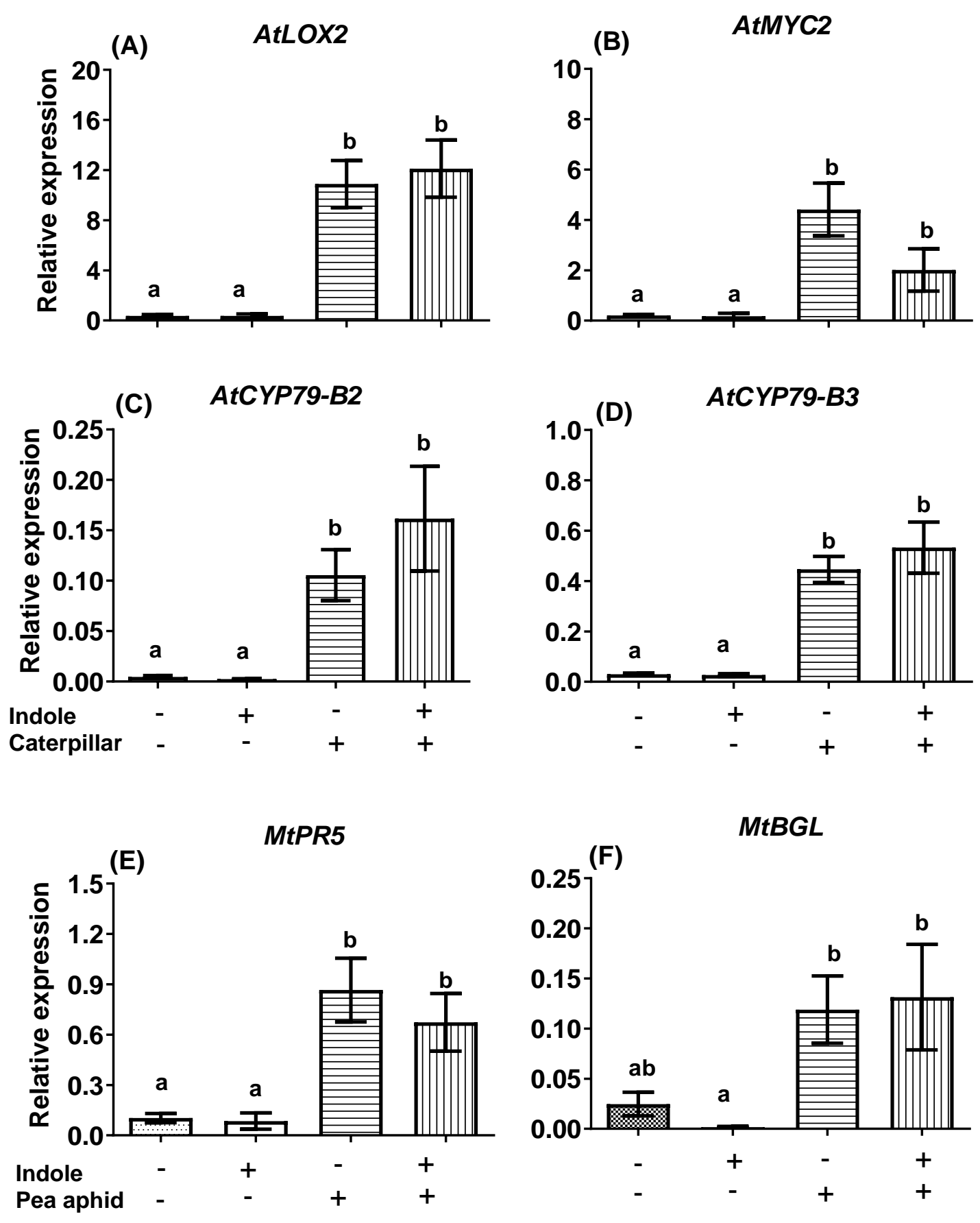
CHAPTER III

\section{VOLATILE IDENTITY AND HERBIVORE HOST BREADTH AFFECT THE DIRECT TOXICITY OF HERBIVORE-INDUCED PLANT VOLATILES}

\section{SUMMARY}

Herbivore-induced plant volatiles (HIPVs) provide direct benefits to plants as antimicrobials and herbivore repellents, but their potential as direct toxins to herbivores is unclear. Here we tested the larvicidal activity of six common HIPV's against Spodoptera exigua. In feeding bioassays, indole was the most toxic to $S$. exigua $\left(\mathrm{LC}_{50}=0.35 \mathrm{mg} / \mathrm{ml}\right)$, followed by the monoterpene linalool $\left(\mathrm{LC}_{50}=2.59 \mathrm{mg} / \mathrm{ml}\right)$, which was required a ca. $700 \%$ higher concentration than indole to cause mortality. Because of the high toxicity of indole, I tested the larvicidal activity of indole against six common, destructive pest caterpillars. Indole toxicity varied with caterpillar host range: indole toxicity was severalfold higher in the specialist Anticarsia gemmatalis $\left(\mathrm{LC}_{50}=0.05 \mathrm{mg} / \mathrm{ml}\right)$ and generalist with host preference Trichoplusia ni $\left(\mathrm{LC}_{50}=0.05 \mathrm{mg} / \mathrm{ml}\right)$ compared to the generalists Heliothis virescens ( $\left.\mathrm{LC}_{50}=0.18 \mathrm{mg} / \mathrm{ml}\right)$, Helicoverpa zea $\left(\mathrm{LC}_{50}=0.27 \mathrm{mg} / \mathrm{ml}\right)$, Spodoptera frugiperda $\left(\mathrm{LC}_{50}=0.29 \mathrm{mg} / \mathrm{ml}\right)$ and $\mathrm{S}$. exigua $\left(\mathrm{LC}_{50}=0.35 \mathrm{mg} / \mathrm{ml}\right)$. Even against the generalist caterpillars, indole toxicity was comparable to other reported anti-herbivore agents (e.g., Cry1F and other essential oils). Yet, indole in headspace had neither larvicidal nor ovicidal activity on S. exigua and T. ni caterpillars. The results of this study are the first to calculate the $\mathrm{LC}_{50}$ of major plant volatiles against $S$. exigua and determine the toxicity of 
indole against six destructive caterpillar pests. The results of this study indicate that indole may be a direct defense against herbivores and has the potential to be used in integrated pest management.

\section{INTRODUCTION}

Plants produce a remarkable variety of volatile organic compounds (VOCs) that can affect the behavior of pollinators (Schiestl \& Ayasse, 2001; Schiestl et al., 1999), seed dispersers (Valenta et al., 2017), and herbivores (Agrawal, 2001; Vickers et al., 2009). Plants release herbivore-induced plant volatiles (HIPVs) in response to herbivore attack which provides both indirect and direct defense benefits (Hare, 2011). HIPVs can act as priming cues that activate plant defenses and reduce herbivory (Erb et al., 2015b; Frost et al., 2007; Frost et al., 2008; Heil \& Bueno, 2007), mediate the attraction of natural enemies (Birkett et al., 2003; Dicke, 1986; Dicke \& Sabelis, 1988; Güimil et al., 2005; Schnee et al., 2006; Turlings et al., 1995; Turlings et al., 1990), and can make the herbivores more susceptible to entomopathogens (Gasmi et al., 2018). HIPVs also have direct defense benefits to the plants that produce them, including protecting plants from microbial infections and inhibiting the germination of pathogen propagules (Atul-Nayyar et al., 2009; Richard et al., 2006). HIPVs deter herbivory (Beale et al., 2006; Bernasconi et al., 1998a; Heil, 2004a; Liu et al., 2014) and oviposition (Kessler \& Baldwin, 2001; Veyrat et al., 2016a; Zakir et al., 2013), and exposure to VOCs alone can reduce caterpillar growth (von Mérey et al., 2013) and food consumption (Veyrat et al., 2016a). The hypothesis that HIPVs directly affect insect herbivores fecundity is not new (Hempel et al., 2009; Pichersky \& Gershenzon, 2002), but the direct larvicidal or ovicidal 
efficacy of HIPVs on insect herbivores is poorly understood. This is due in part to the fact that the consideration of diverse phytochemicals acting as selective pressure driving insect pest feeding strategies has largely excluded volatile constituents (Endara et al., 2017; Feeny, 1976; Howard V. C. \& Bradford A. H., 2003). The vast majority of insects are specialists, feeding on only one or a few closely related species (Forister et al., 2015), while a minority of insect herbivore species have a more generalist host range. Evolutionary theory predicts that phytochemicals that are widespread among different plant taxa will be less toxic to generalist insects compared to specialists (Howard V. C. \& Bradford A. H., 2003). HIPVs tend to be common across plant taxa, and some HIPVs can be pre-synthesized, stored in specialized cells in their original or conjugated forms in various types of plant tissues (Akahane et al., 2012; Baldwin, 2010; Ormeño et al., 2011; Sugimoto et al., 2015; Tominaga \& Dubourdieu, 2000), and released when herbivory disrupts cellular storage compartments (Niinemets et al., 2013). Insect pests must, therefore, cope with the potentially toxic effects of HIPVs by either direct ingestion or in airspace (headspace) exposure.

Many of the major agricultural pests that cause significant damage and economic loss of food crops worldwide belong to the insect order Lepidoptera (butterflies and moths) (Vreysen et al., 2016). These known pests include both specialists and generalists. To control the crop losses to these lepidopteran pests, potent and toxic synthetic chemicals are used in current agricultural systems (Cordero et al., 2006; Ecobichon, 2001; Pimentel, 1996). However, the use of broad-spectrum, and persistent insecticides comes with unintended negative consequences to human health and non- 
target organisms (Cimino et al., 2016; Hahn et al., 2015; Mulé et al., 2017; Tingle et al., 2003). Furthermore, insect pests are developing resistance against commonly used insecticides (Brown, 1958; Sparks \& Nauen, 2015). The vast diversity of plant-derived chemicals may provide alternative approaches to insect control. In recent years, plant essential oils containing blends of VOCs (and HIPVs) have been tested as "ecofriendly" control formulations against lepidopteran pests (da Silva et al., 2019; Feng et al., 2018; Plata-Rueda et al., 2017). Although the potential toxicity of individual HIPVs against lepidopteran pests is limited, the toxicity of some VOCs against other invertebrate groups is known (Hamel et al., 2004; Hubert et al., 2008a; Laquale et al., 2018; Zhao et al., 2017). In addition, blends of plant essential oils are known ovicidal and larvicidal against lepidopteran pests in agricultural systems (Bakkali et al., 2008; El-Zaeddi et al., 2016; Isman, 2016; Mossa, 2016). Essential oils commonly contain volatiles that are also major constituents of HIPV blends (Maffei et al., 2011). Therefore, investigating the larvicidal and ovicidal activity of common individual HIPVs from essential oils may identify alternatives strategies for chemical-mediated pest control in agriculture systems.

In this study, I evaluated the direct toxicity of six individual HIPVs on a common lepidopteran herbivore pest beet-armyworm (Spodoptera exigua). Because plant volatiles may affect herbivores fitness directly through ingested leaf tissues as well as indirectly through air contact, I conducted dose-response assays HIPVs either infused directly into diet or headspace. The first objective was to assess the direct toxicity of six major HIPVs against S.exigua. As terpenes and phenylpropanoids are common 
constituents of plant essential oils toxic to herbivores (Moghaddam \& Mehdizadeh, 2017), I predicted that indole and the terpenes would be relatively more toxic than the GLVs. The second objective was to test the larvicidal activity of indole on six agriculturally important caterpillar species with different host ranges (Table 2). Because indole is produced by a wide range of plant species (Ameye et al., 2015; Cna'ani et al., 2018a), I hypothesized that indole will be more toxic to host specialists. The third objective was to assess the ovicidal effect of indole. Since HIPVs also provide an indirect defense to plants by attracting egg predators (Fatouros et al., 2008), I predicted indole may provide a direct defense benefit by reducing egg hatching success.

\section{MATERIALS AND METHODS}

\section{Synthetic plant volatiles}

Six common HIPVs belonging to different biosynthetic pathways were tested: GLVs cis-3-hexenol (97\%, Density: 0.848 g/ml) (TCl), cis-3-hexenyl acetate (99\%, Density: $0.897 \mathrm{~g} / \mathrm{mL}$ ) (TCl), and trans-2-hexenal (98\%, Density: $0.846 \mathrm{~g} / \mathrm{mL}$ ) (Sigma-Aldrich); terpenes $\beta$-caryophyllene (97\%, Density: $0.902 \mathrm{~g} / \mathrm{mL}$ ) (MP Biomedicals) and linalool (97\%, Density: $0.870 \mathrm{~g} / \mathrm{mL}$ ) (Alfa Aesar); and aromatic volatile indole (97\%, Density: $1.051 \mathrm{~g} / \mathrm{mL})(\mathrm{TCl})$. Caterpillar culture

Eggs of beet armyworm (Spodoptera exigua), fall armyworm (Spodoptera frugiperda), cotton bollworm (Helicoverpa zea), tobacco budworm (Heliothis virescens), velvetbean caterpillar (Anticarsia gemmatalis), and cabbage looper (Trichoplusia ni) were obtained from Benzon Research Inc. USA (Permit \#P526P-16-02563). Egg masses 
were immediately transferred to 2-ounce diet cups. Eggs in diet cups were maintained at $24-27{ }^{\circ} \mathrm{C}$ until the egg hatched, and $1^{\text {st }}$ instar larvae were used within 24 of hatching for all bioassays.

Preparation of test diets for feeding bioassay

Larvicidal effects of HIPVs against S. exigua were tested at five different concentrations $1,2.5,3.75,5$, and $10 \mathrm{mg} / \mathrm{ml}$ or $\mu \mathrm{l} / \mathrm{ml}$ in feeding and headspace bioassays, respectively. The initial concentrations tested were based on the $\mathrm{LC}_{50}$ of trans-2-hexenal against five species of stored-product beetles (Hubert et al., 2008b). Due to the high larvicidal activity of indole in initial feeding bioassays, the toxicity of indole against all six caterpillar species was tested at diet concentrations ranging from 0.005 to $1 \mathrm{mg} / \mathrm{ml}$. Test diets were prepared $12 \mathrm{~h}$ prior to the start of the experiment. Artificial diet powder (Southland Products Incorporated, Arkansas, USA) was prepared per manufactures instructions and aliquoted into $50-\mathrm{ml}$ falcon tubes. Prior to the diet solidifying, an appropriate amount of an individual HIPV was added, and the tube was vortexed thoroughly to cause complete mixing of volatiles in the diet. Control diets were prepared similarly without any volatile. After solidifying at room temperature, the diet was cut into disc-shaped pieces (10 mm diameter, $5 \mathrm{~mm}$ height, ca. $400 \mathrm{mg}$ ) using a 10-cm long cork borer. Each experimental cup received one piece of artificial diet.

Preparation of volatile dispenser for headspace bioassay

Experimental amounts of cis-3-hexenol, cis-3-hexenyl acetate, $\beta$-caryophyllene, Linalool, trans-2-hexenal, and Indole were added into a $2.0 \mathrm{ml}$ amber glass vial (Agilent Technologies) with $1 \mathrm{mg}$ of glass wool (Figure 5). Control dispensers had only glass wool 
without any volatile (Erb et al., 2015a). The amber vials with volatiles were sealed with a rubber septum and connected to the diet cup by piercing the diet cup and amber vial rubber septum with an 18-gauge needle (inner diameter $0.83 \mathrm{~mm}$ ). This allowed for the control of volatiles delivered to the feeding chamber. In a similar type of volatile dispenser containing $20 \mathrm{mg}$ of indole and pierced with a $1 \mu \mathrm{L}$ micro-pipette (inner diameter $0.2 \mathrm{~mm}$ ), the volatile release rate was measured at c.a. $21 \mathrm{ng} / \mathrm{h}$ (Ye et al., 2019).

Test of toxicity of plant volatiles against caterpillars

I used S. exigua as the first model pest because it is destructive generalist agricultural pest (Liburd et al., 2000; Pearson, 1983) that has developed resistance against chemical insecticides (Brewer et al., 1990; Che et al., 2013), and is also a model herbivore in HIPV-mediated direct and indirect plant defense studies (Christensen et al., 2013a; Engelberth et al., 2004b; Huffaker et al., 2013; Jurriaan et al., 2007; Schmelz et al., 2003). In follow up experiments I tested the indole toxicity against larvae of five common pest species ranging from generalist to specialist in their feeding behavior (Table 2). First instar larvae were used for testing the toxicity of plant volatiles because the first instar is the most sensitive stage to secondary plant chemicals (Zalucki et al., 2002). For feeding bioassays, ten first instar larvae were transferred using a fine paintbrush in each diet cup containing either a volatile infused diet or control diet. Similarly, for headspace bioassays, ten first instar larvae were transferred in each diet cup containing control diet, however, the diet cups were connected to either a control dispenser or a volatile dispenser. The unit of replication was the diet cup and each 
treatment group at a specific concentration had 5-10 replicates. The percent survivability at $24 \mathrm{~h}$ was determined for each replicate.

Test of the inhibitory effect of indole in S. exigua and T. ni egg hatching bioassay

For egg hatching assays, I specifically selected caterpillar species most susceptible and tolerant to indole in feeding bioassays. The inhibitory effect of indole on S. exigua and T. ni egg hatching was measured in a headspace bioassay. S. exigua and $T$. ni eggs were transferred to diet cups that were connected to volatile dispensers containing different concentrations of indole; $0.1,0.25,0.5,1,2.5,5,10,15$ and 20 $\mathrm{mg} / \mathrm{ml}$. Each concentration of indole had 5 replicate diet cups. The percent hatch of the eggs was measured at $96 \mathrm{~h}$ after exposure and compared to controls without indole. Statistical analyses

All analyses were conducted with R statistical software (R Core Team, 2018). For calculating the median lethal concentration $\left(\mathrm{LC}_{50}\right)$, the mortality rates of caterpillar larvae after 24 hours of VOC exposure were regressed on concentrations using the logistic regression in gIm function of R. Initially linear logistic regression was used but significant non-linearity was found in the relationship between logit and concentration. To account for the non-linear relationship between logit and concentration, quadratic and cubic logistic regressions were performed and were compared to each other and to the linear logistic regression by the AIC values. The best model was chosen using the lowest AIC values as the criterion. In all analyses, the quadratic model was best using the lowest $\mathrm{AIC}$ value as a criterion and the median lethal concentration ( $\left.\mathrm{LC}_{50}\right)$ was 
calculated using the fitted function in quadratic logistic regression. Survivorship (\%) was plotted against concentration with GraphPad Prism version 8.0.0 (San Diego, California USA) and ggplot2 in R(Wickham, 2011). The effect of concentration on mortality for each individual volatile was analyzed using Dunnett's test, while differences among plant volatiles for mortality at specific concentrations were analyzed using Tukey's HSD. Data were arcsine transformed to satisfy assumptions of statistical tests. Significance was declared at $\mathrm{p}<0.05$.

\section{RESULTS}

HIPV toxicity against S. exigua

Type and concentration of HIPVs affected caterpillar mortality (Tables 3 and 4). The mortality of S. exigua was negligible in the control group. Among all HIPVs tested, indole caused the highest larval mortality, followed by monoterpene linalool and the GLV cis-3-hexenyl acetate (Figure 6A). In contrast to feeding bioassays, no HIPV showed any toxicity to S.exigua when administered in headspace alone (Figure 6B). Based on $\mathrm{LC}_{50}$ values, indole was more than 7 times toxic than the second most potent toxicant (linalool) among all the HIPVs tested against S. exigua (Indole $\mathrm{LC}_{50}=0.35 \mathrm{mg} / \mathrm{ml}$; linalool $\mathrm{LC}_{50}=2.59 \mu \mathrm{l} / \mathrm{ml}$ (or $2.26 \mathrm{mg} / \mathrm{ml}$, calculated using mass, volume, and density formula)) (Figure 7). GLVs were relatively less toxic: cis-3-hexenol $\left(\mathrm{LC}_{50}=3.32 \mu \mathrm{l} / \mathrm{ml}\right.$ or $2.81 \mathrm{mg} / \mathrm{ml}$ diet), cis-3-hexenyl acetate ( $\mathrm{LC}_{50}=4.61 \mu \mathrm{l} / \mathrm{ml}, 4.13 \mathrm{mg} / \mathrm{ml}$ diet $)$ and trans-2-hexenal ( $\mathrm{LC}_{50}$ $=4.85 \mu \mathrm{l} / \mathrm{ml}, 4.1 \mathrm{mg} / \mathrm{ml}$ diet) (Figure 7). $\beta$-caryophyllene was neither toxic in diet nor headspace against S.exigua caterpillars at any of the tested concentrations. Indole toxicity increases as host range decreases 
Indole was highly larvicidal against all caterpillar species tested, but more so to the caterpillars with restricted host ranges. Whereas indole was larvicidal to the specialist caterpillar (A. gemmatalis) and generalist caterpillar with host preference (T.ni) at $0.1 \mathrm{mg} / \mathrm{ml}$ diet, $0.5 \mathrm{mg} / \mathrm{ml}$ diet was required for larvicidal effects for other generalist caterpillars like S.exigua, S. frugiperda, H. zea, H. virescens (Figure 8). Consistently, the $\mathrm{LC}_{50}$ value of indole was lowest for $T$. ni and $A$. gemmatalis $\left(\mathrm{LC}_{50}=0.05\right.$ $\mathrm{mg} / \mathrm{ml}$ diet $)$ followed by $H$. virescens $\left(\mathrm{LC}_{50}=0.18 \mathrm{mg} / \mathrm{ml}\right.$ diet $), H$. zea $\left(\mathrm{LC}_{50}=0.27 \mathrm{mg} / \mathrm{ml}\right.$ diet), and S. frugiperda ( $\mathrm{LC}_{50}=0.29 \mathrm{mg} / \mathrm{ml}$ diet) (Figure 8). The presence of indole in headspace had no significant effect on the mortality of $T$. ni caterpillars (Figure9). Indole does not affect egg hatching rates

S. exigua and T. ni eggs were exposed to varying concentrations of indole. Exposure of $S$. exigua and $T$. ni eggs to headspace vials containing either $0.1,0.25,0.5,1$, $2.5,5,10$, or $20 \mathrm{mg}$ of indole for $96 \mathrm{~h}$ did not show significant inhibitory effect on egg hatching (Figure $10 \mathrm{a}, \mathrm{b}$ ).

\section{DISCUSSION}

I evaluated the $\mathrm{LC}_{50}$ of a select set of common HIPVs against agriculturally destructive crop pest $S$. exigua in headspace and diet. None of the compounds were toxic when present in the only headspace. By contrast, indole and, to a lesser extent, GLVs and volatile terpenes, have direct larvicidal activity against the common crop pest S. exigua. In particular, indole was considerably the most larvicidal of the tested HIPVs against S. exigua, and also had particular larvicidal activity on all six major agricultural caterpillar pests tested in this study. Plant-derived essential oils can be 
effective against herbivores and stored grain pests (Abdelgaleil et al., 2016; Baldin et al., 2015), and it is particularly important to identify causative agents in such essential oil mixtures. The larvicidal effect of some GLVs and terpenes has been reported against stored-pest beetles (Hubert et al., 2008b) and aphids (Sadeghi et al., 2009), and the results are comparable. For example, the $\mathrm{LC}_{50}$ values I obtained for the three GLVs tested, cis-3-hexenol $(3.32 \mu \mathrm{l} / \mathrm{ml}, 2.81 \mathrm{mg} / \mathrm{ml})$, cis-3-hexenyl acetate $(4.61 \mu \mathrm{l} / \mathrm{ml}$, $4.13 \mathrm{mg} / \mathrm{ml})$, and trans-2-hexenal $(4.85 \mu \mathrm{l} / \mathrm{ml}, 4.1 \mathrm{mg} / \mathrm{ml}$ ) (Figure 7), are similar to those reported against stored pest beetles (0.6-3.32 mg/g) (Hubert et al., 2008b). Similarly, the larvicidal activity of the terpene linalool against S.exigua in this study ( LC $_{50}$ of 2.59 $\mu \mathrm{l} / \mathrm{ml}, 2.26 \mathrm{mg} / \mathrm{ml}$ ) is comparable to previous work testing linalool against the European corn borer (Lee et al., 1999b).

Not surprisingly, larvicidal activity against S. exigua varied among HIPVs. While the $L C_{50}$ values of tested HIPVs in this study are higher than emission rates observed in nature (Allmann et al., 2013; Degen et al., 2012), they are likely representative of what might be stored within leaf tissues (Loreto et al., 1998; Loreto et al., 2000; Niinemets et al., 2004) and what insect herbivores may realistically encounter in their natural diets. Indole was considerably more toxic than the other HIPVs tested, and had strong larvicidal activity for all herbivore species tested, with $\mathrm{LC}_{50}$ ranging from $0.35 \mathrm{mg} / \mathrm{ml}$ $(350 \mu \mathrm{g} / \mathrm{ml})$ against S. exigua to $0.05 \mathrm{mg} / \mathrm{ml}(50 \mu \mathrm{g} / \mathrm{ml})$ against $A$. gemmatalis and $T$. ni (Figure 8). In fact, the larvicidal activity of indole is comparable to previously studied natural toxicants such various strains of Bacillus thuringiensis $\left(\right.$ LC $\left._{50}=63.0-153.0 \mu \mathrm{g} / \mathrm{ml}\right)$ (Moar et al., 1989) and purified Cry1 proteins from B.thuringiensis protein ( $L_{50}=1-870$ 
$\mu \mathrm{g} / \mathrm{g}$ ) (Ali et al., 2006; Niu et al., 2013). Moreover, the LC 50 of commercial $B$.

thuringiensis DiPel ES ( $\mathrm{LC}_{50}=2 \mu \mathrm{g} / \mathrm{g}$ ) (Liao et al., 2002) and the synthetic insecticide lambda-cyhalothrin $\left(\mathrm{LC}_{50}=5.27 \mu \mathrm{g} / \mathrm{ml}\right)$ (Hardke et al., 2011) are close to $\mathrm{LC}_{50}$ obtained for indole at $24 \mathrm{~h}$ in this experiments. Therefore, indole may be a promising candidate as a natural biological control agent with high larvicidal activity.

HIPVs in headspace alone did not affect caterpillar survival or egg hatching. In previous work, indole had an inhibitory effect even in headspace alone against the generalist herbivore S. littoralis (Veyrat et al., 2016b). While I did not find similar effects with S.exigua, this study was focused on larvicidal activity and not differential weight gain or growth. That said, exposure of eggs to indole in headspace also had no effect on the hatching success of either S. exigua or T.ni. (Figure 10). Plants volatiles can clearly have repellent effects on insect pests (Beale et al., 2006; Bernasconi et al., 1998b; Heil, 2004b; Sandra et al., 2014), but this study indicates that larvicidal efficacy of HIPVs depends on their direct consumption by herbivores.

In this study, the larvicidal activity of indole varied with the caterpillar host range. A long-standing hypothesis is that generalist herbivores are well-equipped to detoxify wide array of common phytochemicals (Agrawal \& Ali, 2012; Krieger et al., 1971), whereas specialist herbivores are more tolerant to compounds specific to their host range but sensitive to more common phytochemicals (Whittaker \& Feeny, 1971). Since indole is an inter-kingdom signal molecule (Lee et al., 2015) that is common in plants (Cna'ani et al., 2018b), I predicted that it would be relatively toxic to specialist caterpillars compared to generalist caterpillars. The results of this study support this 
prediction: concentration needed for the larvicidal activity of indole was approximately seven times lower for specialist $A$. gemmatalis compared to generalist S. exigua and, in general, all the generalist caterpillar showed higher tolerance to indole. The exception was $T$. ni, which had an $\mathrm{LC}_{50}$ to indole approximately the same as the specialist $A$. gemmatalis ( $\mathrm{LC}_{50}=0.05 \mathrm{mg} / \mathrm{ml}$ of diet) (Figure 8). While $T . n i$ is a generalist, it is also recognized to preferentially feed on Brassicaceae species (RiveraVega et al., 2017). The efficacy of indole as a biological control agent may, therefore, be dependent on the insect pest species that is being targeted.

More than 500 insect pest species have developed documented resistance to chemical insecticides (Bass et al., 2015; Georghiou, 1990). Agriculturally destructive caterpillars are particularly capable of developing such resistance (Ahmad et al., 2008; Che et al., 2013; Elzen, 1997; Hardee et al., 2001; McEwen \& Splittstoesser, 1970; Yu et al., 2003). Plant secondary metabolites can provide alternatives to synthetic insecticides in pest management, while also potentially avoiding or ameliorating negative impacts on beneficial organisms. This study identifies that indole, and potentially other plant-derived volatiles, may be important additions to the arsenal of chemical defenses in pest management. To my knowledge, this is the first study to measure the $\mathrm{LC}_{50}$ of indole using caterpillars as the target organism. Indole might be particularly useful as a biopesticide and part of integrated pest management for managing generalist and specialist caterpillars given its larvicidal effect is similar or stronger than to some commercial pesticides and potent biopesticides like the Cry1F bacillus thuringiensis protein. Even the larvicidal activity of the GLVs and linalool 
against S. exigua in this study is approximately the same as reported for other pests. HIPVs warrant attention as a component of biological control strategies against insect pests. 


\section{TABLES}

Table 2 Host range and common hosts of six tested caterpillars

\begin{tabular}{|c|c|c|c|}
\hline Insect & Common name & Host Range & Common Hosts \\
\hline $\begin{array}{c}\text { Spodoptera } \\
\text { exigua }\end{array}$ & Beet armyworm & Generalist & $\begin{array}{l}\text { Alfalfa, broccoli, corn, cabbage, } \\
\text { cotton, chickpea, Maize, peanut, } \\
\text { pepper, potato, pigweed, } \\
\text { sunflower, sorghum, soybean, } \\
\text { sugar-beet, tobacco, tomato etc. } \\
\text { (Capinera, 1999a; Greenberg et } \\
\text { al., 2001) }\end{array}$ \\
\hline $\begin{array}{l}\text { Spodoptera } \\
\text { frugiperda }\end{array}$ & Fall armyworm & Generalist & $\begin{array}{l}\text { Apple, bean, barley, cotton, } \\
\text { grapes, maize, orange, oat, } \\
\text { papaya, millet, peanut, rice, } \\
\text { sorghum, sugar beet, soybean, } \\
\text { sugarcane, tobacco, and wheat } \\
\text { etc. (CABI; Capinera, 1999c) }\end{array}$ \\
\hline $\begin{array}{c}\text { Helicoverpa } \\
\text { zea }\end{array}$ & $\begin{array}{c}\text { Corn earworm/ } \\
\text { Cotton } \\
\text { bollworm/tomato } \\
\text { fruitworm }\end{array}$ & Generalist & $\begin{array}{l}\text { Asparagus, cauliflower, chickpea, } \\
\text { cucumber, lettuce, lima bean, } \\
\text { millet, okra, pigeon pea, pea, } \\
\text { pepper, potato, pumpkin, } \\
\text { sorghum, soybean, sweet corn, }\end{array}$ \\
\hline
\end{tabular}




\begin{tabular}{|c|c|c|c|}
\hline & & & $\begin{array}{l}\text { sweet potato etc.(CABI; Martin et } \\
\qquad \text { al., 1976) }\end{array}$ \\
\hline $\begin{array}{l}\text { Heliothis } \\
\text { virescens }\end{array}$ & $\begin{array}{l}\text { Tobacco } \\
\text { budworm }\end{array}$ & Generalist & $\begin{array}{l}\text { Alfalfa, cabbage, cotton, lettuce, } \\
\text { pea, soybean, cotton, tobacco etc. } \\
\text { (Capinera, 2001; Harding, 1976; } \\
\text { Martin et al., 1976) }\end{array}$ \\
\hline $\begin{array}{l}\text { Trichoplusia } \\
\text { ni. }\end{array}$ & Cabbage Lopper & $\begin{array}{l}\text { Generalist with } \\
\text { host preference } \\
\text { for crucifers }\end{array}$ & $\begin{array}{l}\text { Beans, broccoli, cotton, cabbage, } \\
\text { cucumber, cauliflower, kale, } \\
\text { mustard, potato, radish, spinach, } \\
\text { tomato etc. (Capinera, 1999b; } \\
\text { Hoo et al., 1984; Martin et al., } \\
\text { 1976) }\end{array}$ \\
\hline $\begin{array}{l}\text { Anticarsia } \\
\text { gemmatalis }\end{array}$ & $\begin{array}{l}\text { velvetbean } \\
\text { caterpillar }\end{array}$ & $\begin{array}{l}\text { Specialist on } \\
\text { legume crops } \\
\text { (Slansky, 1993) }\end{array}$ & $\begin{array}{l}\text { Soybean, chickpea, pea, peanut } \\
\text { etc. (Waters \& Barfield, 1989) }\end{array}$ \\
\hline
\end{tabular}


Table 3 Between-treatment effect of plant volatiles at each concentration on S. exigua survival in feeding bioassays. Mortality was checked at $24 \mathrm{~h}$ after exposure to volatile infused diet.

\begin{tabular}{|c|c|c|c|c|c|}
\hline Concentrations $(\mathrm{mg} / \mathrm{ml} / \mu \mathrm{l} / \mathrm{ml})$ & 1 & 2.5 & 3.75 & 5 & 10 \\
\hline Treatment comparison & \multicolumn{5}{|c|}{ ( $p$ values $)^{a}$} \\
\hline Indole- $B$ caryophyllene & $<0.001$ & $<0.001$ & $<0.001$ & $<0.001$ & $<0.001$ \\
\hline Indole-Linalool & $<0.001$ & $<0.001$ & 0.985 & 1 & 1 \\
\hline Indole-Trans-2-hexenal & $<0.001$ & $<0.001$ & $<0.001$ & $<0.001$ & 1 \\
\hline Indole-Cis-3-hexenyl acetate & $<0.001$ & $<0.001$ & $<0.001$ & 0.0835 & 1 \\
\hline Indole-Cis-3-hexenol & $<0.001$ & $<0.001$ & 0.930 & 0.985 & 1 \\
\hline B caryophyllene-Linalool & 0.977 & 0.992 & $<0.001$ & $<0.001$ & $<0.001$ \\
\hline B caryophyllene-Trans-2-hexenal & 0.815 & 0.998 & 0.853 & $<0.001$ & $<0.001$ \\
\hline $\begin{array}{c}\text { B caryophyllene-Cis-3-hexenyl } \\
\text { acetate }\end{array}$ & 0.971 & 0.999 & 0.145 & $<0.001$ & $<0.001$ \\
\hline B caryophyllene-Cis-3-hexenol & 0.977 & 0.998 & $<0.001$ & $<0.001$ & $<0.001$ \\
\hline Linalool-Trans-2-hexanal & 0.352 & 0.901 & $<0.001$ & $<0.001$ & 1 \\
\hline Linalool-Cis-3-hexenol & 1 & 0.901 & 0.591 & 0.984 & 1 \\
\hline Linalool-Cis-3-hexenyl acetate & 0.651 & 0.999 & $<0.001$ & 0.0834 & 1 \\
\hline $\begin{array}{c}\text { Cis-3-hexenyl acetate-Trans-2- } \\
\text { hexanal }\end{array}$ & 0.997 & 0.982 & 0.803 & 0.570 & 1 \\
\hline
\end{tabular}




\begin{tabular}{|c|c|c|c|c|c|}
\hline $\begin{array}{c}\text { Cis-3-hexenyl acetate- Cis-3- } \\
\text { hexenol }\end{array}$ & 0.652 & 0.982 & $<0.001$ & 0.351 & 1 \\
\hline Cis-3-hexenol- Trans-2-hexanal & 0.351 & 1 & $<0.001$ & 0.004 & 1 \\
\hline
\end{tabular}

${ }^{a} p$-values are based on ANOVA analysis followed by tukey post-hoc test 
Table 4 Within treatment effect of plant volatile concentrations on S. exigua survival in feeding bioassays. Mortality was checked at $24 \mathrm{~h}$ after exposure to volatile infused diet

\begin{tabular}{|c|c|c|c|c|c|c|}
\hline Treatment & Indole & $\begin{array}{c}\text { Cis-3- } \\
\text { hexenol }\end{array}$ & $\begin{array}{c}\text { Cis-3- } \\
\text { hexenyl } \\
\text { acetate }\end{array}$ & $\begin{array}{c}\text { Trans-2- } \\
\text { hexenal }\end{array}$ & Linalool & $\begin{array}{c}\text { B } \\
\text { caryophyllene }\end{array}$ \\
\hline $\begin{array}{c}\text { Concentrations values) } \\
\text { (mg/ml/ } \mathbf{\mu l} / \mathbf{m l})\end{array}$ & \multicolumn{5}{|c|}{} \\
\hline $\mathbf{0 - 0 . 1}$ & 0.996 & NA & NA & NA & NA & NA \\
\hline $\mathbf{0 - 0 . 2 5}$ & 0.996 & NA & NA & NA & NA & NA \\
\hline $\mathbf{0 - 0 . 3 7}$ & $<0.001$ & NA & NA & NA & NA & NA \\
\hline $\mathbf{0 - 0 . 5}$ & $<0.001$ & NA & NA & NA & NA & NA \\
\hline $\mathbf{0 - 1 . 0}$ & $<0.001$ & 0.920 & 0.878 & 0.710 & 0.899 & 1 \\
\hline $\mathbf{0 . 2 . 5}$ & $<0.001$ & 0.999 & 0.680 & 0.999 & 0.162 & 0.945 \\
\hline $\mathbf{0 - 3 . 7 5}$ & $<0.001$ & $<0.001$ & 0.892 & 0.895 & $<0.001$ & 0.010 \\
\hline $\mathbf{0 - 5 . 0}$ & $<0.001$ & $<0.001$ & $<0.001$ & $<0.001$ & $<0.001$ & 0.872 \\
\hline $\mathbf{0 - 1 0 . 0}$ & $<0.001$ & $<0.001$ & $<0.001$ & $<0.001$ & $<0.001$ & 0.999 \\
\hline
\end{tabular}

${ }^{a} p$-values are based on ANOVA analysis followed by Dunnett's post-hoc test 


\section{FIGURE LEGENDS}

Figure 5. A volatile delivery system for headspace bioassay.

Figure 6. Direct toxicity of plant volatiles at different concentrations on the survival of $S$. exigua in feeding bioassays (A) and headspace bioassay (B). Values at each concentration represent the mean of five-ten biological replicates \pm 1 SEM.

Figure 7. $\mathrm{LC}_{50}$ of individual plant volatiles on S. exigua caterpillars in feeding bioassay. Graphs for each volatile refer to fitted values based on quadratic logistic regression. LC50 represent lethal concentration causing 50 percent mortality. Data are reproduced individually from Figure2A for easy visualization.

Figure 8. Direct toxicity of indole on the survival of five different caterpillar species in feeding bioassays. Graph A, B, C and D represent generalist herbivores, graph E represent generalist with feeding preference while graph $\mathrm{F}$ represent specialist herbivore. Values at each concentration represent the mean of five-ten biological replicates \pm 1SEM. S. exigua data are reproduced (dashed lines) from Figure 2 to aid in comparison.

Figure 9. Effect of varying concentrations of indole on the survival of $T$. ni in headspace bioassays. Values at each concentration represent the mean of five-ten biological replicates \pm 1 SEM.

Figure 10. Effect of varying concentrations of indole on percent egg hatch of S.exigua (A) and T. ni (B). Values represent the mean of five biological replicates \pm 1 SEM. 
Figure 5

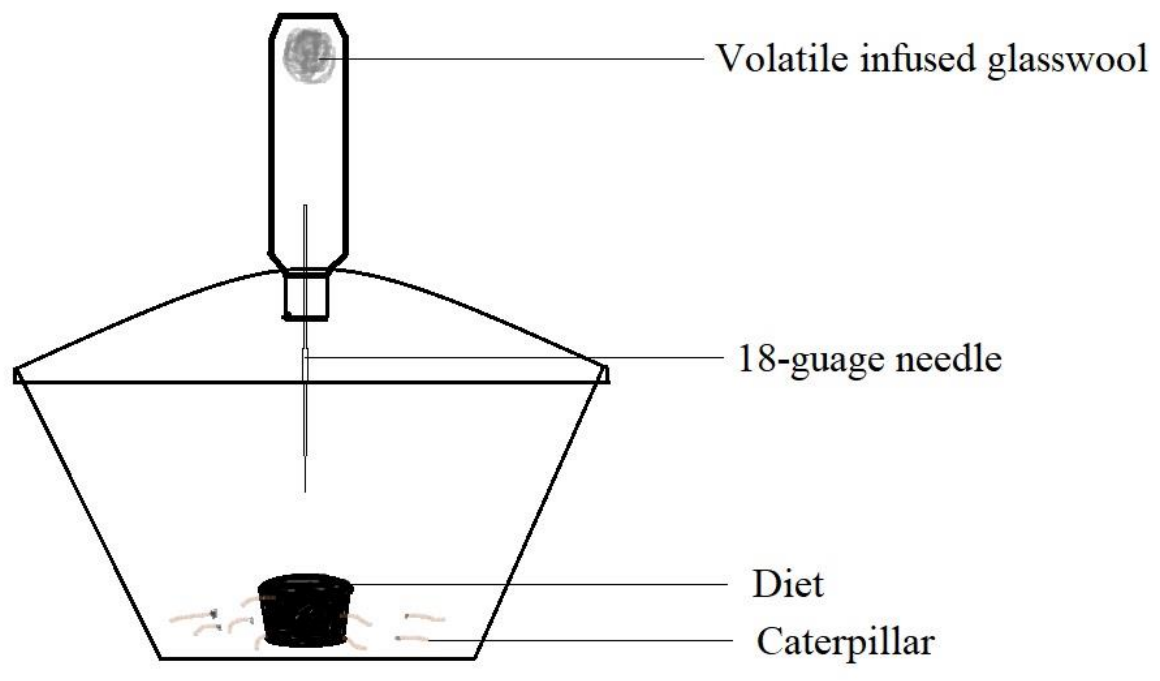


Figure 6

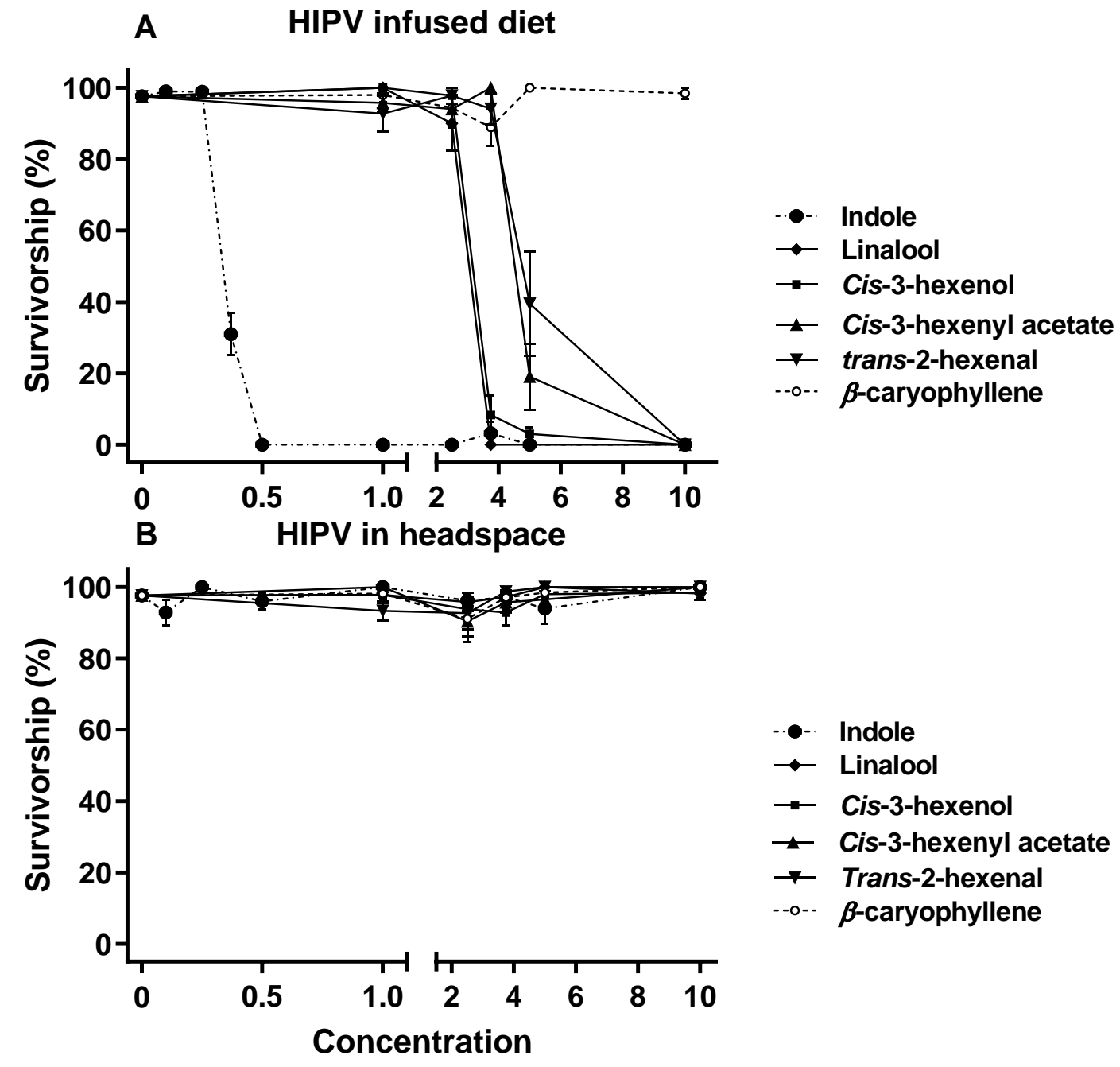

$\mathrm{mg} / \mathrm{ml}$ for indole $\& \mu \mathrm{l} / \mathrm{ml}$ for others 
Figure 7
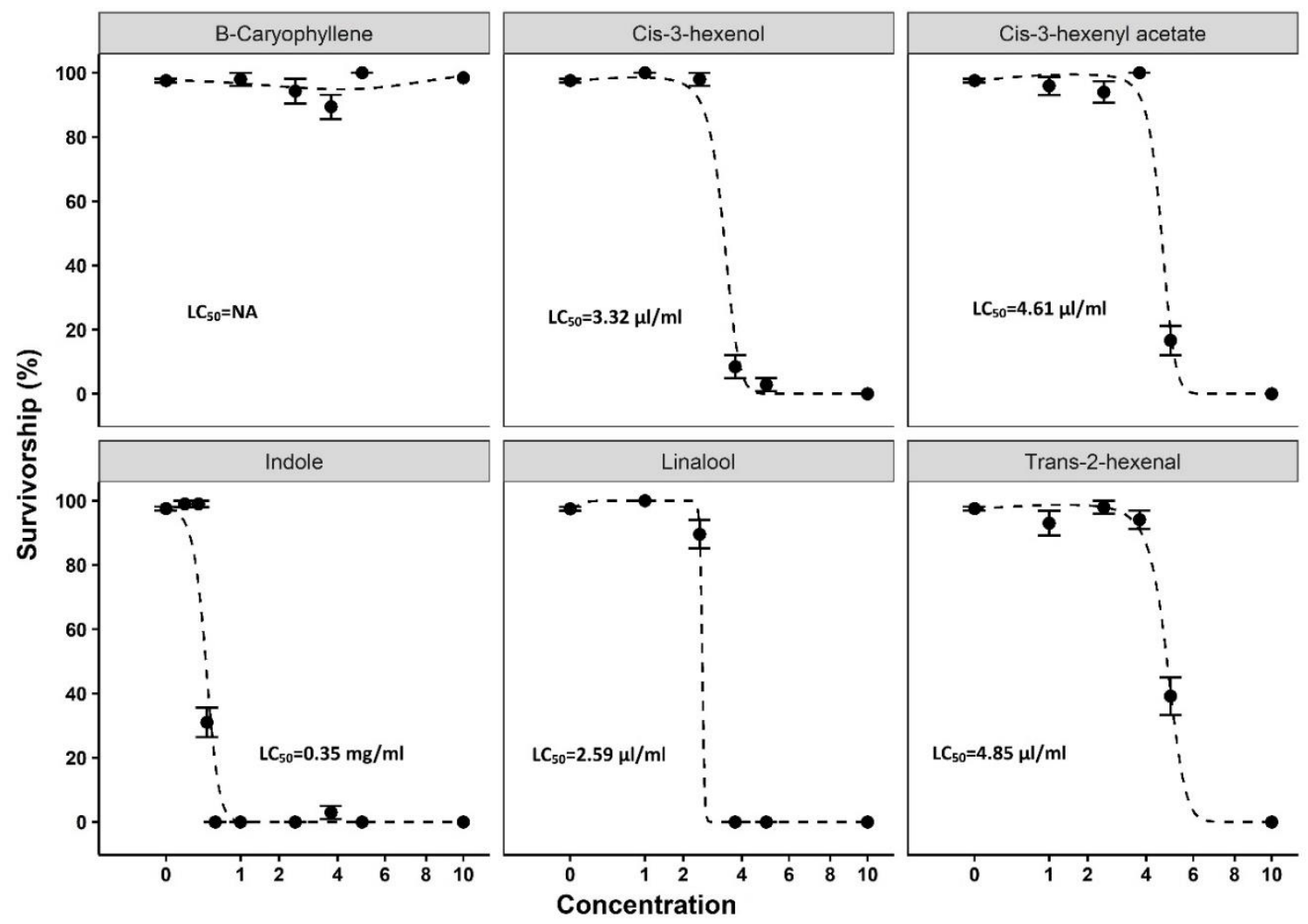
Figure 8
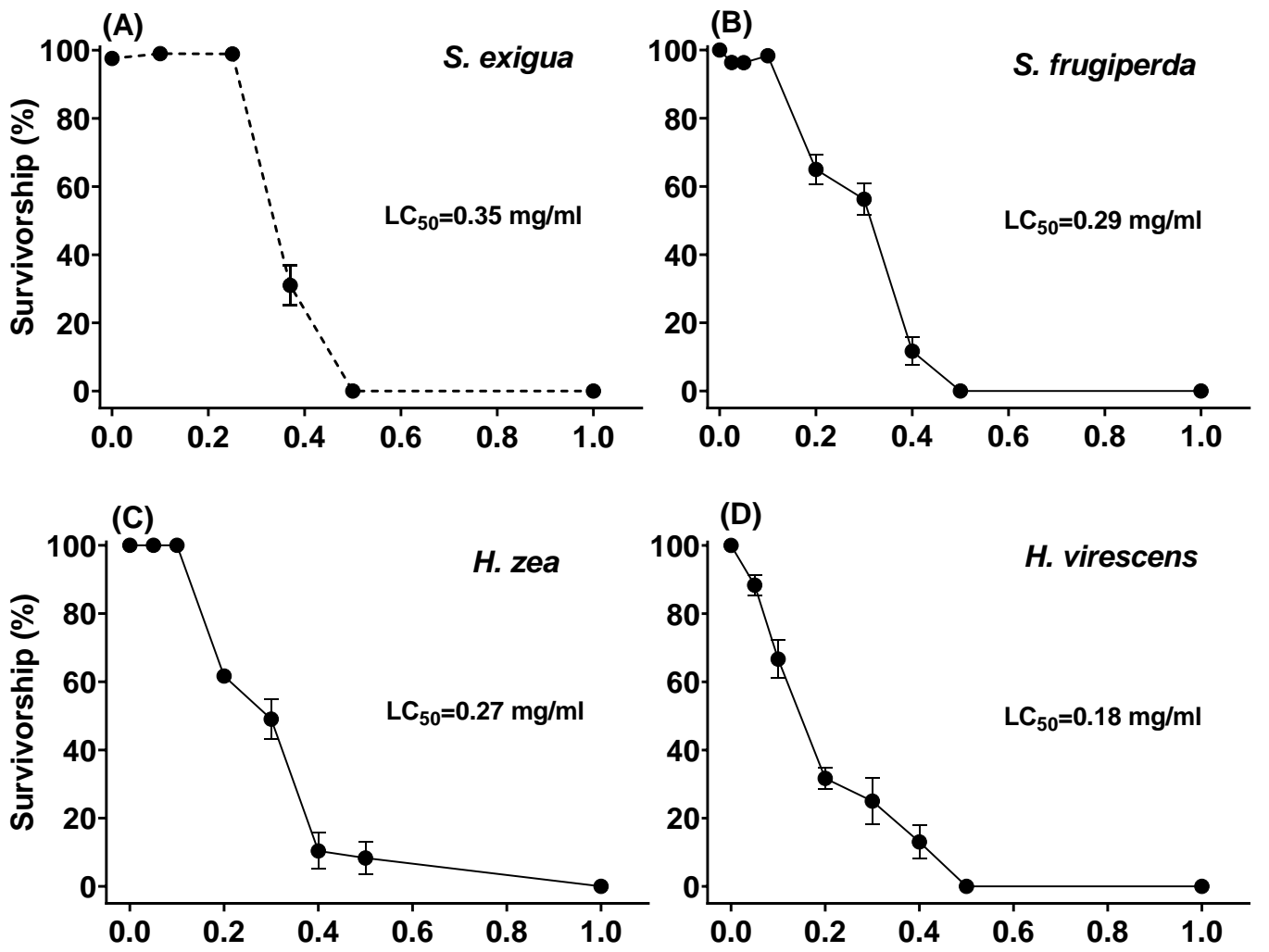

(E)

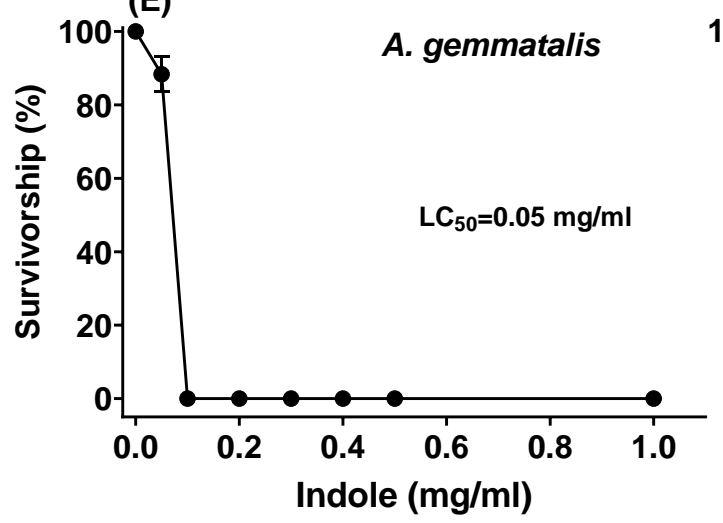

(F)

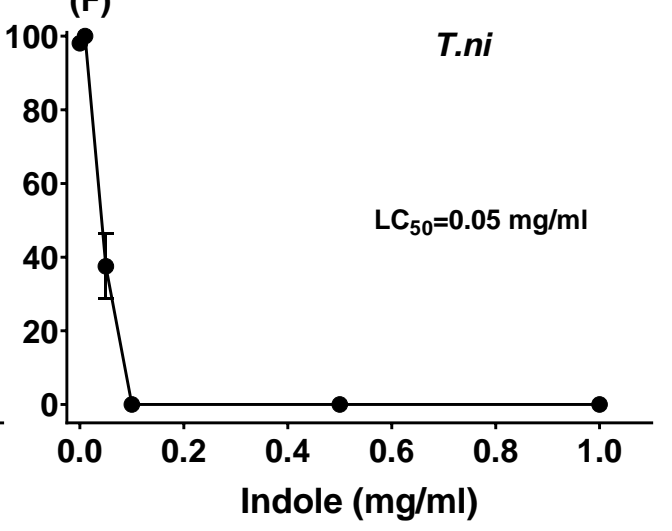


Figure 9

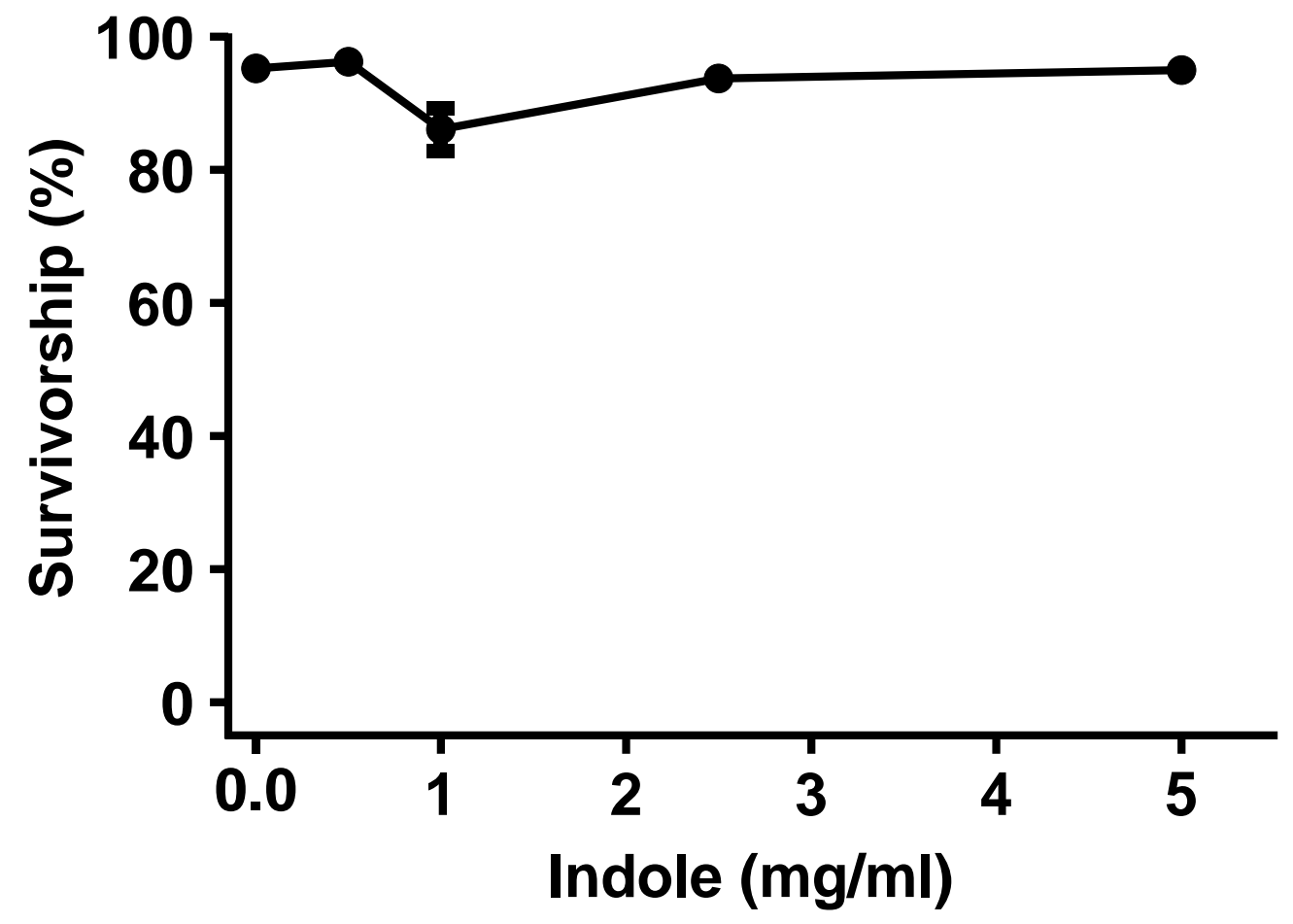


Figure 10
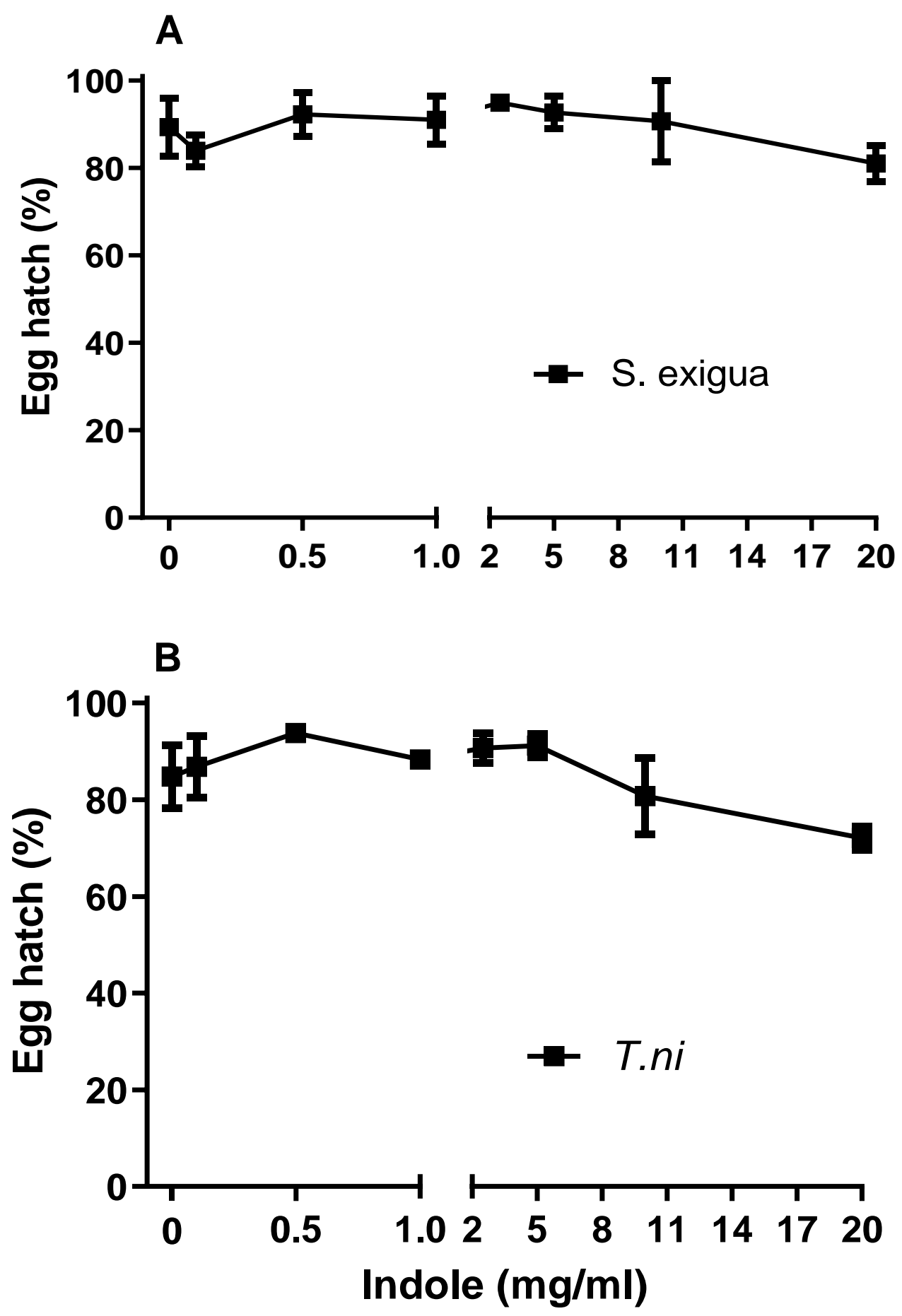
CHAPTER IV

REPELLENT AND ANTIFEEDANT ACTIVITY OF PLANT VOLATILE COMPOUNDS TO BEET

ARMYWORM LARVAE

\section{SUMMARY}

The beet armyworm, Spodoptera exigua, is an important agricultural pest of staple food crops and edible vegetables around the world. Since multiple field strains of beet armyworm are known to be resistant to insecticides of different classes, the development of alternative control measures of beet armyworm is indispensable. In this study, I evaluated the repellent activity of two plant volatiles, indole, and linalool, against beet armyworm using maize leaf disc choice assays. The results from choice experiments showed that indole spray on leaf discs was repellent to beet armyworm, while linalool elicited no behavioral response from beet armyworm. However, both indole and linalool reduced caterpillar feeding. I tested the direct toxicity of indole and linalool spray in detached leaf no-choice assays. Indole and linalool showed no direct toxicity in terms of leaf area removed or caterpillar relative weight gain. Finally, I measured the effects of indole and linalool spray on the growth of maize plants and found that volatile sprays had no effects. The results of this study suggest that the treatment of maize plants with indole will have a repellent effect against beet armyworm, but both volatiles were non-toxic at concentrations tested. The deterrent 
activity of indole spray in addition to reduced feeding might provide a new tool that when combined with other control measures could contribute to the management of beet armyworm.

\section{INTRODUCTION}

Lepidopteran insects are major agricultural pests that cause huge economic damage to food crops throughout the world (Muralidharan \& Pasalu, 2006; Zalucki et al., 2012b; Zheng et al., 2011). To control crop losses due to these pests, various management strategies such as chemical control and utilization of transgenic crops are practiced across the world. However, insect resistance to chemical pesticides is increasing at alarming rates (Dawkar et al., 2013). In addition, there can be unintended consequences of chemical insecticides on human and non-target organisms such as pollinators and natural enemies, and so many growers are looking for alternative solutions for insect control (Brittain et al., 2010; Chensheng et al., 2014; Cloyd \& Bethke, 2011; Han et al., 2018; Liu et al., 2016).

Plant essential oils have emerged as an alternative to synthetic chemical pesticides due to their low risk of unintended consequences on human health and non-target organisms (Miresmailli \& Isman, 2014; Said-Al Ahl et al., 2017). Botanical oils are well documented for their potential antifeedant, repellent, and toxicant activity against several insect taxa, including Lepidopterans (Kostic et al., 2008; Krishnaiah \& Kalode, 1990; Reddy \& Antwi, 2016; Ulrichs et al., 2007). However, these botanical oils can have a complex chemical composition and contain both volatile and non-volatile compounds (Shaaban et al., 2012). Plant-produced volatiles are often a major constituent of 
botanically-derived pesticides (Maffei et al., 2011), and are capable of mass production which may provide a good alternative for pest control at large scale agriculture systems. For example, individual plant volatiles such as E-2-nonadienal, E-2-nonenal, and E-2hexenal are active against stored grain beetles (Hubert et al., 2008a) and plant-parasitic nematodes (Laquale et al., 2018; Zhao et al., 2017). However, understanding of the potential toxicity of plant volatiles against other herbivores, especially caterpillars, is limited (Lee et al., 1999a). One study has shown that the volatiles indole and linalool were among the most directly toxic to beet armyworm (Spodoptera exigua) (Maurya et al., 2019). However, almost no information regarding whether the spray application of plant volatiles affects the behavior and feeding activity of caterpillars is available. This might be due to the high evaporation rate of volatile compounds in open field conditions and/or possible negative effects on plant fitness (Song \& Ryu, 2013a).

Plant-derived volatiles may have strong effects on crop growth, for example by reducing plant growth while increasing internal plant defenses, which may have negative effects on crop yields (Herms \& Mattson, 1992; Neilson et al., 2013). However, studies have shown conflicting results. For example, direct spraying of volatile limonene reduces photosynthesis and cause damage in cabbage leaves (Ibrahim et al., 2004), while soil drenching of 3-Pentanol and 2-Butanone in cucumber increases fruit yield without affecting the vegetative growth (Song \& Ryu, 2013b).

In this study, I evaluated the toxic effects of two plant volatiles; aromatic volatile indole and terpenoid linalool, on beet armyworm larvae feeding and growth, using nochoice assays. I also measured the repellent effects of indole and linalool on beet 
armyworm behavior using choice assays. The effect of indole and linalool on maize plant growth was also quantified. I expected that indole and linalool would reduce caterpillar growth and leaf consumption in no-choice assays and would have repellent and antifeedant effects in choice assays. I expected that these effects would diminish over time due to the evaporation of volatile sprays. I also expected that the volatile spray would reduce plant growth due to growth-defense tradeoffs.

\section{MATERIALS AND METHODS}

\section{Plant material}

Behavior and feeding assays (described below) were done using detached leaf pieces of maize (var. Golden Bantam, Territorial seed company, Oregon). Maize is one of the world's leading crops (Shiferaw et al., 2011), and is susceptible to lepidopteran herbivores of the family Noctuidae, including beet armyworms (Mardani-Talaei et al., 2012). To prepare leaf material for these experiments, maize seeds were surface sterilized in $75 \%(\mathrm{v} / \mathrm{v})$ ethanol for five minutes followed by $20 \%$ bleach $(\mathrm{v} / \mathrm{v})$ in $0.1 \%$ Tween-20 for ten minutes. After sterilization, the seeds were washed three times with distilled water and transferred individually in plastic pots $(9 \times 6.5 \times 6.5 \mathrm{~cm})$ with commercial potting soil (Lambert potting mix, Premium Horticultural Supply, KY, USA). The pots were placed in the climate-controlled growth chamber $\left(25^{\circ} \mathrm{C}, 12 \mathrm{~h}\right.$ light: $12 \mathrm{~h}$ dark cycle) for ten days and regularly watered. Two to three weeks old maize plants with 3-4 fully developed leaves were used for the feeding assays.

Insects 
I used beet armyworm caterpillars as the test subject because it is a destructive generalist pest of agricultural importance that feeds on more than 90 different species of food crops and edible vegetables belonging to 18 families across the USA (Liburd et al., 2000; Pearson, 1983). Beet armyworm is commonly used in studies of plant-insect interactions and pesticide assays and thus provides an opportunity to compare results with other studies (Christensen et al., 2013b; Engelberth et al., 2004a; Huffaker et al., 2013; Jurriaan et al., 2007; Schmelz et al., 2003). Beet-armyworm eggs were obtained from Benzon Research Inc. USA (Permit \#P526P-19-02794 to Sarah Emery). Eggs were immediately transferred to $60 \mathrm{ml}$ plastic cups, each with an artificial diet for hatching (Southland Products Incorporated, Arkansas, USA). The insect eggs were kept at room temperature until the eggs hatched. First to third instar larvae were used in these experiments.

Plant volatiles

I tested the effects of indole (97\%) (CAS: 120-72-9; TCI America) and linalool (97\%) (CAS: 78-70-6; Alfa Aesar) on beet armyworm behavior and growth, and on maize plant growth. For the plant volatile treatments, I prepared $\mathrm{LC}_{50}$ treatment solutions (Maurya et al., 2019), using commercially available sources. For the indole treatment, I dissolved $0.35 \mathrm{mg} / \mathrm{ml}$ of indole (i.e., equal to its $L C_{50}$ ) in $100 \mathrm{ml}$ solution of $1 \%$ DMSO (v/v) and $0.05 \%$ tween $20(\mathrm{v} / \mathrm{v})$ in DI water. I also created a control solution that lacked volatiles and had only $1 \%$ DMSO with $0.05 \%$ tween 20 in DI water. 
For the linalool treatment, I dissolved $2.59 \mu \mathrm{l} / \mathrm{ml}$ of linalool (i.e., equal to its $\mathrm{LC}_{50}$ ) in a $100 \mathrm{ml}$ solution of $0.05 \%$ tween 20 in DI water. I also created a control solution for linalool that lacked volatiles and had only $0.05 \%$ tween 20 in DI water.

No-choice assays

To evaluate the repellent and antifeedant effects of plant volatiles on herbivores, no-choice assays were performed in petri-dish $(5.5 \mathrm{~cm}$ diameter) arenas lined with moistened filter paper. Fresh leaf squares were harvested from living plants was weighed then the adaxial side was sprayed with either indole, linalool, or the control solution. The abaxial sides of the leaf squares were wiped and dried before transfer into petri dishes. Late $2^{\text {nd }}$ or early $3^{\text {rd }}$ instar caterpillars were weighed, added individually to petri dishes, and then allowed to feed for $24 \mathrm{~h}$. After $24 \mathrm{~h}$, the leaf squares and caterpillars were weighed again.

\section{Choice assays}

I investigated the repellency of plant volatiles against $1^{\text {st }}$ instar beet armyworm caterpillars in choice assays. I used $1^{\text {st }}$ instar larvae as it is the most sensitive stage to secondary plant chemicals and plant volatiles (Zalucki et al., 2002). Choice assays were also conducted in petri-dish (5.5 cm diameter) arenas lined with moistened filter paper. A leaf disc (10mm diameter) sprayed with one of the two volatiles was placed in one half of each petri dish, while a control-sprayed leaf disc was placed in the other half. A $1^{\text {st }}$ instar caterpillar was then released along the centerline of the arena. Caterpillars had the freedom to choose and feed on either the control or volatile-sprayed leaf disc. 
Caterpillar choice was scored at $1 \mathrm{~h}$ after the start of the experiment by recording which leaf disc the caterpillar was on. After $18 \mathrm{~h}$, the leaf area removed from both leaf discs was measured using a semiquantitative Daubenmire scale (Dnubenmire, 1959). Because I saw the strong effect of indole in particular on caterpillar choice, I followed up these assays with another assay where leaf discs were sprayed with indole or controlsolution, then left alone for $24 \mathrm{~h}$ before exposing to caterpillars. This assay was performed to evaluate whether the caterpillar repellent activity of indole extended beyond 24 hours as indole has an atmospheric half-life of 2-3 h (NCBI, 2019).

\section{Maize growth responses}

To examine whether volatiles have any direct effects on crop growth, maize plants were grown in climate-controlled chambers as described above and fertilized once a week with a $10 \mathrm{ml}$ Miracle-Grow ${ }^{\circledR}$ solution. Once plants had 3-4 fully developed leaves, each was sprayed with the indole, linalool, or control solutions, fully soaking leaves. Maize plant height was measured before spraying, and then daily after spraying, for 7-21 days.

\section{Data analysis}

For no-choice assays, caterpillar weight gain and leaf mass-consumed were analyzed using t-tests. For choice assays, two-tailed binomial exact tests were used to determine the significance of preference between volatile-treated and control leaf discs (replicates in which caterpillars did not make a choice were excluded from this analysis). Differences in percent leaf area removed between the treatments in the choice assay 
were analyzed with t-tests. For Maize plant growth, the plant height was analyzed using repeated-measures ANOVAs. Student's t-tests and binomial exact tests were performed in GraphPad Prism version 8.0.0 (San Diego, California USA) while repeated-measures ANOVA was performed in R (R Core Team 2019). Figures were plotted with GraphPad Prism version 8.0.0 (San Diego, California USA).

\section{RESULTS}

No-choice assays

Indole and linalool showed no toxicity or antifeedant effects on beet armyworm in no-choice detached leaf assays. I found no significant effect of indole spray on leaf consumption ( $P=0.9454$, Figure $11 \mathrm{a})$ and weight gain by beet armyworm $(P=0.1143$, Figure 11b). Likewise, linalool treatment had no effect on leaf consumption $(P=0.3692$, Figure $11 \mathrm{c}$ ) or weight gain $(P=0.7932$, Figure $11 d)$ by beet armyworm caterpillars.

Choice assays

Beet armyworm caterpillars were repelled by indole as more caterpillars chose leaf discs sprayed with control solution over the leaf discs sprayed with indole at $1 \mathrm{~h}$ $(P=0.0093$, Figure $12 a)$ after assay initiation. Leaf area removed was more than four times less in indole sprayed leaf discs compared to control leaf discs $(P<0.0001$, Figure 12b). For the follow-up assay in which plants were sprayed with indole a day before being presented to caterpillars, there was no significant difference in caterpillar preference for leaf discs from plants sprayed with control solution compared to indole solution $1 \mathrm{~h}$ after exposure $(\mathrm{P}=0.1601$, Figure $12 \mathrm{c})$, but the repellent effect of indole 
persisted in terms of leaf disc damage after $18 \mathrm{~h}$ of feeding ( $42 \mathrm{~h}$ after indole spray), with four times lower damage in leaf discs sprayed with indole compared to the control $(P<0.0001$, Figure $12 d)$.

In contrast to indole, linalool had no effect on beet armyworm caterpillar preference at $1 \mathrm{~h}$ or $18 \mathrm{~h}$ following assay initiation $(\mathrm{p}=\mathrm{P}=0.7905$, Figure $13 \mathrm{a})$. However, linalool significantly reduced the leaf area removed by half after $18 \mathrm{~h}$ of the experiment $(P=0.0337$, Figure $13 b)$.

Plant growth assay

Indole and linalool had no significant effects on maize plant growth. I found no differences in 7-day growth (Figures 14a, c), nor 21-day growth patterns (Figure 14b, d) between volatile-exposed plants and control plants.

DISCUSSION

In this study, I showed that sprays of plant volatile solutions, especially indole, can effectively repel and have antifeedant effects on lepidopteran herbivores. The repellent and antifeedant effects of indole were apparent in assays performed immediately after sprays and in assays performed a day after the indole spray, indicating that the repellent effects of plant volatiles can persist for more than 24 hours after application. This is novel because the atmospheric half-life of indole at $25^{\circ} \mathrm{C}$ is $2-3$ $\mathrm{h}(\mathrm{NCBI}, 2019)$. Therefore, the results of this study demonstrate that indole spray repels caterpillars even after a significant loss due to volatilization. This research work supports other studies that show the repellent effects of indole on generalist caterpillar 
Spodoptera littoralis (Veyrat et al., 2016a). together, these studies suggest a use for indole in the future management of lepidopteran pests.

While the evidence for linalool as a repellent and antifeedant were minimal in this work, the repellent properties of linalool have been reported in many other studies. For example, transgenic tobacco plants emitting higher amounts of linalool repelled egglaying female adults of cotton bollworm Helicoverpa armigera and phloem-feeding green peach aphids Myzus persicae in a choice assay (Huang et al., 2018). Repellent properties of exogenous linalool applications are also well documented against insects such as mosquito, ticks, beetles and gypsy moth caterpillars (Kostic et al., 2008; Müller et al., 2009; Ojimelukwe \& Adler, 2000; Tabari et al., 2017). These results instead demonstrate that linalool may have antifeedant effects on beet armyworms, even if changes in behavior are not detected. These results indicate a potential application of linalool in eco-friendly pest management strategies.

Although indole and linalool had repellent and antifeedant effects on beet armyworms in the choice assays, I saw no antifeedant effects in the no-choice assays. One possible explanation for this lack of effect might be due to the use of late $2^{\text {nd }}$ and early $3^{\text {rd }}$ instar caterpillars. Caterpillar ontogeny has been reported to affect sensitivity towards phytochemicals, and early instar caterpillars are more sensitive relative to older instar caterpillars (Hochuli, 2001; Veyrat et al., 2016a; Zalucki et al., 2012a). Therefore, further studies are needed to test the susceptibility of specific instars to maximize pest control efficacy of plant volatiles. Surprisingly, caterpillars actually tended to grow better when feeding on indole-sprayed leaves relative to control sprayed leaves, though 
this was not statistically significant in this study. Similar results were found by Veyrat et al. (2016a) where S. littoralis caterpillars grew more when they fed on indole-producing plants or an artificial diet supplemented with indole. Indole exposure changes the composition of the gut microbiome of caterpillars (Gasmi et al., 2019), and such shifts might change the food-to-biomass conversion rates and increase weight gain in caterpillars (Veyrat et al., 2016a). Therefore, future studies should investigate the effect of exposure to plant volatiles on caterpillar gut microbiomes and overall food-tobiomass conversion rates.

Finally, I was able to show that exposing crops directly to linalool and indole sprays had no adverse effect on vegetative growth, at least for young plants. Similar findings have been shown in other studies. For example, foliar spraying of tomato seedlings with rosemary essential oils had no negative effects on seedling growth (Souri \& Bakhtiarizade, 2019). However, other studies have shown that some plant volatiles can directly decrease plant growth. One study demonstrated that the direct spraying of another plant volatile, limonene, caused a significant reduction in photosynthesis and visible damage in cabbage plants (Ibrahim et al., 2004). In another study, persistent lowdose exposure to the plant volatile $\mathrm{z} 3 \mathrm{HAC}$ enhanced vegetative and reproductive growth of lima bean plants, but reduced growth in pepper plants (Freundlich \& Frost, 2019). It seems clear that the direct effects of plant volatile applications for crops are not universal and might depend on the identity and concentration of volatiles, as well as crop identity. 
In conclusion, the results of this study demonstrate that indole and linalool are two plant volatiles that may hold promise as herbivore repellents or feeding deterrents in integrated pest management without having adverse effects on plant growth. 


\section{FIGURE LEGENDS}

Figure 11. Indole and linalool are non-toxic to beet armyworms at tested concentrations. Leaf consumption and caterpillar weight gain were measured after $24 \mathrm{~h}$ for late $2^{\text {nd }}$ instar caterpillars feeding on detached leaf squares sprayed with indole or control solution $(n=22)(A, B)$ or early $3^{\text {rd }}$ instar caterpillars feeding on leaf squares sprayed with linalool or control solution $(n=44)(C, D)$. No statistically significant differences were found for leaf consumption and caterpillar weight gain between indole and control sprayed leaves (A, B) or linalool and control sprayed leaf $(C, D)(P>0.05)$. Bars represent mean \pm SE.

Figure 12. Indole shows repellent and antifeedant activity to beet armyworms in choice assays. $1^{\text {st }}$ instar beet armyworm caterpillars significantly chose leaf discs sprayed with control solution after $1 \mathrm{~h}(\mathrm{n}=30)(A)$, and also removed more leaf area from controls after $18 \mathrm{~h}$ of feeding (B). In the follow-up experiment in which plants were sprayed a day before choice assay, no statistical difference was found in caterpillar preference between leaf discs sprayed with control or indole solution after $1 \mathrm{~h}(n=30)(C)$, but caterpillars consumed more leaf area from controls after $18 \mathrm{~h}$ of feeding (D). Bars represent mean $\pm S E$, and significant effects $(p<0.05)$ are indicated with asterisks.

Figure 13. Linalool shows antifeedant activity to beet armyworms in choice assays. $1^{\text {st }}$ instar beet armyworm caterpillars showed no preference between leaf discs sprayed with control solution or linalool after $1 \mathrm{~h}(\mathrm{n}=30)(\mathrm{A})$ but did remove more leaf area from 
controls after $18 \mathrm{~h}$ of feeding (B). Bars represent mean $\pm S E$, and significant effects $(p<$ $0.05)$ are indicated with asterisks.

Figure 14. Volatile spray had no effect on plant growth. The effect of indole spray on plant height within 7 days $(n=24)(A)$ and 21 days $(n=24)(B)$. The effect of linalool spray on plant height within 7 days $(n=30)$ (C) and 21 days $(n=20)$ (D). Error bars represent means $\pm \mathrm{SE}$. 
Figure 11
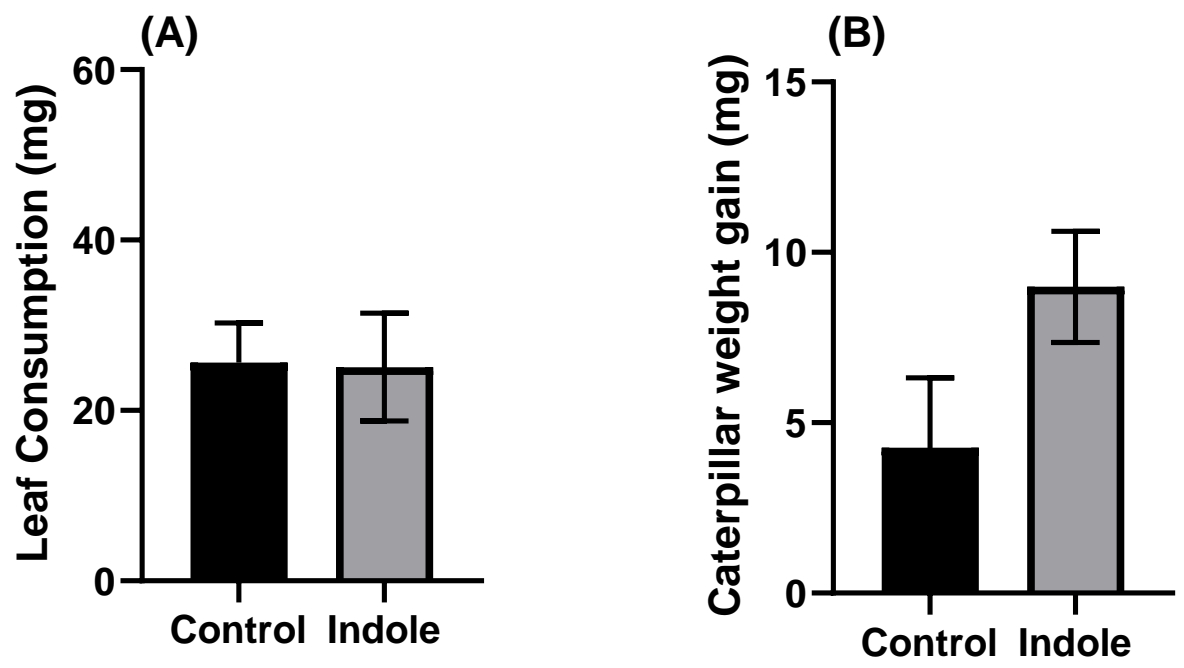

(C)
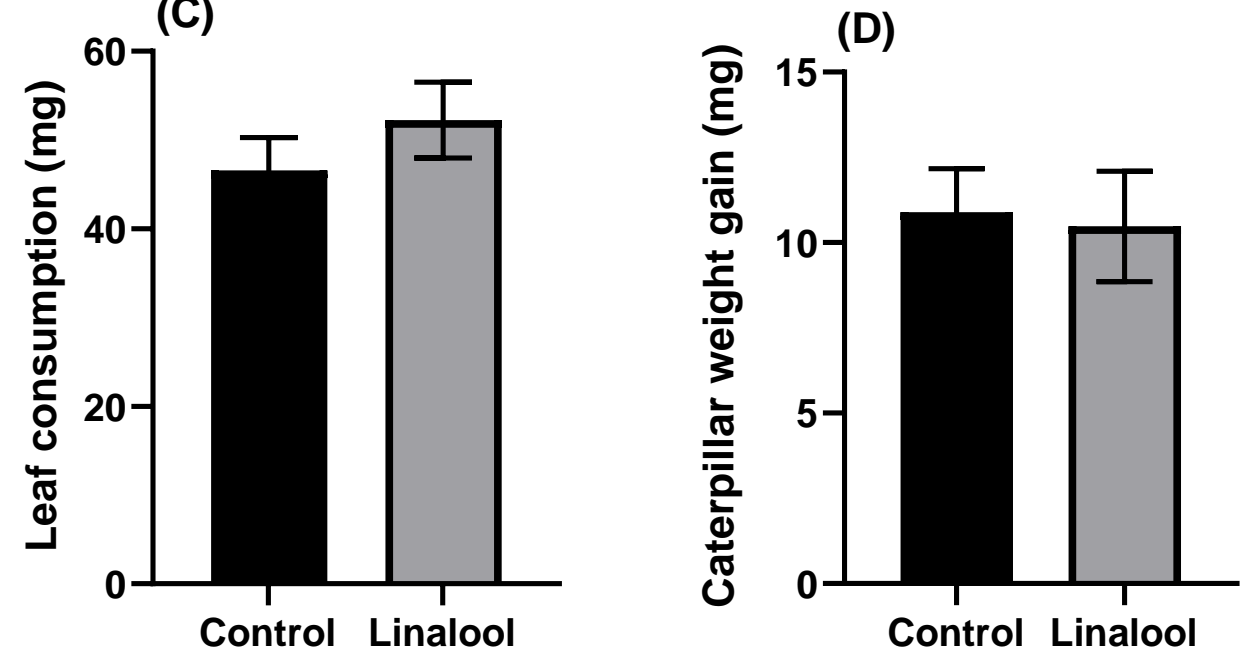
Figure 12
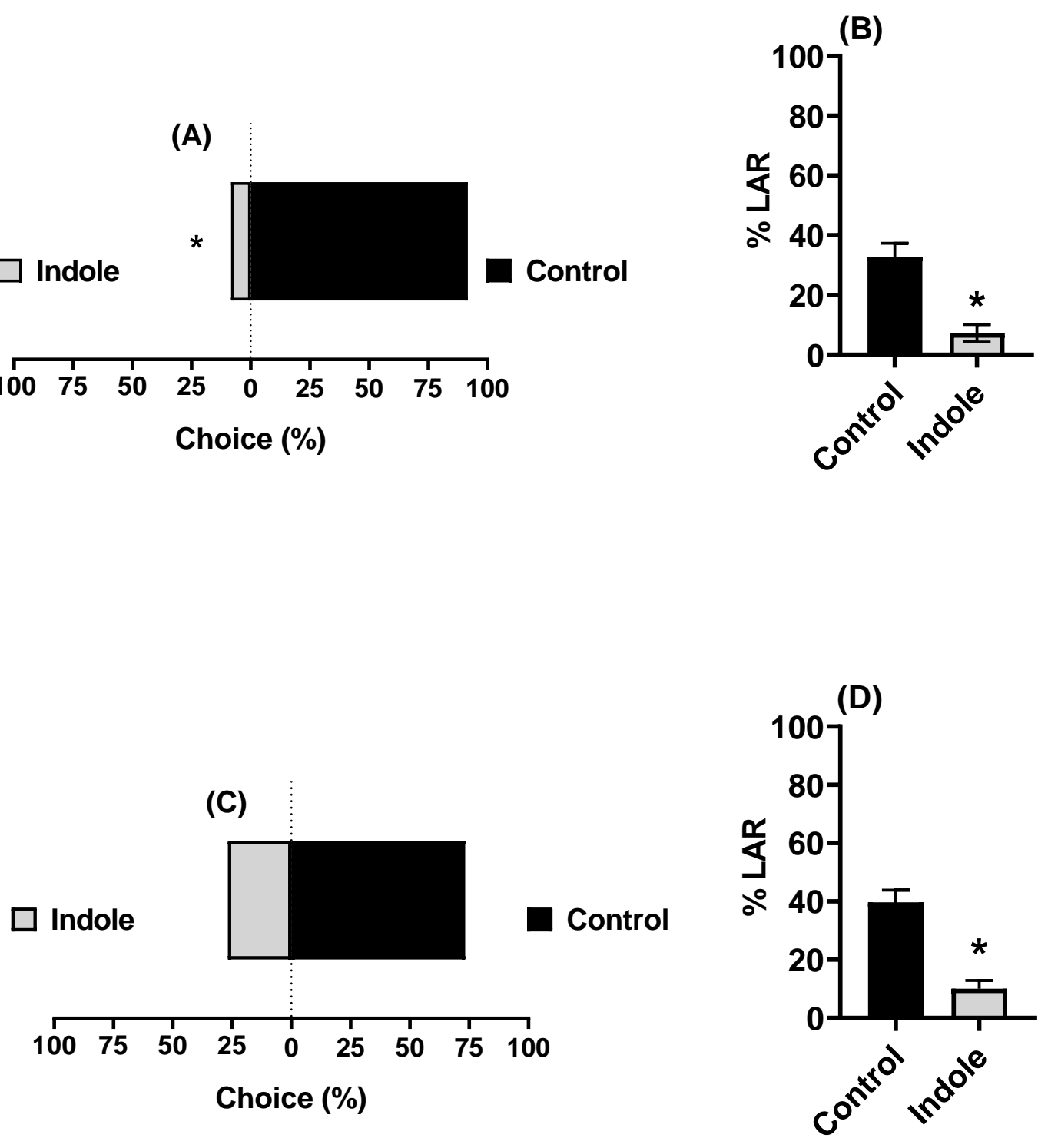
Figure 13

(A)

(B)

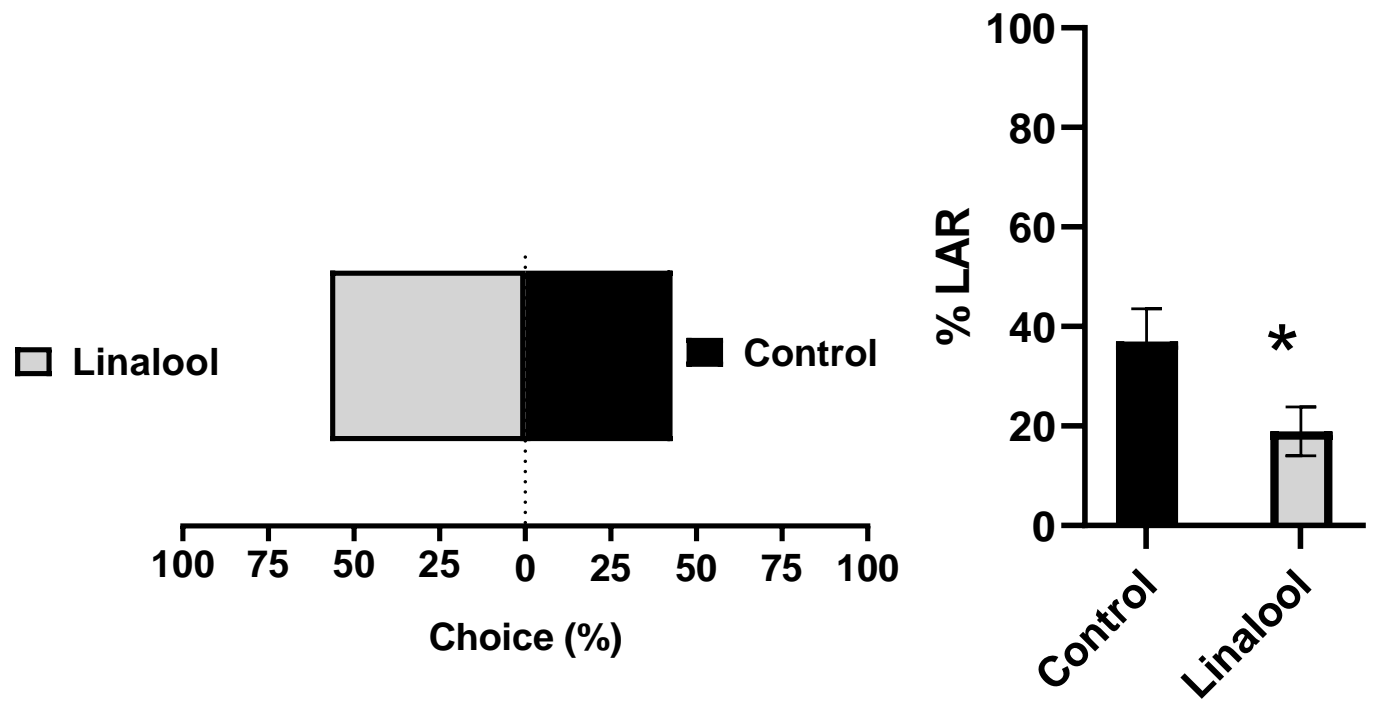


Figure 14

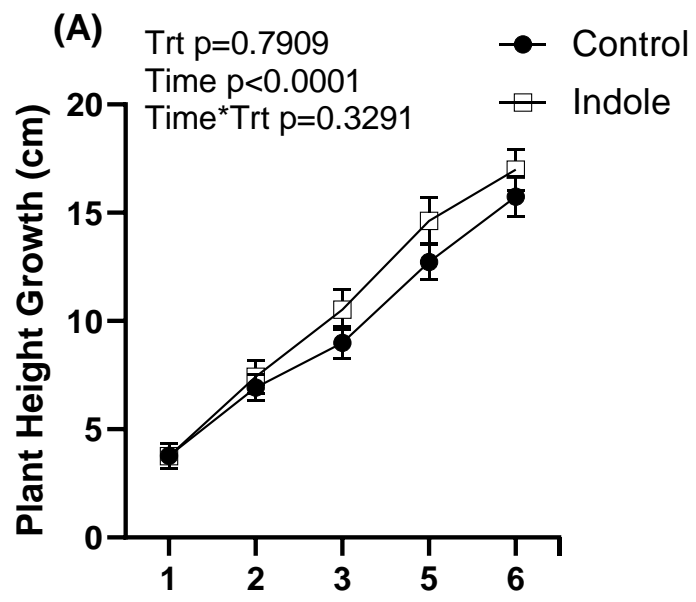

Days after indole exposure

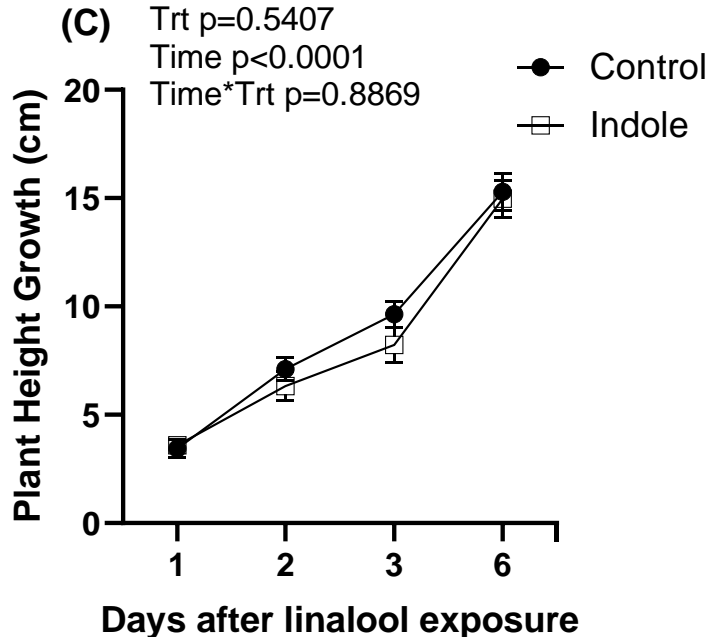

Days after linalool exposure

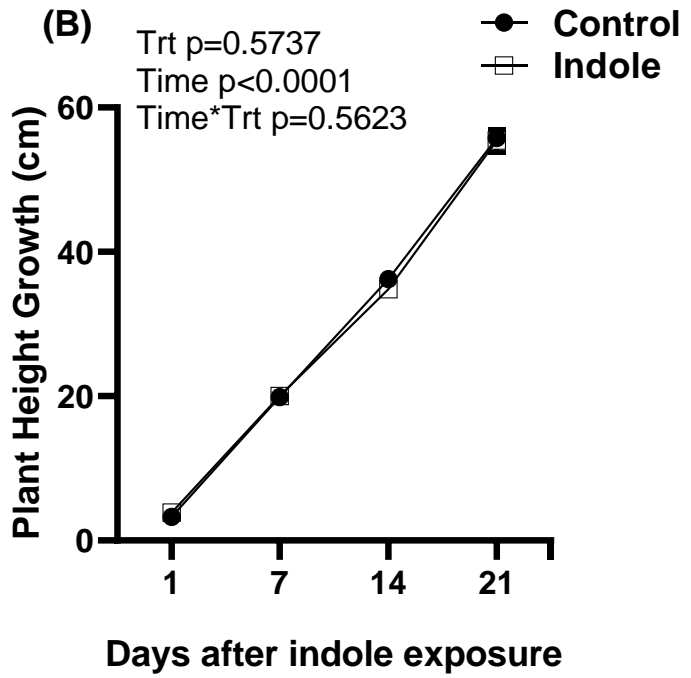

(D) Trt $\mathrm{p}=0.9824 \quad \rightarrow$ Control

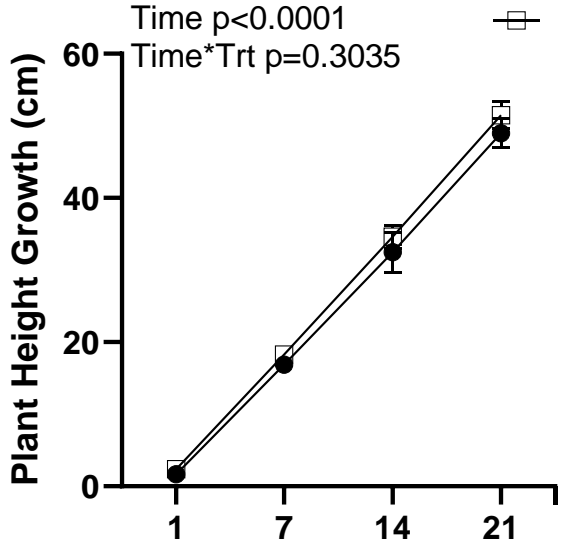

Days after linalool exposure 


\section{CHAPTER V}

\section{SUMMARY AND CONCLUSIONS}

The results presented in this dissertation explore a new dimension of plant volatile mediated interactions with seeds and herbivores. The dissertation provides new insights into the role of plant volatiles in seed priming and direct defense against herbivores.

Plant volatiles released in response to herbivory, prime the plant defenses against future stress and affect their fitness (Engelberth et al., 2004a; Engelberth \& Engelberth, 2019; Erb et al., 2015b; Frost et al., 2007). Seeds in the soil can be exposed to an array of plant volatiles and other secondary metabolites released from plant roots or in the rhizosphere through precipitation and leaching, (H B Tukey, 1970). Plant volatiles also inhibit seed germination, and seedling growth but the long term effect on future plants is still unknown (Mirabella et al., 2008; Romagni et al., 2000). Therefore, I hypothesized that plant volatiles will affect the growth, development, and defense profiles when volatile exposed seeds grow into mature plants. I showed that seeds can perceive HIPVs in ways that prime defenses and affect the fitness of future plants that

grow from such seeds (Chapter II). Seeds exposed to the plant volatiles $z-3$-hexenol and z-3-hexenyl acetate show increased plant vegetative growth in Medicago plants while indole primed the defenses of Arabidopsis and Medicago 
against caterpillar and aphids respectively. HIPV-mediated defense priming in plants has been demonstrated to operate via stress-related signaling pathways (Frost et al., 2008; Hilker et al., 2016). However, the results from gene expression analysis show that the seed exposure with indole did not directly induce any marker genes before herbivory. After herbivory by caterpillars and aphids, defense marker genes were induced, but gene expression was not further induced by seed exposure to indole. These results rule out the possibility of direct activation or priming of inducible resistance and indicate the possible involvement of a mechanism that is autonomous of inducible plant resistance. The underlying mechanisms of seed priming are still unclear and need to be addressed in future studies. One possible explanation of enhanced defense in indole-exposed seed plants can be the basal changes in plant nutritive and defense chemistry. Future studies can test this by quantifying the primary and secondary metabolites in volatile exposed and non-exposed seed plants. In addition, the effect of dose, duration time and synergistic combination of plant volatile on seed exposure might provide more information on seed priming.

Plant volatiles such as indole and GLVs have been reported to provide direct plant defenses by herbivore intoxication but their acute toxicity is not quantified (Maag et al., 2015; Veyrat et al., 2016a; von Mérey et al., 2013). The studies described here quantified the feeding and headspace larvicidal activity of six common plant volatiles on beet armyworm. I found that indole was most toxic in diet followed by linalool while $\beta$ Caryophyllene was nontoxic in the diet. In further experiments I showed that the toxicity of indole against caterpillars from six species varies with the herbivore's host range i.e., 
indole was most toxic to specialist caterpillars while least toxic to the generalist. Indole toxicity range is similar to some commercial pesticides and biopesticides like the Cry1F Bacillus thuringiensis protein (Ali et al., 2006) which shows the potential applicability of indole in pest management strategy for generalist and specialist pest caterpillars. Contrary to previously published studies, none of the tested volatiles causes significant caterpillar mortality in headspace assays (Veyrat et al., 2016a). One possible explanation of this might be the lower concentration of volatile used in this bioassay. The results of this study results regarding the toxicity of plant volatiles have potential application in pest control, therefore, further research is warranted to quantify the toxicity of other plant volatiles that play a role in plant defense such as DMNT (Meents et al., 2019). In addition, future research should also account for the amount of food consumed and insect weight gain to decipher the antifeedant effect and antinutritive effects of the plant volatiles.

In Chapter IV, I examined the effect of indole and linalool spray on plant growth, beet armyworm caterpillar performance and behavior. The results of this study suggest that the $\mathrm{LC}_{50}$ concentration of indole and linalool sprays (quantified in chapter III) on maize leaf had an antifeedant effect against beet armyworm in the choice assay and the antifeedant effect persisted even a day after the spray. In contrast, indole and linalool sprays had no effect on the caterpillar survival and mortality at concentrations tested in the no-choice assay. Multiple reasons could explain the non-toxic effect of indole against beet-armyworm in maize experiments. One explanation is that the beet armyworm caterpillars were late $2^{\text {nd }}$ and early $3^{\text {rd }}$ instar instead of $1^{\text {st }}$ instar used in 
chapter II. I used $2^{\text {nd }}$ and early $3^{\text {rd }}$ instar caterpillars to have visible damage in $24 \mathrm{~h}$ period on maize leaves but based on the results of this study the indole concentration used for the spray was non-toxic. Another possible explanation can be the atmospheric half-life of indole and linalool which is only 2-3 $\mathrm{h}$ at room temperature. Therefore, the indole concentration might be reduced to non-toxic levels as time pass. The future experiment should account for the caterpillar growth stage and atmospheric half-life of plant volatiles while quantifying their toxicity against insect pests. Indole and linalool sprays had no effect on plant growth suggesting each can be developed as a potential tool in pest management. Based on the results of this study, indole and linalool sprays might be inadequate as an individual management tool for beet armyworm but could represent good candidates to use as in combination with other pest control methods. 


\section{REFERENCES}

Abdelgaleil SAM, Mohamed MIE, Shawir MS \& Abou-Taleb HK (2016) Chemical composition, insecticidal and biochemical effects of essential oils of different plant species from Northern Egypt on the rice weevil, Sitophilus oryzae L. Journal of Pest Science 89: 219-229.

Agrawal AA (2001) Phenotypic plasticity in the interactions and evolution of species. Science 294: 321-326.

Agrawal Aa \& Ali JG (2012) Specialist versus generalist insect herbivores and plant defense. Trends in plant science 17: 293-302.

Ahmad M, Sayyed AH, Saleem MA \& Ahmad M (2008) Evidence for field evolved resistance to newer insecticides in Spodoptera litura (Lepidoptera: Noctuidae) from Pakistan. Crop Prot 27: 1367-1372.

Akahane K, Yonai S \& Fukuda S (2012) The Fukushima Nuclear Power Plant accident and exposures in the environment. 136-143.

Ali M, Luttrell R \& Young III S (2006) Susceptibilities of Helicoverpa zea and Heliothis virescens (Lepidoptera: Noctuidae) populations to Cry1Ac insecticidal protein. J Econ Entomol 99: 164-175.

Allmann S, Späthe A, Bisch-Knaden S, Kallenbach M, Reinecke A, Sachse S, Baldwin IT \& Hansson BS (2013) Feeding-induced rearrangement of green leaf volatiles reduces moth oviposition. elife 2: e00421.

Ameye M, Audenaert K, De Zutter N, Steppe K, Van Meulebroek L, Vanhaecke L, De Vleesschauwer D, Haesaert G \& Smagghe G (2015) Priming of Wheat with the Green Leaf Volatile Z-3-Hexenyl Acetate Enhances Defense against Fusarium graminearum But Boosts Deoxynivalenol Production. Plant physiology 167: 16711684.

Atul-Nayyar a, Hamel C, Hanson K \& Germida J (2009) The arbuscular mycorrhizal symbiosis links $\mathrm{N}$ mineralization to plant demand. Mycorrhiza 19: 239-246.

Azooz M (2009) Salt stress mitigation by seed priming with salicylic acid in two faba bean genotypes differing in salt tolerance. Int J Agric Biol 11: 343-350.

Bailly A, Groenhagen U, Schulz S, Geisler M, Eberl L \& Weisskopf L (2014) The interkingdom volatile signal indole promotes root development by interfering with auxin signalling. The Plant Journal 80: 758-771.

Baker TC, Obrycki JJ \& Zhu J (2003) Attractants of beneficial insects: Google Patents.

Bakkali F, Averbeck S, Averbeck D \& Idaomar M (2008) Biological effects of essential oils-a review. Food and chemical toxicology 46: 446-475.

Baldin ELL, Aguiar GP, Fanela TLM, Soares MCE, Groppo M \& Crotti AEM (2015) Bioactivity of Pelargonium graveolens essential oil and related monoterpenoids 
against sweet potato whitefly, Bemisia tabaci biotype B. Journal of Pest Science 88: 191199.

Baldwin IT (2010) Plant volatiles. Current Biology 20: R392-R397.

Ballaré CL (2011) Jasmonate-induced defenses: a tale of intelligence, collaborators and rascals. Trends in plant science 16: 249-257.

Barsics F, Delory BM, Delaplace P, Francis F, Fauconnier ML, Haubruge E \& Verheggen FJ (2017) Foraging wireworms are attracted to root-produced volatile aldehydes. Journal of Pest Science 90: 69-76.

Bass C, Denholm I, Williamson MS \& Nauen R (2015) The global status of insect resistance to neonicotinoid insecticides. Pesticide Biochemistry and Physiology 121: 78-87.

Bate NJ \& Rothstein SJ (1998) C6-volatiles derived from the lipoxygenase pathway induce a subset of defense-related genes. The Plant Journal 16: 561-569.

Beale MH, Birkett MA, Bruce TJA, Chamberlain K, Field LM, Huttly AK, Martin JL, Parker R, Phillips AL, Pickett JA, Prosser IM, Shewry PR, Smart LE, Wadhams LJ, Woodcock CM \& Zhang YH (2006) Aphid alarm pheromone produced by transgenic plants affects aphid and parasitoid behavior. Proc Natl Acad Sci USA 103: 10509-10513.

Bentsink L \& Koornneef M (2008) Seed dormancy and germination. The Arabidopsis Book 6: e0119-e0119.

Bergmann C, Wegmann K, Frischmuth K, Samson E, Kranz A, Weigelt D, Koll P \& Welzel P (1993) Stimulation of Orobanche crenata seed germination by (+)-strigol and structural analogues dependence on constitution and configuration of the germination stimulants. Journal of Plant Physiology 142: 338-342.

Bernasconi ML, Turlings TCJ, Ambrosetti L, Bassetti P \& Dorn S (1998a) Herbivoreinduced emissions of maize volatiles repel the corn leaf aphid, Rhopalosiphum maidis. Entomol. Exp. Appl. 87: 133-142.

Bernasconi ML, Turlings TCJ, Ambrosetti L, Bassetti P \& Dorn S (1998b) Herbivoreinduced emissions of maize volatiles repel the corn leaf aphid, Rhopalosiphum maidis. Entomol Exp Appl 87: 133-142.

Beyaert I, Köpke D, Stiller J, Hammerbacher A, Yoneya K, Schmidt A, Gershenzon J \& Hilker M (2012) Can insect egg deposition 'warn' a plant of future feeding damage by herbivorous larvae? Proceedings of the Royal Society B: Biological Sciences 279: 101-108.

Bhattacharyya D, Garladinne M \& Lee YH (2015) Volatile indole produced by Rhizobacterium proteus vulgaris JBLS202 stimulates growth of Arabidopsis thaliana through auxin, cytokinin, and brassinosteroid pathways. Journal of Plant Growth Regulation 34: 158-168.

Birkett M, Chamberlain K, Guerrieri E, Pickett J, Wadhams L \& Yasuda T (2003) Volatiles from whitefly-infested plants elicit a host-locating response in the parasitoid, Encarsia formosa. Journal of chemical ecology 29: 1589-1600.

Blom D, Fabbri C, Connor EC, Schiestl FP, Klauser DR, Boller T, Eberl L \& Weisskopf L (2011) Production of plant growth modulating volatiles is widespread among 
rhizosphere bacteria and strongly depends on culture conditions. Environmental Microbiology 13: 3047-3058.

Bradow JM \& Connick WJ (1990) Volatile seed germination inhibitors from plant residues. Journal of chemical ecology 16: 645-666.

Brewer MJ, Trumble JT, Alvarado-Rodriguez B \& Chaney WE (1990) Beet armyworm (Lepidoptera: Noctuidae) adult and larval susceptibility to three insecticides in managed habitats and relationship to laboratory selection for resistance. Journal of Economic Entomology 83: 2136-2146.

Brittain CA, Vighi M, Bommarco R, Settele J \& Potts SG (2010) Impacts of a pesticide on pollinator species richness at different spatial scales. Basic and Applied Ecology 11: 106-115.

Brown AWA (1958) Insecticide resistance in arthropods. Insecticide resistance in arthropods.

Bruce TJA, Martin JL, Pickett JA, Pye BJ, Smart LE \& Wadhams LJ (2003) Cis-Jasmone treatment induces resistance in wheat plants against the grain aphid, Sitobion avenae (Fabricius) (Homoptera: Aphididae). Pest management science 59: 10311036.

Bucciarelli B, Hanan J, Palmquist D \& Vance CP (2006) A Standardized Method for Analysis of Medicago truncatula Phenotypic Development. Plant physiology 142: 207-219.

Buswell W, Schwarzenbacher RE, Luna E, Sellwood M, Chen B, Flors V, Pétriacq P \& Ton J Chemical priming of immunity without costs to plant growth. New Phytologist: n/a-n/a.

CABI American cotton bollworm (Helicoverpa zea), Vol. 2018.

CABI Fall armyworm (Spodoptera frugiperda), Vol. 2018.

Capinera JL (1999a) Beet Armyworm; Spodoptera exigua (Hübner) (Insecta: Lepidoptera: Noctuidae) Vol. 2018: University of Florida.

Capinera JL (1999b) Cabbage lopper; Trichoplusia ni (Hübner) (Insecta: Lepidoptera: Noctuidae), Vol. 2018.

Capinera JL (1999c) Fall armyworm; Spodoptera frugiperda (Insecta: Lepidoptera: Noctuidae), Vol. 2018.

Capinera JL (2001) Tobacco budworm; Heliothis virescens (Fabricius) (Insecta: Lepidoptera: Noctuidae), Vol. 2018.

Che W, Shi T, Wu Y \& Yang Y (2013) Insecticide resistance status of field populations of Spodoptera exigua (Lepidoptera: Noctuidae) from China. J Econ Entomol 106: 1855-1862.

Chen H, Zhang J, Neff MM, Hong S-W, Zhang H, Deng X-W \& Xiong L (2008) Integration of light and abscisic acid signaling during seed germination and early seedling development. Proceedings of the National Academy of Sciences USA 105: 44954500.

Chen PK \& Leather GR (1990) Plant growth regulatory activities of artemisinin and its related compounds. Journal of chemical ecology 16: 1867-1876. 
Chensheng L, Warchol KM \& Callahan RA (2014) Sub-lethal exposure to neonicotinoids impaired honey bees winterization before proceeding to colony collapse disorder. Bulletin of Insectology 67: 125-130.

Christensen SA, Andriy N, Eli B, Ian M, S. SI, Liz B, Stacy D, Matthias E, A.M. RC, A. VK, Cornelia H, Jim T, Ivo F, David J, C.J. TT, Jurgen E, Christian N, Robert M \& V. KM (2013a) The maize lipoxygenase, ZmLOX10, mediates green leaf volatile, jasmonate and herbivore-induced plant volatile production for defense against insect attack. The Plant Journal 74: 59-73.

Christensen SA, Nemchenko A, Borrego E, Murray I, Sobhy IS, Bosak L, DeBlasio S, Erb M, Robert CAM, Vaughn KA, Herrfurth C, Tumlinson J, Feussner I, Jackson D, Turlings TCJ, Engelberth J, Nansen C, Meeley R \& Kolomiets MV (2013b) The maize lipoxygenase, ZmLOX10, mediates green leaf volatile, jasmonate and herbivoreinduced plant volatile production for defense against insect attack. The Plant Journal 74: 59-73.

Cimino AM, Boyles AL, Thayer KA \& Perry MJ (2016) Effects of neonicotinoid pesticide exposure on human health: a systematic review. Environmental Health Perspectives 125: 155-162.

Cloyd RA \& Bethke JA (2011) Impact of neonicotinoid insecticides on natural enemies in greenhouse and interiorscape environments. Pest management science 67: 3-9.

Cna'ani A, Seifan M \& Tzin V (2018a) Indole is an essential molecule for plant interactions with herbivores and pollinators.

Cna'ani A, Seifan M \& Tzin V (2018b) Indole is an essential molecule for plant interactions with herbivores and pollinators. J Plant Biol Crop Res 1: 1-5.

Conrath U, Beckers GJ, Flors V, García-Agustín P, Jakab G, Mauch F, Newman M-A, Pieterse CM, Poinssot B \& Pozo MJ (2006) Priming: getting ready for battle. Molecular Plant-Microbe Interactions 19: 1062-1071.

Cook C, Whichard LP, Turner B, Wall ME \& Egley GH (1966) Germination of witchweed (Striga lutea Lour.): isolation and properties of a potent stimulant. Science 154: 1189-1190.

Cordero RJ, Kuhar TP, Speese III J, Youngman RR, Lewis EE, Bloomquist JR, Kok LT \& Bratsch AD (2006) Field efficacy of insecticides for control of lepidopteran pests on collards in Virginia. Plant health progress 7: 32.

da Silva JCP, Campos VP, Barros AF, Pedroso LA, Silva MdF, de Souza JT, Pedroso MP \& de Medeiros FHV (2019) Performance of volatiles emitted from different plant species against juveniles and eggs of Meloidogyne incognita. Crop Protection 116: 196-203.

Dawkar VV, Chikate YR, Lomate PR, Dholakia BB, Gupta VS \& Giri AP (2013) Molecular insights into resistance mechanisms of lepidopteran insect pests against toxicants. Journal of Proteome Research 12: 4727-4737.

Degen T, Bakalovic N, Bergvinson D \& Turlings TCJ (2012) Differential Performance and Parasitism of Caterpillars on Maize Inbred Lines with Distinctly Different Herbivore-Induced Volatile Emissions. PloS one 7: e47589. 
Dervinis C, Frost CJ, Lawrence SD, Novak NG \& Davis JM (2010) Cytokinin primes plant responses to wounding and reduces insect performance. Journal of Plant Growth Regulation 29: 289-296.

Dicke M (1986) Volatile spider-mite pheromone and host-plant kairomone, involved in spaced-out gregariousness in the spider mite Tetranychus urticae. Physiological Entomology 11: 251-262.

Dicke M \& Sabelis MW (1988) How Plants Obtain Predatory Mites as Bodyguards. Netherlands Journal of Zoology 38: 148-165.

Dickens JC (2002) Green leaf volatiles as synergists for insect pheromones: Google Patents.

Dixon KW, Merritt DJ, Flematti GR \& Ghisalberti EL (2009) Karrikinolide - a phytoreactive compound derived from smoke with applications in horticulture, ecological restoration and agriculture. Vi International Symposium on New Floricultural Crops 813: 155-170.

Dnubenmire R (1959) A canopy-coverage method of vegetation analysis. Northwest Sci 33: 43364.

Ecobichon DJ (2001) Pesticide use in developing countries. Toxicology 160: 27-33. El-Zaeddi H, Martínez-Tomé J, Calín-Sánchez Á, Burló F \& Carbonell-Barrachina ÁA (2016) Volatile Composition of Essential Oils from Different Aromatic Herbs Grown in Mediterranean Regions of Spain. Foods (Basel, Switzerland) 5: 41.

Elzen $G$ (1997) Changes in resistance to insecticides in tobacco budworm populations in Mississippi, 1993-1995. Southwest Entomol 22: 61-72.

Endara M-J, Coley PD, Ghabash G, Nicholls JA, Dexter KG, Donoso DA, Stone GN, Pennington RT \& Kursar TA (2017) Coevolutionary arms race versus host defense chase in a tropical herbivore-plant system. Proceedings of the National Academy of Sciences 114: E7499-E7505.

Engelberth J, Alborn HT, Schmelz EA \& Tumlinson JH (2004a) Airborne signals prime plants against insect herbivore attack. Proceedings of the National Academy of Sciences of the United States of America 101: 1781-1785.

Engelberth J, Alborn HT, Schmelz EA \& Tumlinson JH (2004b) Airborne signals prime plants against insect herbivore attack. Proc Natl Acad Sci USA 101: 1781-1785.

Engelberth J \& Engelberth M (2019) The Costs of Green Leaf Volatile-Induced Defense Priming: Temporal Diversity in Growth Responses to Mechanical Wounding and Insect Herbivory. Plants (Basel, Switzerland) 8: 23.

Engelberth J, Seidl-Adams I, Schultz JC \& Tumlinson JH (2007) Insect Elicitors and Exposure to Green Leafy Volatiles Differentially Upregulate Major Octadecanoids and Transcripts of 12-Oxo Phytodienoic Acid Reductases in Zea mays. Molecular Plant-Microbe Interactions 20: 707-716.

Erb M, Veyrat N, Robert CA, Xu H, Frey M, Ton J \& Turlings TC (2015a) Indole is an essential herbivore-induced volatile priming signal in maize. Nat Commun 6: 6273.

Erb M, Veyrat N, Robert CA, Xu H, Frey M, Ton J \& Turlings TC (2015b) Indole is an essential herbivore-induced volatile priming signal in maize. Nature communications 6 . 
Fatouros NE, Dicke M, Mumm R, Meiners T \& Hilker M (2008) Foraging behavior of egg parasitoids exploiting chemical information. Behav Ecol 19: 677-689.

Feeny P (1976) Plant Apparency and Chemical Defense: Biochemical Interaction Between Plants and Insects (ed. by JW Wallace \& RL Mansell) Springer US, Boston, MA, pp. 1-40.

Feng Y, Chen J \& Zhang A (2018) Commercially Available Natural Benzyl Esters and Their Synthetic Analogs Exhibit Different Toxicities against Insect Pests. Scientific Reports 8: 7902.

Fenner M (2000) Seeds: the ecology of regeneration in plant communities. Cabi. Flematti GR, Ghisalberti EL, Dixon KW \& Trengove RD (2004) A Compound from Smoke That Promotes Seed Germination. Science 305: 977-977.

Flores J, Jurado E \& Arredondo A (2006) Effect of light on germination of seeds of Cactaceae from the Chihuahuan Desert, Mexico. Seed science research 16: 149155.

Forcat S, Bennett MH, Mansfield JW \& Grant MR (2008) A rapid and robust method for simultaneously measuring changes in the phytohormones ABA, JA and SA in plants following biotic and abiotic stress. Plant Methods 4: 16.

Forister ML, Novotny V, Panorska AK, Baje L, Basset Y, Butterill PT, Cizek L, Coley PD, Dem F, Diniz IR, Drozd P, Fox M, Glassmire AE, Hazen R, Hrcek J, Jahner JP, Kaman O, Kozubowski TJ, Kursar TA, Lewis OT, Lill J, Marquis RJ, Miller SE, Morais HC, Murakami M, Nickel H, Pardikes NA, Ricklefs RE, Singer MS, Smilanich AM, Stireman JO, Villamarín-Cortez S, Vodka S, Volf M, Wagner DL, Walla T, Weiblen GD \& Dyer LA (2015) The global distribution of diet breadth in insect herbivores. Proceedings of the National Academy of Sciences 112: 442-447.

Freundlich GE \& Frost C (2018) Variable costs of eavesdropping a green leaf volatile on two plant species in a common garden experiment. bioRxiv.

Freundlich GE \& Frost C (2019) Variable costs and benefits of eavesdropping a green leaf volatile on two plant species in a common garden. bioRxiv: 370692.

Friis EM, Crane PR \& Pedersen KR (2011) Introduction to angiosperms: Early flowers and angiosperm evolution (ed. Cambridge University Press, pp. 1-22.

Frost CJ, Appel HM, Carlson JE, De Moraes CM, Mescher MC \& Schultz JC (2007) Withinplant signalling via volatiles overcomes vascular constraints on systemic signalling and primes responses against herbivores. Ecology Letters 10: 490-498.

Frost CJ, Mescher MC, Carlson JE \& De Moraes CM (2008) Plant Defense Priming against Herbivores: Getting Ready for a Different Battle. Plant physiology 146: 818-824.

Frost CJ, Nyamdari B, Tsai C-J \& Harding SA (2012) The tonoplast-localized sucrose transporter in Populus (PtaSUT4) regulates whole-plant water relations, responses to water stress, and photosynthesis. PloS one 7: e44467.

Gao L-L, Klingler JP, Anderson JP, Edwards OR \& Singh KB (2008) Characterization of pea aphid resistance in Medicago truncatula. Plant physiology 146: 996-1009.

Gao LL, Anderson JP, Klingler JP, Nair RM, Edwards OR \& Singh KB (2007) Involvement of the octadecanoid pathway in bluegreen aphid resistance in Medicago truncatula. Molecular Plant-Microbe Interactions 20: 82-93. 
Gasmi L, Martinez-Solis M, Frattini A, Ye M, Collado MC, Turlings T, Erb M \& Herrero S (2018) Can herbivore-induced volatiles protect plants by increasing the herbivores' susceptibility to natural pathogens? bioRxiv.

Gasmi L, Martínez-Solís M, Frattini A, Ye M, Collado MC, Turlings TCJ, Erb M \& Herrero S (2019) Can Herbivore-Induced Volatiles Protect Plants by Increasing the Herbivores' Susceptibility to Natural Pathogens? Applied and Environmental Microbiology 85: e01468-01418.

GenScript C (2006) Real-time PCR primer design. GenScript Corporation.

Georghiou G (1990) Overview of Insecticide Resistance, Vol. 421: Managing Resistance to Agrochemicals (ed. ACS, pp. 18-41.

Gfeller A, Laloux M, Barsics F, Kati DE, Haubruge E, du Jardin P, Verheggen FJ, Lognay G, Wathelet J-P \& Fauconnier M-L (2013) Characterization of Volatile Organic Compounds Emitted by Barley (Hordeum vulgare L.) Roots and Their Attractiveness to Wireworms. Journal of chemical ecology 39: 1129-1139.

Greenberg SM, Sappington TW, Legaspi BC, Liu TX \& Setamou M (2001) Feeding and life history of Spodoptera exigua (Lepidoptera : Noctuidae) on different host plants. Annals of the Entomological Society of America 94: 566-575.

Güimil S, Chang H-S, Zhu T, Sesma A, Osbourn A, Roux C, loannidis V, Oakeley EJ, Docquier M \& Descombes $P$ (2005) Comparative transcriptomics of rice reveals an ancient pattern of response to microbial colonization. Proc Nat Acad Sci USA 102: 8066-8070.

Gutterman Y (1994) Strategies of seed dispersal and germination in plants inhabiting deserts. The botanical review 60: 373-425.

H B Tukey J (1970) The Leaching of Substances from Plants. Annual Review of Plant Physiology 21: 305-324.

Hahn M, Schotthöfer A, Schmitz J, Franke LA \& Brühl CA (2015) The effects of agrochemicals on Lepidoptera, with a focus on moths, and their pollination service in field margin habitats. Agriculture, Ecosystems \& Environment 207: 153-162.

Hamel F, Monneau R \& Roquejoffre JM (2004) Stability of travelling waves in a model for conical flames in two space dimensions. Annales Scientifiques De L Ecole Normale Superieure 37: 469-506.

Han W, Tian Y \& Shen X (2018) Human exposure to neonicotinoid insecticides and the evaluation of their potential toxicity: An overview. Chemosphere 192: 59-65.

Hardee D, Adams L \& Elzen G (2001) Monitoring for changes in tolerance and resistance to insecticides in bollworm/tobacco budworm in Mississippi, 1996-1999. Southwestern Entomologist 26: 365-372.

Harding JA (1976) Heliothis spp.: seasonal occurrence, hosts and host importance in the lower Rio Grande Valley. Environ Entomol 5: 666-668.

Hardke JT, Temple JH, Leonard BR \& Jackson RE (2011) Laboratory toxicity and field efficacy of selected insecticides against fall armyworm (Lepidoptera: Noctuidae). Fla Entomol 94: 272-278.

Hare JD (2011) Ecological Role of Volatiles Produced by Plants in Response to Damage by Herbivorous Insects. Annual Review of Entomology 56: 161-180. 
Heil M (2004a) Direct defense or ecological costs: responses of herbivorous beetles to volatiles released by wild lima bean (Phaseolus lunatus). Journal of chemical ecology 30: 1289-1295.

Heil M (2004b) Direct defense or ecological costs: responses of herbivorous beetles to volatiles released by wild lima bean (Phaseolus Iunatus). J Chem Ecol 30: 12891295.

Heil M \& Bueno JCS (2007) Within-plant signaling by volatiles leads to induction and priming of an indirect plant defense in nature. Proc Nat Acad Sci USA 104: 54675472.

Hempel S, Stein C, Unsicker SB, Renker C, Auge H, Weisser WW \& Buscot F (2009) Specific bottom-up effects of arbuscular mycorrhizal fungi across a plantherbivore-parasitoid system. Oecologia 160: 267-277.

Herms DA \& Mattson WJ (1992) The dilemma of plants: to grow or defend. The quarterly review of biology 67: 283-335.

Hilker M, Schwachtje J, Baier M, Balazadeh S, Bäurle I \& Geiselhardt S (2016) Priming and memory of stress responses in organisms lacking a nervous system. Biol Rev Camb Philos Soc 91.

Hochuli DF (2001) Insect herbivory and ontogeny: How do growth and development influence feeding behaviour, morphology and host use? Austral Ecology 26: 563 570.

Holopainen JK (2004) Multiple functions of inducible plant volatiles. Trends in plant science 9: 529-533.

Hoo CS, Coudriet D \& Vail P (1984) Trichoplusia ni (Lepidoptera: Noctuidae) larval development on wild and cultivated plants. Environ Entomol 13: 843-846.

Hopkins R, Griffiths D, Birch A \& McKinlay R (1998) Influence of increasing herbivore pressure on modification of glucosinolate content of swedes (Brassica napus spp. rapifera). Journal of chemical ecology 24: 2003-2019.

Howard V. C. \& Bradford A. H. (2003) Herbivore Responses to Plant Secondary Compounds: A Test of Phytochemical Coevolution Theory. The American naturalist 161: 507-522.

Huang J, Cardoza YJ, Schmelz EA, Raina R, Engelberth J \& Tumlinson JH (2003) Differential volatile emissions and salicylic acid levels from tobacco plants in response to different strains of Pseudomonas syringae. Planta 217: 767-775.

Huang X, Xiao Y, Köllner TG, Jing W, Kou J, Chen J, Liu D, Gu S, Wu J, Zhang Y \& Guo Y (2018) The terpene synthase gene family in Gossypium hirsutum harbors a linalool synthase GhTPS12 implicated in direct defence responses against herbivores. Plant, cell \& environment 41: 261-274.

Hubert J, Münzbergová Z \& Santino A (2008a) Plant volatile aldehydes as natural insecticides against stored-product beetles. Pest management science 64: 57-64.

Hubert J, Münzbergová Z \& Santino A (2008b) Plant volatile aldehydes as natural insecticides against stored-product beetles. Pest Manag Sci 64: 57-64.

Huffaker A, Pearce G, Veyrat N, Erb M, Turlings TCJ, Sartor R, Shen Z, Briggs SP, Vaughan MM, Alborn HT, Teal PEA \& Schmelz EA (2013) Plant elicitor peptides are 
conserved signals regulating direct and indirect antiherbivore defense.

Proceedings of the National Academy of Sciences 110: 5707-5712.

Ibrahim M, Oksanen E \& Holopainen J (2004) Effects of limonene on the growth and physiology of cabbage (Brassica oleracea $\mathrm{L}$ ) and carrot (Daucus carota $\mathrm{L}$ ) plants. Journal of the Science of Food and Agriculture 84: 1319-1326.

Isman MB (2016) Pesticides based on plant essential oils: phytochemical and practical considerations, Vol. 1218: Medicinal and aromatic crops: production, phytochemistry, and utilization (ed. American Chemical Society, pp. 13-26.

Jucelaine H, Ricardi LE, Shimomura HK, Miguel MS, Edgar SV \& M. PG (2018) Getting ready for battle: do cabbage seeds treated with jasmonic acid and chitosan affect chewing and sap-feeding insects? Entomologia Experimentalis et Applicata 166: 412-419.

Jurriaan T, Marco DA, Violaine J, Gabor J, Danielle K, Matthias H, Brigitte MM \& C.J. TT (2007) Priming by airborne signals boosts direct and indirect resistance in maize. The Plant Journal 49: 16-26.

Kanchiswamy CN, Malnoy M \& Maffei ME (2015) Chemical diversity of microbial volatiles and their potential for plant growth and productivity. Frontiers in plant science 6: 151.

Karban R (2007) Experimental clipping of sagebrush inhibits seed germination of neighbours. Ecology Letters 10: 791-797.

Karban R, Yang LH \& Edwards KF (2014) Volatile communication between plants that affects herbivory: a meta-analysis. Ecology Letters 17: 44-52.

Karssen CM \& Hilhorst HWM (2000) Effect of chemical environment on seed germination: Seeds. The ecology of regeneration in plants communities (ed. by M Fenner) Cabi, pp. 293-309.

Kessler A \& Baldwin IT (2001) Defensive function of herbivore-induced plant volatile emissions in nature. Science (New York, N.Y.) 291: 2141-2144.

Koitabashi R, Suzuki T, Kawazu T, Sakai A, Kuroiwa H \& Kuroiwa T (1997) 1,8-Cineole inhibits root growth and DNA synthesis in the root apical meristem ofBrassica campestris L. Journal of Plant Research 110: 1-6.

Kostic M, Popovic Z, Brkic D, Milanovic S, Sivcev I \& Stankovic S (2008) Larvicidal and antifeedant activity of some plant-derived compounds to Lymantria dispar L. (Lepidoptera : Limantriidae). Bioresource Technology 99: 7897-7901.

Koul O, Walia S \& Dhaliwal G (2008) Essential oils as green pesticides: potential and constraints. Biopestic Int 4: 63-84.

Krieger RI, Feeny PP \& Wilkinson CF (1971) Detoxication enzymes in the guts of caterpillars: an evolutionary answer to plant defenses? Science 172: 579-581.

Krishnaiah N \& Kalode M (1990) Efficacy of selected botanicals against rice insect pests under green house and field conditions. Indian Journal of Plant Protection 18: 197-205.

Kuśnierczyk A, Winge P, Midelfart H, Armbruster WS, Rossiter JT \& Bones AM (2007) Transcriptional responses of Arabidopsis thaliana ecotypes with different glucosinolate profiles after attack by polyphagous Myzus persicae and oligophagous Brevicoryne brassicae. Journal of Experimental Botany 58. 
Laetz CA, Baldwin DH, Collier TK, Hebert V, Stark JD \& Scholz NL (2009) The synergistic toxicity of pesticide mixtures: implications for risk assessment and the conservation of endangered pacific salmon. Environmental Health Perspectives 117: 348-353.

Laquale S, Avato P, Argentieri MP, Bellardi MG \& D'Addabbo T (2018) Nematotoxic activity of essential oils from Monarda species. Journal of Pest Science.

Lawo NC, Weingart GJF, Schuhmacher R \& Forneck A (2011) The volatile metabolome of grapevine roots: First insights into the metabolic response upon phylloxera attack. Plant Physiology and Biochemistry 49: 1059-1063.

Lee J-H, Wood TK \& Lee J (2015) Roles of indole as an interspecies and interkingdom signaling molecule. Trends in Microbiology 23: 707-718.

Lee S, Tsao R \& Coats JR (1999a) Influence of Dietary Applied Monoterpenoids and Derivatives on Survival and Growth of the European Corn Borer (Lepidoptera: Pyralidae). Journal of Economic Entomology 92: 56-67.

Lee S, Tsao R \& Coats JR (1999b) Influence of dietary applied monoterpenoids and derivatives on survival and growth of the european corn borer (lepidoptera: pyralidae). J Econ Entomol 92: 56-67.

Levine JM, McEachern AK \& Cowan C (2008) Rainfall effects on rare annual plants. Journal of Ecology 96: 795-806.

Liao C, Heckel DG \& Akhurst R (2002) Toxicity of Bacillus thuringiensis insecticidal proteins for Helicoverpa armigera and Helicoverpa punctigera (Lepidoptera: Noctuidae), major pests of cotton. J Invertebr Pathol 80: 55-63.

Liburd O, Funderburk J \& Olson S (2000) Effect of biological and chemical insecticides on Spodoptera species (Lep., Noctuidae) and marketable yields of tomatoes. Journal of Applied Entomology 124: 19-25.

Liu J, Maldonado-Mendoza I, Lopez-Meyer M, Cheung F, Town CD \& Harrison MJ (2007) Arbuscular mycorrhizal symbiosis is accompanied by local and systemic alterations in gene expression and an increase in disease resistance in the shoots. The Plant journal : for cell and molecular biology 50: 529-544.

Liu W, Kohlen W, Lillo A, Camp ROD, Ivanov S, Hartog M, Limpens E, Jamil M, Smaczniak C, Kaufmann K, Yang C, Hooiveld GJEJ, Charnikhova T, Bouwmeester HJ, Bisseling T \& Köhlen W (2014) Strigolactone Biosynthesis in Medicago truncatula and Rice Requires the Symbiotic GRAS- Type Transcription Factors NSP1 and NSP2 and René Geurts Stable URL : http://www.jstor.org/stable/41433881.

Liu Y, Li X, Zhou C, Liu F \& Mu W (2016) Toxicity of nine insecticides on four natural enemies of Spodoptera exigua. Scientific Reports 6: 39060.

Livak KJ \& Schmittgen TD (2001) Analysis of relative gene expression data using realtime quantitative PCR and the 2(-Delta Delta C(T)) Method. Methods (San Diego, Calif.) 25: 402-408.

Lopez Jr JD, Shaver TN, Beerwinkle KR \& Lingren PD (2000) Feeding attractant and stimulant for adult control of noctuid and/or other lepidopteran species: Google Patents.

Loreto F, Ciccioli P, Brancaleoni E, Cecinato A \& Frattoni M (1998) Measurement of isoprenoid content in leaves of Mediterranean Quercus spp. by a novel and 
sensitive method and estimation of the isoprenoid partition between liquid and gas phase inside the leaves. Plant Science 136: 25-30.

Loreto F, Nascetti P, Graverini A \& Mannozzi M (2000) Emission and content of monoterpenes in intact and wounded needles of the Mediterranean Pine, Pinus pinea. Funct Eol 14: 589-595.

Maag D, Erb M, Köllner TG \& Gershenzon J (2015) Defensive weapons and defense signals in plants: Some metabolites serve both roles. Bioessays 37: 167-174.

Maffei ME, Gertsch J \& Appendino G (2011) Plant volatiles: production, function and pharmacology. Natural product reports 28: 1359-1380.

Mardani-Talaei M, Nouri-Ganbalani G, Naseri B \& Hassanpour M (2012) Life history studies of the beet armyworm, Spodoptera exigua (Hübner)(Lepidoptera: Noctuidae) on 10 corn hybrids. Journal of the Entomological Research Society 14: 9-18.

Martin P, Lingren P \& Greene G (1976) Relative abundance and host preferences of cabbage looper, soybean looper, tobacco budworm, and corn earworm on crops grown in northern Florida. Environ Entomol 5: 878-882.

Martínez-Medina A, Van Wees S \& Pieterse CM (2017) Airborne signals by Trichoderma fungi stimulate iron uptake responses in roots resulting in priming of jasmonic acid-dependent defences in shoots of Arabidopsis thaliana and Solanum lycopersicum. Plant, cell \& environment.

Maurya AK, Patel RC \& Frost CJ (2019) Acute toxicity of the plant volatile indole depends on herbivore specialization. bioRxiv: 784165.

McEwen F \& Splittstoesser C (1970) Resistance to organophosphate insecticides in the cabbage looper in New York. J Econ Entomol 63.

Meents AK, Chen S-P, Reichelt M, Lu H-H, Bartram S, Yeh K-W \& Mithöfer A (2019) Volatile DMNT systemically induces jasmonate-independent direct antiherbivore defense in leaves of sweet potato (Ipomoea batatas) plants. Scientific Reports 9: 17431.

Milberg P, Andersson L \& Thompson K (2000) Large-seeded spices are less dependent on light for germination than small-seeded ones. Seed science research 10: 99-104.

Mirabella R, Rauwerda H, Struys EA, Jakobs C, Triantaphylidès $C$, Haring MA \& Schuurink RC (2008) The Arabidopsis her1 mutant implicates GABA in E-2-hexenal responsiveness. The Plant Journal 53: 197-213.

Miresmailli S \& Isman MB (2014) Botanical insecticides inspired by plant-herbivore chemical interactions. Trends in plant science 19: 29-35.

Moar WJ, Trumble JT \& Federici BA (1989) Comparative toxicity of spores and crystals from the nrd-12 and hd-1 strains of Bacillus thuringiensis suhsp. kurstaki to neonate beet armyworm (lepidoptera: noctuidae). J Econ Entomol 82: 15931603.

Moghaddam M \& Mehdizadeh L (2017) Chemistry of Essential Oils and Factors Influencing Their Constituents: Soft Chemistry and Food Fermentation (ed. Elsevier, pp. 379-419. 
Mohan M, Haider SZ, Andola HC \& Purohit VK (2011) Essential oils as green pesticides: for sustainable agriculture. Research Journal of Pharmaceutical, Biological and Chemical Sciences 2: 100-106.

Moran PJ \& Thompson GA (2001) Molecular responses to aphid feeding in Arabidopsis in relation to plant defense pathways. Plant Physiol 125: 1074-1085.

Mossa A-TH (2016) Green pesticides: Essential oils as biopesticides in insect-pest management. Int. J. Environ. Sci. Technol 9: 354.

Mozgova I, Wildhaber T, Liu Q, Abou-Mansour E, L'Haridon F, Metraux JP, Gruissem W, Hofius D \& Hennig L (2015) Chromatin assembly factor CAF-1 represses priming of plant defence response genes. Nat Plants 1: 15127.

Mulé R, Sabella G, Robba L \& Manachini B (2017) Systematic Review of the Effects of Chemical Insecticides on Four Common Butterfly Families. Frontiers in Environmental Science 5.

Muller CH, Muller WH \& Haines BL (1964) Volatile growth inhibitors produced by aromatic shrubs. Science 143: 471-473.

Müller GC, Junnila A, Butler J, Kravchenko VD, Revay EE, Weiss RW \& Schlein Y (2009) Efficacy of the botanical repellents geraniol, linalool, and citronella against mosquitoes. Journal of Vector Ecology 34: 2-8.

Muller WH (1965) Volatile Materials Produced by Salvia leucophylla: Effects on Seedling Growth and Soil Bacteria. Botanical Gazette 126: 195-200.

Muller WH \& Muller CH (1964) Volatile growth inhibitors produced by Salvia species. Bulletin of the Torrey Botanical Club: 327-330.

Muralidharan K \& Pasalu I (2006) Assessments of crop losses in rice ecosystems due to stem borer damage (Lepidoptera: Pyralidae). Crop Protection 25: 409-417.

Muscolo A, Panuccio MR \& Sidari M (2001) The effect of phenols on respiratory enzymes in seed germination. Plant Growth Regulation 35: 31-35.

NCBI I (2019) PubChem Database. Indole, CID=798, Vol. 2019.

Neilson EH, Goodger JQD, Woodrow IE \& Møller BL (2013) Plant chemical defense: at what cost? Trends in plant science 18: 250-258.

Nelson DC, Flematti GR, Ghisalberti EL, Dixon KW \& Smith SM (2012) Regulation of Seed Germination and Seedling Growth by Chemical Signals from Burning Vegetation. Annual review of plant biology 63: 107-130.

Niinemets Ü, Kännaste A \& Copolovici L (2013) Quantitative patterns between plant volatile emissions induced by biotic stresses and the degree of damage. Frontiers in plant science 4 .

Niinemets Ü, Loreto F \& Reichstein M (2004) Physiological and physicochemical controls on foliar volatile organic compound emissions. Trends in plant science 9: 180186.

Ninkovic V (2003) Volatile communication between barley plants affects biomass allocation. Journal of Experimental Botany 54: 1931-1939.

Niu Y, Meagher Jr RL, Yang F \& Huang F (2013) Susceptibility of field populations of the fall armyworm (Lepidoptera: Noctuidae) from Florida and Puerto Rico to purified Cry1F protein and corn leaf tissue containing single and pyramided Bt genes. Fla Entomol 96: 701-713. 
Ojimelukwe P \& Adler C (2000) Toxicity and repellent effects of eugenol, thymol, linalool, menthol and other pure compounds on Dinoderus bifloveatus (Coleoptera: Bostrichidae). Journal of Sustainable Agriculture and the Environment 2: 47-54.

Oleszek W (1987) Allelopathic effects of volatiles from some Cruciferae species on lettuce, barnyard grass and wheat growth. Plant and Soil 102: 271-273.

Ormeño E, Goldstein A \& Niinemets Ü (2011) Extracting and trapping biogenic volatile organic compounds stored in plant species. TrAC Trends in Analytical Chemistry 30: 978-989.

Pair SD \& Horvat RJ (1997) Volatiles of Japanese honeysuckle flowers as attractants for adult Lepidopteran insects: Google Patents.

Pake CE \& Venable DL (1996) Seed banks in desert annuals: Implications for persistence and coexistence in variable environments. Ecology 77: 1427-1435.

Palma R, Mutis A, Manosalva L, Ceballos R \& Quiroz A (2012) Behavioral and electrophysiological responses of Hylastinus obscurus to volatiles released from the roots of Trifolium pratense L. Journal of soil science and plant nutrition 12: 183-193.

Paparella S, Araújo SS, Rossi G, Wijayasinghe M, Carbonera D \& Balestrazzi A (2015) Seed priming: state of the art and new perspectives. Plant Cell Reports 34: 12811293.

Pearson AC (1983) Biology, population dynamics, and pest status of the beet armyworm (Spodoptera exigua) in the Imperial Valley of California.

Peñuelas J, Asensio D, Tholl D, Wenke K, Rosenkranz M, Piechulla B \& Schnitzler JP (2014) Biogenic volatile emissions from the soil. Plant, cell \& environment 37: 1866-1891.

Pichersky E \& Gershenzon J (2002) The formation and function of plant volatiles: perfumes for pollinator attraction and defense. Current opinion in plant biology 5: 237-243.

Pickett JA \& Khan ZR (2016) Plant volatile-mediated signalling and its application in agriculture: successes and challenges. New Phytologist 212: 856-870.

Pimentel D (1996) Green revolution agriculture and chemical hazards. Science of The Total Environment 188: S86-S98.

Plata-Rueda A, Martínez LC, Santos MHD, Fernandes FL, Wilcken CF, Soares MA, Serrão JE \& Zanuncio JC (2017) Insecticidal activity of garlic essential oil and their constituents against the mealworm beetle, Tenebrio molitor Linnaeus (Coleoptera: Tenebrionidae). Scientific Reports 7: 46406.

Preston CA, Betts H \& Baldwin IT (2002) Methyl jasmonate as an allelopathic agent: sagebrush inhibits germination of a neighboring tobacco, Nicotiana attenuata. Journal of chemical ecology 28: 2343-2369.

Probert RJ (2000) The role of temperature in the regulation of seed dormancy and germination, Vol. 2: Seeds: the ecology of regeneration in plant communities (ed. by M Fenner) CABI, pp. 261-292. 
R Core Team (2018) A language and environment for statistical computing URL http://www. R-project. org (ed. R foundation for statistical computing, Vienna, Austria.

Raguso RA (2008) Wake up and smell the roses: the ecology and evolution of floral scent. Annual Review of Ecology, Evolution, and Systematics 39: 549-569.

Rajjou L, Belghazi M, Huguet R, Robin C, Moreau A, Job C \& Job D (2006) Proteomic Investigation of the Effect of Salicylic Acid on Arabidopsis Seed Germination and Establishment of Early Defense Mechanisms. Plant physiology 141: 910-923.

Rasmann S, Kollner TG, Degenhardt J, Hiltpold I, Toepfer S, Kuhlmann U, Gershenzon J \& Turlings TC (2005) Recruitment of entomopathogenic nematodes by insectdamaged maize roots. Nature 434: 732-737.

Reddy GVP \& Antwi FB (2016) Toxicity of natural insecticides on the larvae of wheat head armyworm, Dargida diffusa (Lepidoptera: Noctuidae). Environmental Toxicology and Pharmacology 42: 156-162.

Reymond P, Bodenhausen N, Van Poecke RMP, Krishnamurthy V, Dicke M \& Farmer EE (2004) A conserved transcript pattern in response to a specialist and a generalist herbivore. Plant Cell 16.

Reynolds SA, Corbin JD \& D'Antonio CM (2001) The effects of litter and temperature on the germination of native and exotic grasses in a coastal California grassland. Madrono 48: 230-235.

Richard K, Kaori S, Mikaela H \& C. MA (2006) DAMAGE-INDUCED RESISTANCE IN SAGEBRUSH: VOLATILES ARE KEY TO INTRA- AND INTERPLANT COMMUNICATION. Ecology 87: 922-930.

Rivera-Vega LJ, Galbraith DA, Grozinger CM \& Felton GW (2017) Host plant driven transcriptome plasticity in the salivary glands of the cabbage looper (Trichoplusia ni). PloS one 12: e0182636.

Rodriguez-Saona CR \& Frost CJ (2010) New evidence for a multi-functional role of herbivore-induced plant volatiles in defense against herbivores. Plant Signaling \& Behavior 5: 58-60.

Rodriguez-Saona CR, Rodriguez-Saona LE \& Frost CJ (2009) Herbivore-induced volatiles in the perennial shrub, Vaccinium corymbosum, and their role in inter-branch signaling. Journal of chemical ecology 35: 163-175.

Romagni JG, Allen SN \& Dayan FE (2000) Allelopathic effects of volatile cineoles on two weedy plant species. Journal of chemical ecology 26: 303-313.

Rudrappa T, Biedrzycki ML, Kunjeti SG, Donofrio NM, Czymmek KJ, Paul W P \& Bais HP (2010) The rhizobacterial elicitor acetoin induces systemic resistance in Arabidopsis thaliana. Communicative \& Integrative Biology 3: 130-138.

Ryu C, Farag MA, Hu C, Reddy MS, Kloepper JW \& Pare PW (2004) Bacterial volatiles induce systemic resistance in Arabidopsis. Plant Physiol 134.

Sadeghi A, Van Damme EJM \& Smagghe G (2009) Evaluation of the susceptibility of the pea aphid, Acyrthosiphon pisum, to a selection of novel biorational insecticides using an artificial diet. J Insect sci 9: 1-8.

Said-Al Ahl H, Hikal WM \& Tkachenko KG (2017) Essential oils with potential as insecticidal agents: A review. Inter J Environ Plan Manag 3: 23-33. 
Sandra I, Andrea CM, Jan G, Axel S, Andreas BG, Jonathan G, B. US \& G. KT (2014) Herbivore-induced poplar cytochrome P450 enzymes of the CYP71 family convert aldoximes to nitriles which repel a generalist caterpillar. Plant J 80: 10951107.

Schiestl FP \& Ayasse M (2001) Post-pollination emission of a repellent compound in a sexually deceptive orchid: a new mechanism for maximising reproductive success? Oecologia 126: 531-534.

Schiestl FP, Ayasse M, Paulus HF, Löfstedt C, Hansson BS, Ibarra F \& Francke W (1999) Orchid pollination by sexual swindle. Nature 399: 421.

Schmelz EA, Alborn HT, Banchio E \& Tumlinson JH (2003) Quantitative relationships between induced jasmonic acid levels and volatile emission in Zea mays during Spodoptera exigua herbivory. Planta 216: 665-673.

Schnee C, Köllner TG, Held M, Turlings TC, Gershenzon J \& Degenhardt J (2006) The products of a single maize sesquiterpene synthase form a volatile defense signal that attracts natural enemies of maize herbivores. Proceedings of the National Academy of Sciences of the United States of America 103: 1129-1134.

Seo M, Nambara E, Choi G \& Yamaguchi S (2008) Interaction of light and hormone signals in germinating seeds. Plant Molecular Biology 69: 463.

Shaaban HAE, El-Ghorab AH \& Shibamoto T (2012) Bioactivity of essential oils and their volatile aroma components: Review. Journal of Essential Oil Research 24: 203212.

Sharifi R, Lee S-M \& Ryu C-M (2018) Microbe-induced plant volatiles. New Phytologist 220: 684-691.

Sharifi R \& Ryu C-M (2016) Are bacterial volatile compounds poisonous odors to a fungal pathogen Botrytis cinerea, alarm signals to Arabidopsis seedlings for eliciting induced resistance, or both? Frontiers in microbiology 7.

Sharkey TD \& Singsaas EL (1995) Why plants emit isoprene. Nature 374: 769-769.

Shiferaw B, Prasanna BM, Hellin J \& Bänziger M (2011) Crops that feed the world 6. Past successes and future challenges to the role played by maize in global food security. Food Security 3: 307.

Simonin KA \& Roddy AB (2018) Genome downsizing, physiological novelty, and the global dominance of flowering plants. PLoS biology 16: e2003706.

Slansky F (1993) Xanthine toxicity to caterpillars synergized by allopurinol, a xanthine dehydrogenase/oxidase inhibitor. J Chem Ecol 19: 2635-2650.

Smart LE, Martin JL, Limpalaër M, Bruce TJA \& Pickett JA (2013) Responses of Herbivore and Predatory Mites to Tomato Plants Exposed to Jasmonic Acid Seed Treatment. Journal of chemical ecology 39: 1297-1300.

Song G \& Ryu C-M (2013a) Two Volatile Organic Compounds Trigger Plant Self-Defense against a Bacterial Pathogen and a Sucking Insect in Cucumber under Open Field Conditions. International Journal of Molecular Sciences 14: 9803.

Song GC \& Ryu CM (2013b) Two volatile organic compounds trigger plant self-defense against a bacterial pathogen and a sucking insect in cucumber under open field conditions. Int J Mol Sci 14. 
Souri MK \& Bakhtiarizade M (2019) Biostimulation effects of rosemary essential oil on growth and nutrient uptake of tomato seedlings. Scientia Horticulturae 243: 472476.

Sparks TC \& Nauen R (2015) IRAC: Mode of action classification and insecticide resistance management. Pesticide Biochemistry and Physiology 121: 122-128.

Sugimoto K, Matsui K \& Takabayashi J (2015) Conversion of volatile alcohols into their glucosides in Arabidopsis. Communicative \& Integrative Biology 8: e992731.

Tabari MA, Youssefi MR, Maggi F \& Benelli G (2017) Toxic and repellent activity of selected monoterpenoids (thymol, carvacrol and linalool) against the castor bean tick, Ixodes ricinus (Acari: Ixodidae). Veterinary Parasitology 245: 86-91.

Thelen GC, Vivanco JM, Newingham B, Good W, Bais HP, Landres P, Caesar A \& Callaway RM (2005) Insect herbivory stimulates allelopathic exudation by an invasive plant and the suppression of natives. Ecology Letters 8: 209-217.

Tingle CC, Rother JA, Dewhurst CF, Lauer S \& King WJ (2003) Fipronil: environmental fate, ecotoxicology, and human health concerns: Reviews of environmental contamination and toxicology (ed. Springer, pp. 1-66.

Tomczak VV \& Müller C (2017) Influence of arbuscular mycorrhizal stage and plant age on the performance of a generalist aphid. Journal of Insect Physiology 98: 258266.

Tominaga T \& Dubourdieu D (2000) Identification of Cysteinylated Aroma Precursors of Certain Volatile Thiols in Passion Fruit Juice. Journal of Agricultural and Food Chemistry 48: 2874-2876.

Tumlinson III JH, Alborn HT, Loughrin JH, Turlings TC \& Jones TH (2001) Plant volatile elicitor from insects: Google Patents.

Turlings TC, Loughrin JH, McCall PJ, Röse US, Lewis WJ \& Tumlinson JH (1995) How caterpillar-damaged plants protect themselves by attracting parasitic wasps. Proceedings of the National Academy of Sciences 92: 4169-4174.

Turlings TC, Tumlinson JH \& Lewis WJ (1990) Exploitation of herbivore-induced plant odors by host-seeking parasitic wasps. Science(Washington) 250: 1251-1253.

Ulrichs C, Mewis I, Adhikary S, Bhattacharyya A \& Goswami A (2007) Antifeedant activity and toxicity of leaf extracts from Porteresia coarctata Takeoka and their effects on the physiology of Spodoptera litura (F.). Journal of Pest Science 81: 79.

Valenta K, Nevo O, Martel C \& Chapman CA (2017) Plant attractants: integrating insights from pollination and seed dispersal ecology. Evolutionary Ecology 31: 249-267.

van Hulten M, Pelser M, van Loon LC, Pieterse CMJ \& Ton J (2006) Costs and benefits of priming for defense in Arabidopsis. Proceedings of the National Academy of Sciences 103: 5602-5607.

Veyrat N, Robert CAM, Turlings TCJ \& Erb M (2016a) Herbivore intoxication as a potential primary function of an inducible volatile plant signal. Journal of Ecology 104: 591-600.

Veyrat N, Robert CAM, Turlings TCJ \& Erb M (2016b) Herbivore intoxication as a potential primary function of an inducible volatile plant signal. Journal of Ecology 104: 591-600. 
Vickers CE, Gershenzon J, Lerdau MT \& Loreto F (2009) A unified mechanism of action for volatile isoprenoids in plant abiotic stress. Nature chemical biology 5: 283.

von Mérey G, Veyrat N, D’Alessandro M \& Turlings T (2013) Herbivore-induced maize leaf volatiles affect attraction and feeding behavior of Spodoptera littoralis caterpillars. Frontiers in plant science 4.

Vreysen MJ, Klassen W \& Carpenter JE (2016) Overview of technological advances toward greater efficiency and efficacy in sterile insect-inherited sterility programs against moth pests. Florida Entomologist 99: 1-13.

Walling LL (2008) Avoiding effective defenses: strategies employed by phloem-feeding insects. Plant physiology 146: 859-866.

Wasternack C (2007) Jasmonates: An update on biosynthesis, signal transduction and action in plant stress response, growth and development. Annals of botany 100.

Waters DJ \& Barfield CS (1989) Larval development and consumption by Anticarsia gemmatalis (Lepidoptera: Noctuidae) fed various legume species. Environ Entomol 18: 1006-1010.

Wesson G \& Wareing PF (1969) The role of light in the germination of naturally occurring populations of buried weed seeds. Journal of Experimental Botany 20: 402-413.

Whittaker RH \& Feeny PP (1971) Allelochemics: chemical interactions between species. Science 171: 757-770.

Wickham H (2011) ggplot2: Elegant Graphics for Data Analysis. Springer-Verlag New York.

Worrall D, Holroyd GH, Moore JP, Glowacz M, Croft P, Taylor JE, Paul ND \& Roberts MR (2012) Treating seeds with activators of plant defence generates long-lasting priming of resistance to pests and pathogens. New Phytologist 193: 770-778.

Yan Z-G \& Wang C-Z (2006) Wound-induced green leaf volatiles cause the release of acetylated derivatives and a terpenoid in maize. Phytochemistry 67: 34-42.

Yang C, Hu L, Ali B, Islam F, Bai Q, Yun X, Yoneyama K \& Zhou W (2016) Seed treatment with salicylic acid invokes defence mechanism of Helianthus annuus against Orobanche cumana. Annals of Applied Biology 169: 408-422.

Ye M, Glauser G, Lou Y, Erb M \& Hu L (2019) Molecular dissection of early defense signaling underlying volatile-mediated defense regulation and herbivore resistance in rice. The Plant cell: tpc.00569.02018.

Yu SJ, Nguyen SN \& Abo-Elghar GE (2003) Biochemical characteristics of insecticide resistance in the fall armyworm, Spodoptera frugiperda (J.E. Smith). Pestic Biochem Physiol 77: 1-11.

Zakir A, Bengtsson M, Sadek MM, Hansson BS, Witzgall P \& Anderson P (2013) Specific response to herbivore-induced de novo synthesized plant volatiles provides reliable information for host plant selection in a moth. The Journal of Experimental Biology 216: 3257-3263.

Zalucki MP, Clarke AR \& Malcolm SB (2002) Ecology and behavior of first instar larval Lepidoptera. Annual Review of Entomology 47: 361-393. 
Zalucki MP, Malcolm SB, Hanlon CC \& Paine TD (2012a) First-instar monarch larval growth and survival on milkweeds in southern California: effects of latex, leaf hairs and cardenolides. Chemoecology 22: 75-88.

Zalucki MP, Shabbir A, Silva R, Adamson D, Shu-Sheng L \& Furlong MJ (2012b) Estimating the Economic Cost of One of the World's Major Insect Pests, Plutella xylostella (Lepidoptera: Plutellidae): Just How Long Is a Piece of String? Journal of Economic Entomology 105: 1115-1129.

Zhao Y, Hull AK, Gupta NR, Goss KA, Alonso J, Ecker JR, Normanly J, Chory J \& Celenza JL (2002) Trp-dependent auxin biosynthesis in Arabidopsis: involvement of cytochrome P450s CYP79B2 and CYP79B3. Genes \& development 16: 3100-3112.

Zhao Y, Xu S, Lu H, Zhang D, Liu F, Lin J, Zhou C \& Mu W (2017) Effects of the plant volatile trans-2-hexenal on the dispersal ability, nutrient metabolism and enzymatic activities of Bursaphelenchus xylophilus. Pesticide Biochemistry and Physiology.

Zheng X, Cong X, Wang X \& Lei C (2011) A review of geographic distribution, overwintering and migration in Spodoptera exigua Hübner (Lepidoptera: Noctuidae). Journal of the Entomological Research Society 13: 39-48. 


\section{APPENDIX I - Supplement for Chapter II}

SUPPLEMENTARY FIGURES

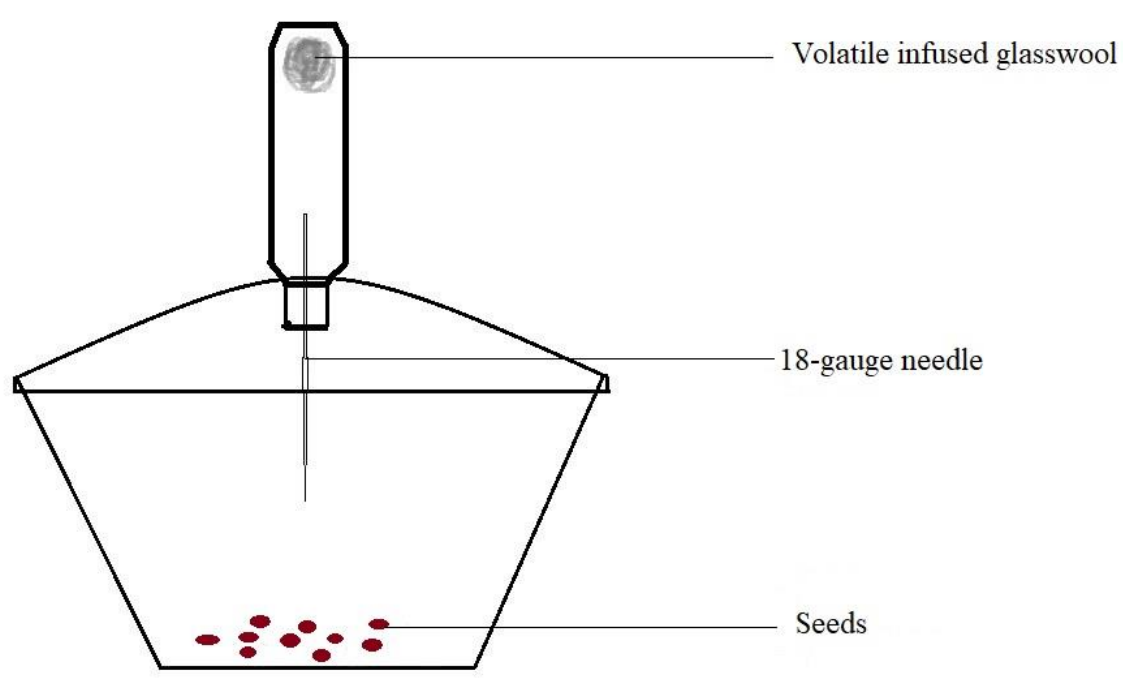

Figure S1 Pictorial representation of volatile dispensers used to expose seeds to synthetic plant volatiles. 

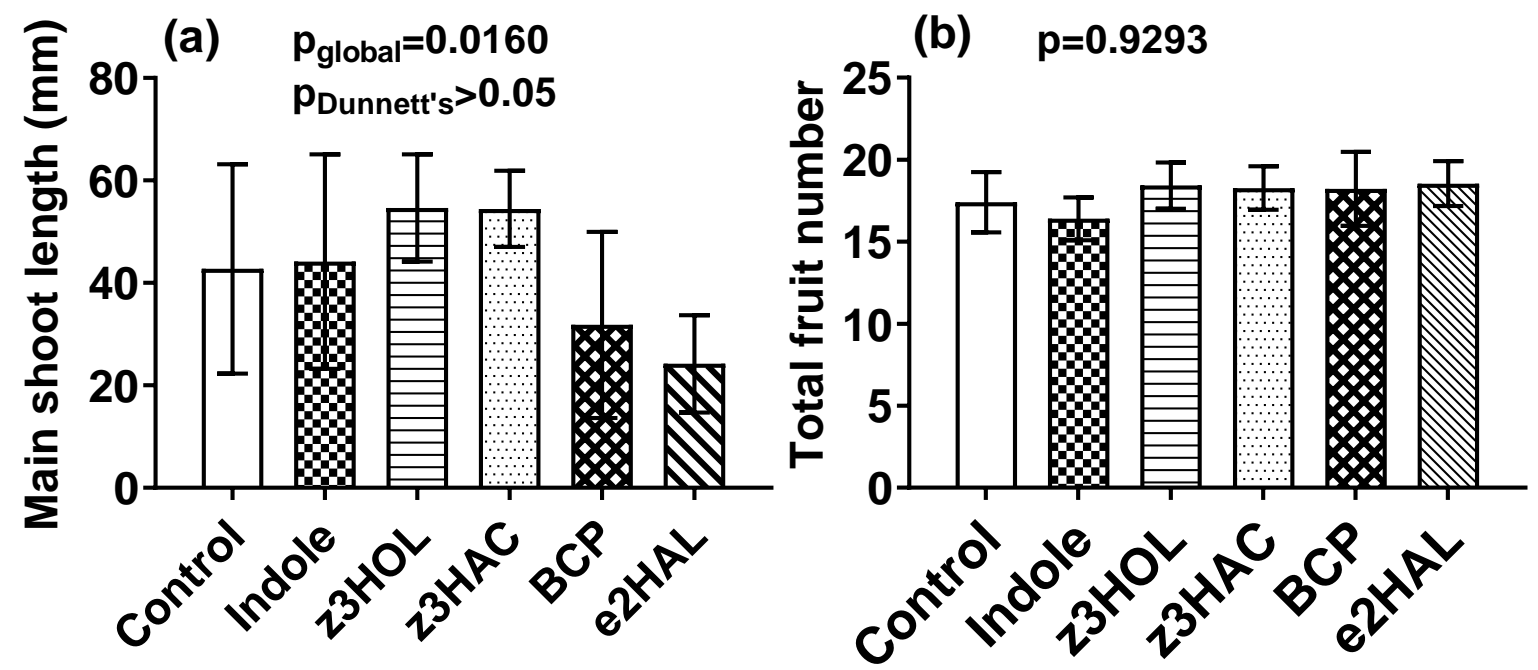

Figure S2 Seed exposure to plant-derived volatiles have no effect on (a) Main shoot length and (b) Total fruit number of $M$. truncatula plants. Values are shown as means \pm 95\% CI ( $\mathrm{n}=5-10)$ significance was calculated by one-way ANOVA followed by Dunnett's post-hoc test. 


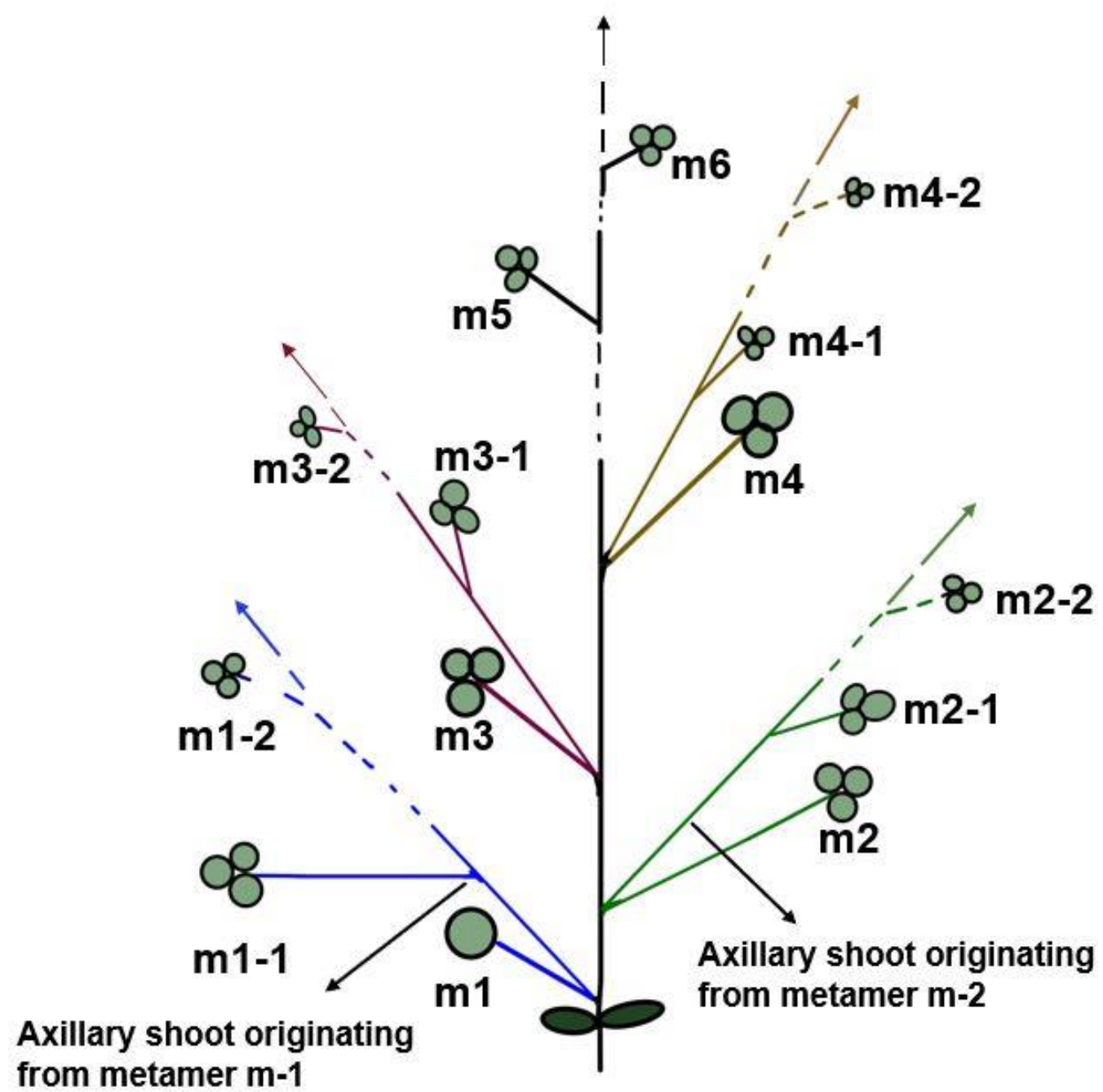

Figure S3 Pictorial representation of the numerical nomenclature coding system for vegetative growth of $M$. truncatula. Nomenclature coding started with unifoliate leaf as first metamers and subsequent trifoliate are labeled along the main shoot in ascending order. Axillary shoots are named as per the metamer of origin. 


\section{CURRICULUM VITAE}

Abhinav Kumar Maurya

Biology of Department

University of Louisville

Louisville, KY 40208
Email:mauryaabhi902@gmail.com

Alt.email: abhinav.maurya@louisville.edu

\section{Education}

2020 Ph.D. Biology - University of Louisville, Louisville, KY (PI: Sarah M. Emery)

2016 M.S. Biology - University of Northern Colorado, Greeley, CO (PI: Susana Gomez)

2013 B.Sc. Agricultural Sciences - Banaras Hindu University, Varanasi, India

\section{Professional Development}

2019 Undergraduate Research Mentoring Academy. School of Interdisciplinary and Graduate Studies, University of Louisville. May 2019-July 2019.

2016 Laser Capture Microdissection \& RNA Sequencing Workshop. Clemson University, 11-6 June 2016 


\section{Teaching Experience}

2019 Guest Instructor, BIOL 571: Chemical Ecology, UofL

$2018 \quad$ Guest Instructor, BIOL 571: Chemical Ecology, UofL

2016, 2019 Graduate Teaching Assistant, BIOL 104: Introduction to Biological

Systems, UofL

2016 Guest Instructor, BIOL 104: Introduction to Biological Systems, UofL

2016 Graduate Teaching Assistant, BIOL 244: Principles of Quantitative Biology, UofL

2013-16 Graduate Teaching Assistant, BIOL 101 \& 110: Biological Perspectives, UNCO

Publications (*denotes mentored undergraduate)

5. Maurya, A. K. (2019). In Press. Application of plant-volatile organic compounds in agriculture. In A. Rakshit \& S. B. Harikesh (Eds.), New Frontiers in Stress Management for Durable Agriculture. Springer Nature, Singapore.

4. Maurya, A. K., *Patel, R. C., Frost, C. (2019). Under review. Acute toxicity of the plant volatile indole depends on herbivore specialization. bioRxiv: 784165 . https://doi.org/10.1101/784165.

3. Maurya, A. K., Pazouki, L., Frost, C. (2019). Under review. Plant seeds are primed by herbivore-induced plant volatiles. bioRxiv: 522839 .

https://doi.org/10.1101/522839. 
2. Pazouki, L., Maurya, A. K., Frost, C. (2019). Under review. Spatial modulation of ferric reduction oxidase genes in Arabidopsis thaliana upon iron deficiency: relationships with exogenous application of volatiles, and abscisic acid.

1. Maurya, A. K., *Kelly, M. P., *Mahaney, S. M., Gomez, S.K. (2018). Arbuscular mycorrhizal symbiosis alters plant gene expression and aphid weight in a tripartite interaction. Journal of Plant Interactions. 13.1 294-305.

https://doi.org/10.1080/17429145.2018.1475020.

\section{Fellowships and Awards}

2019 Doctoral Dissertation Completion Fellowship [\$12000]

2019 Plant Synthetic Biology Travel Award, American Society of Plant Biology [\$350]

2019 GSC Travel Award, Graduate School Council, University of Louisville [\$350]

2019 Undergraduate lab design award, University of Louisville $[\$ 1,000]$

2019 Biology Graduate Student Association Travel Award to ASPB Meeting [\$125]

2019 Arts \& Sciences Research \& Creative Activities Grant, University of Louisville $[\$ 500]$

2017 A\&S Research Grant, University of Louisville [\$500]

2017 First prize in ecology Presentation, Kentucky Academy of Science [\$500]

2016 University fellowship, University of Louisville $[\$ 89,274]$

2015 Graduate Student Association Research Grant, University of Northern Colorado $[\$ 350]$ 
2015 Graduate Student Association Research Grant, University of Northern Colorado [\$515]

2015 NSF supported travel award, American Society of Plant Biology \$500

2015 Graduate Student Association Travel Award, University of Northern Colorado [\$600]

2015 Early Career Travel Award, Phytobiomes Initiative [\$1300]

2015 College of Natural and Health Sciences Research Grant, University of Northern Colorado $[\$ 400]$

2014 Winchester Graduate Fellowship, University of Northern Colorado [\$800]

2014 Graduate Academic Excellence Award, University of Northern Colorado [\$900]

Conference Presentations - Papers \& Posters (*denotes mentored undergraduate)

Maurya A.K., Pazouki L., and Frost. C. 2019. An herbivore-induced plant volatile (HIPV) primes seeds for long-term anti-herbivore defense. In: ESA 2019: Aug 11-Aug 16, 2019, Louisville, Kentucky, USA, p178.

Maurya A.K., Pazouki L., and Frost. C. 2019. Volatile indole prime seeds for long-term anti-herbivore defense. In: Plant Biology 2019: Aug 2-Aug 7, 2015, San Jose, California, USA.

*Patel, R., Maurya A.K., and Frost. C. 2018. Accessing the direct toxicity of the plant volatile indole on herbivores. In: Kentucky Academy of Science: November 2-3, Bowling Green, Kentucky, USA. 
Maurya A.K., and Frost. C. 2017. Memory of seeds: Effect of plant volatile exposure to seeds on plant growth, development and defense across generations. In: Kentucky Academy of Science: November 3-4, Murray, Kentucky, USA.

Maurya A.K., and Gomez S.K. 2015. An Established Mycorrhizal Symbiosis Makes Barrel Medic Plants More Attractive to Pea Aphids. In: Plant Biology 2015: July 26-July 30, 2015, Minneapolis, Minnesota, USA, p284.

Maurya A.K., and Gomez S.K. 2015. Belowground plant associations with mycorrhizal fungi and their influence on phloem-feeding insects. In: Phytobiomes 2015: Designing a New Paradigm for Crop Improvement Meeting, June 30-July 2, 2015, Washington-DC, USA, 15p.

Maurya A.K., Sarkar, and Chandra. 2013. Extinction of traditional water resources - A threat to modern Indian agriculture In National Seminar on Enhancing Water Productivity in Agriculture: 8th - 9th March 2013, BHU, Varanasi, UP, India, 77-80p.

Maurya A.K., 2012. Agro-volunteering - Strengthening sustainable agriculture and woman empowerment in India. In National Seminar on Agricultural Education, Research and Extension: Problems and Prospects: 11 April 2012, BHU, Varanasi, UP, India, 52p.

Maurya A.K., 2011. Cultivation of cash crop and its impact on the migration of rural people. In: International Conference on Managing Sustainable Development of Rural Economy and Agri-Business (ICON BHU):21st -23rd January 2011, BHU, Varanasi, UP, India,98p. 


\section{Mentoring Experience \\ University of Louisville}

Five undergraduate students (Rachel Haslem, Rakhi Patel, Allie Peot, Amit Lamba, Travis Ray, McHugh, Griffin)

Outcomes: One undergraduate thesis, one manuscript in review, and one presentation.

\section{University of Northern Colorado}

Three undergraduate students (Michael Kelly, Sean Mahaney, Viva Rase)

Outcomes: One publication.

\section{Professional Services \& Public Outreach}

2019 Student Volunteering in annual ESA meeting- Ecological Society of America.

2019 Speed Mentoring of high school students- Kentucky Academy of Sciences.

2018-2019 Undergraduate Student Representative- BGSA. University of Louisville.

2018 Donate a sapling program- Primary schools in India

2014 Grant Reviewer, McNair Scholars Program. University of Northern Colorado.

2009-2013 Area Coordinator and Host, WWOOF India Organics Private Limited.

\section{Affiliations}

2016-Present Kentucky Academy of Science,

2015, 2018-Present American Society of Plant Biologists,

2018- Present Ecological Society of America 